\title{
Highly Diastereo- and Enantioselective Synthesis of Isoxazolone- Spirooxindoles via Squaramide-Catalyzed Cascade Michael/Michael Addition Reactions
}

\author{
Yu Wang and Da-Ming Du* \\ School of Chemistry and Chemical Engineering, Beijing Institute of Technology, \\ Beijing 100081, People's Republic of China \\ dudm@bit.edu.cn
}

Supporting Information

\section{Contents}

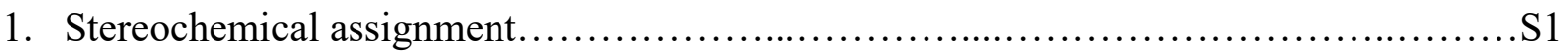

2. Copies of ${ }^{1} \mathrm{H},{ }^{13} \mathrm{C}$ and ${ }^{19} \mathrm{~F}$ NMR spectra of products............................................ 3

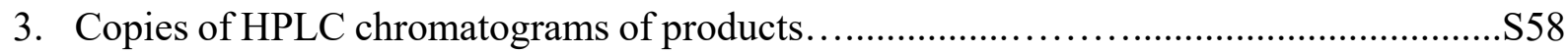




\section{Stereochemical assignment}

\subsection{Single crystal X-ray diffraction analysis and crystal data}

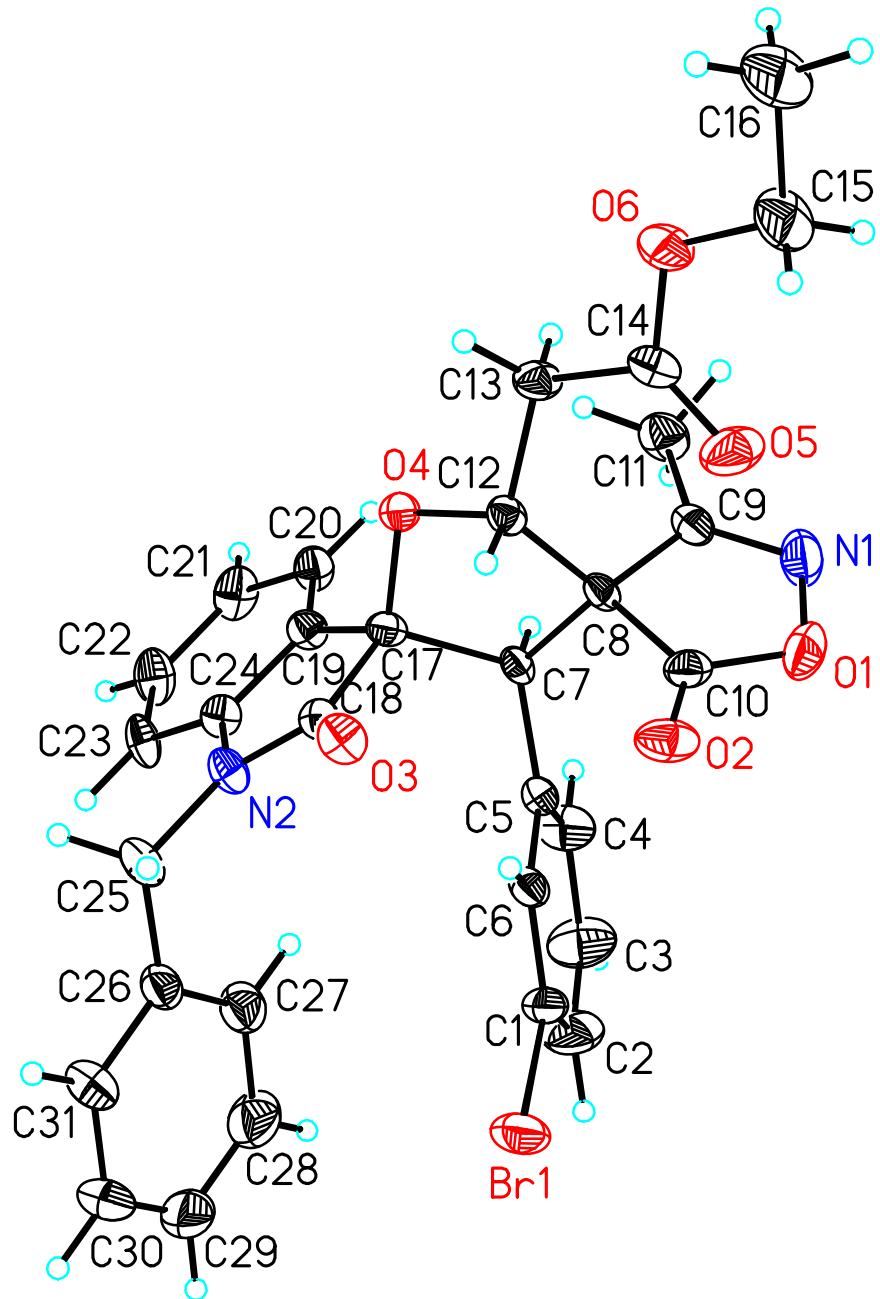

Figure S1. X-ray crystal structure of $\mathbf{3 g}$ (Displacement ellipsoids are drawn at the $50 \%$ probability level)

Sample preparation and crystal structure determination: Single crystal $\mathbf{3 g}$ was obtained using AcOEt/petroleum ether as solvent and the structure was analyzed by single-crystal X-ray diffraction. A suitable crystal of suitable dimensions was selected and mounted on a 'multiwire proportional' diffractometer. Diffraction intensities were collected with graphitemonochromated MoKa $(0.71073 \AA)$ radiation and the $\omega-2 \theta$ variable-scan mode. The crystal was kept at $153.15 \mathrm{~K}$ during data collection. The structure was solved by direct methods and subsequent difference Fourier maps and then refined on $\mathrm{F}^{2}$ to final $\mathrm{R}_{1}=0.0465$ and $\mathrm{wR}_{2}$ (all data $)=0.0890$ by a full-matrix least-squares procedure using anisotropic displacement parameters. All non-hydrogen atoms were refined with anisotropic displacement parameters. Hydrogen atoms were placed in ideal positions and refined as riding atoms with relative isotropic displacement parameters. The structure was solved with the SHELXS (Sheldrick 2008) structure solution program using Direct Methods and refined with the SHELXL (Sheldrick 2015) refinement package using Least Squares minimisation. 
Table S1 Crystal data and structure refinement for $\mathbf{3 g}$

Identification code

Empirical formula

Formula weight

Temperature/K

Crystal system

Space group

$\mathrm{a} / \AA$

$\mathrm{b} / \AA$

$\mathrm{c} / \AA ̊$

$\alpha /^{\circ}$

$\beta /{ }^{\circ}$

$\gamma /{ }^{\circ}$

Volume $/ \AA^{3}$

Z

$\rho_{\text {calc }} / \mathrm{cm}^{3}$

$\mu / \mathrm{mm}^{-1}$

$\mathrm{F}(000)$

Crystal size $/ \mathrm{mm}^{3}$

Radiation

$2 \Theta$ range for data collection ${ }^{\circ}$

Index ranges

Reflections collected

Independent reflections

Data/restraints/parameters

Goodness-of-fit on $\mathrm{F}^{2}$

Final R indexes $[\mathrm{I}>=2 \sigma(\mathrm{I})]$

Final R indexes [all data]

Largest diff. peak/hole / e $\AA^{-3}$

Flack parameter
BWN19457

$\mathrm{C}_{31} \mathrm{H}_{27} \mathrm{BrN}_{2} \mathrm{O}_{6}$

603.45

163.15

monoclinic

$\mathrm{P} 21$

$11.320(2)$

$10.926(2)$

$11.687(2)$

90

97.55(3)

90

$1433.0(5)$

2

1.399

1.480

620.0

$0.24 \times 0.21 \times 0.15$

$\operatorname{MoK} \alpha(\lambda=0.71073)$

5.376 to 54.996

$-14 \leq \mathrm{h} \leq 14,-14 \leq \mathrm{k} \leq 14,-15 \leq 1 \leq 15$

9761

$5904\left[\mathrm{R}_{\text {int }}=0.0335, \mathrm{R}_{\text {sigma }}=0.0589\right]$

$5904 / 1 / 363$

1.084

$\mathrm{R}_{1}=0.0427, \mathrm{wR}_{2}=0.0861$

$\mathrm{R}_{1}=0.0465, \mathrm{wR}_{2}=0.0890$

$0.32 /-0.40$

$-0.003(7)$ 


\subsection{Stereochemical analysis of compound 4}

As can be seen from Figure S2 and S3, the NOE spectrum of compound $\mathbf{4}$ shows an important correlation among the $\mathrm{H}$. As shown in the figure S3, firstly, the NOE observed between $\mathrm{OH}$ and $\mathrm{C} 1-\mathrm{H}$ (point 1). Then, there is correlation between $\mathrm{OH}$ and $\mathrm{C} 2-\mathrm{H}$ (point 2) and the correlation between $\mathrm{C} 1-\mathrm{H}$ and $\mathrm{Ar}-\mathrm{H}$ is also detected (point 3). So the hydroxy turned to the behind in the compound 4. If not, the correlation between $\mathrm{OH}$ and $\mathrm{Ar}-\mathrm{H}$ should be detected in the NOE spectrum (point 4), but there is no signal. Thus, the relative configuration of compound 4 is determined as Figure S4 depicted.

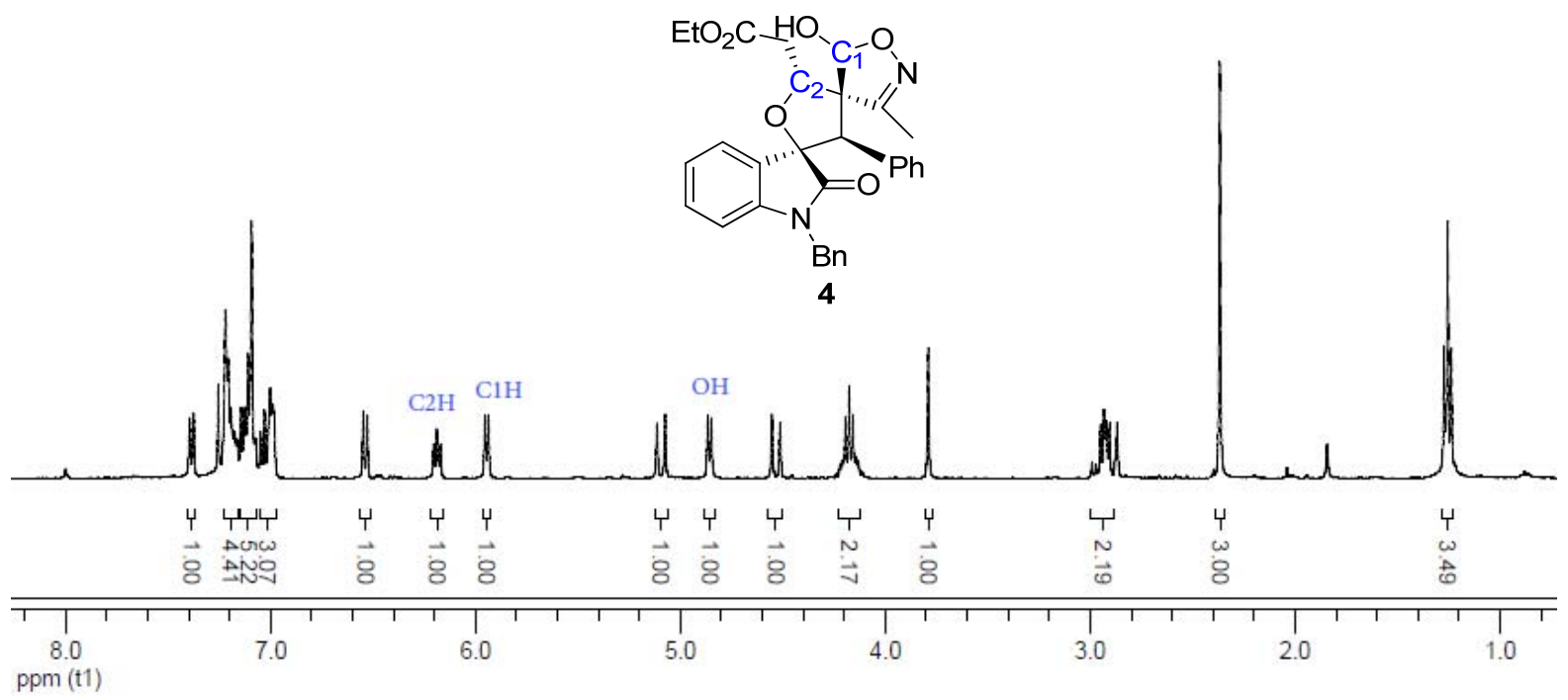

Figure S2. ${ }^{1}$ H NMR Spectra of compound 4

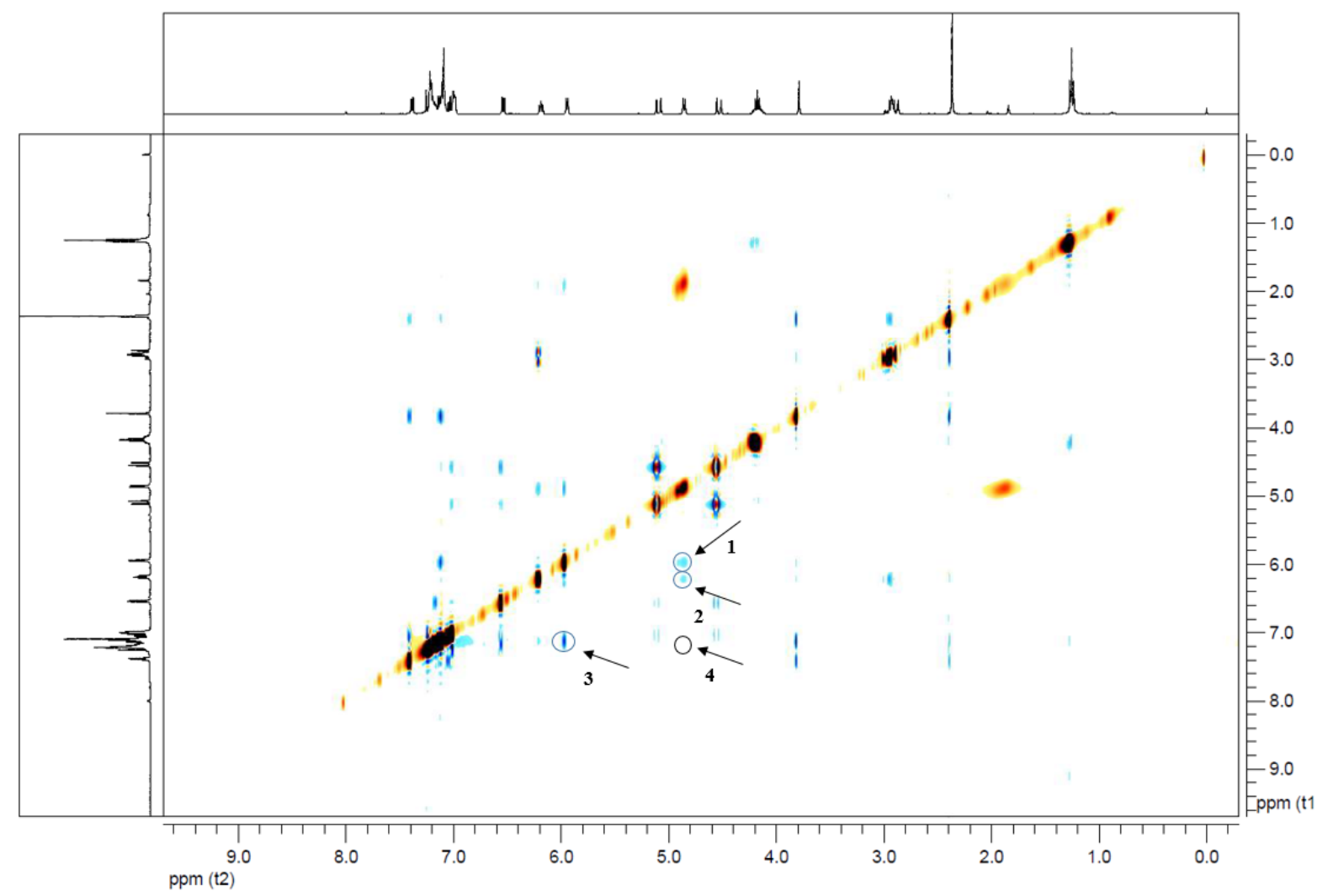

Figure S3. H-H NOESY of compound 4 


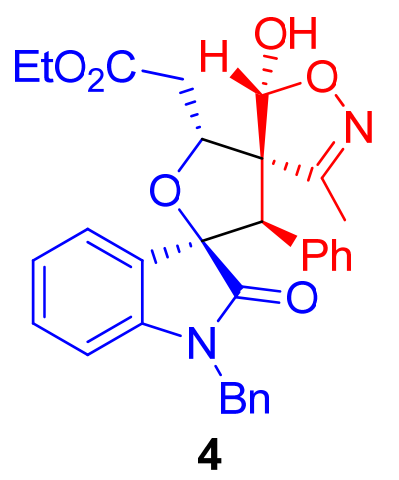

Figure S4. The relative configuration of compound 4 
2. Copies of ${ }^{1} \mathrm{H},{ }^{13} \mathrm{C}$ and ${ }^{19} \mathrm{~F}$ NMR spectra of compounds

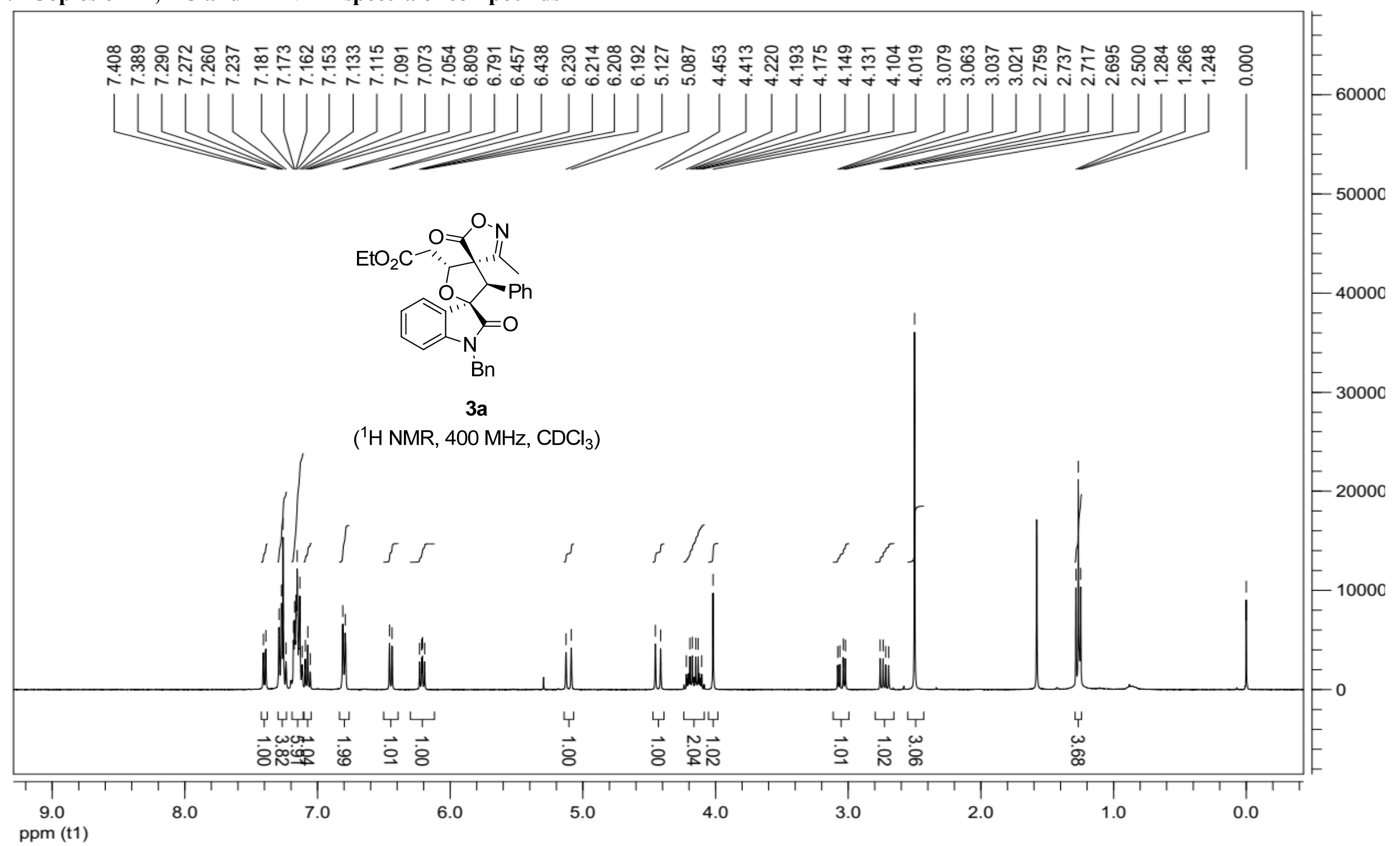




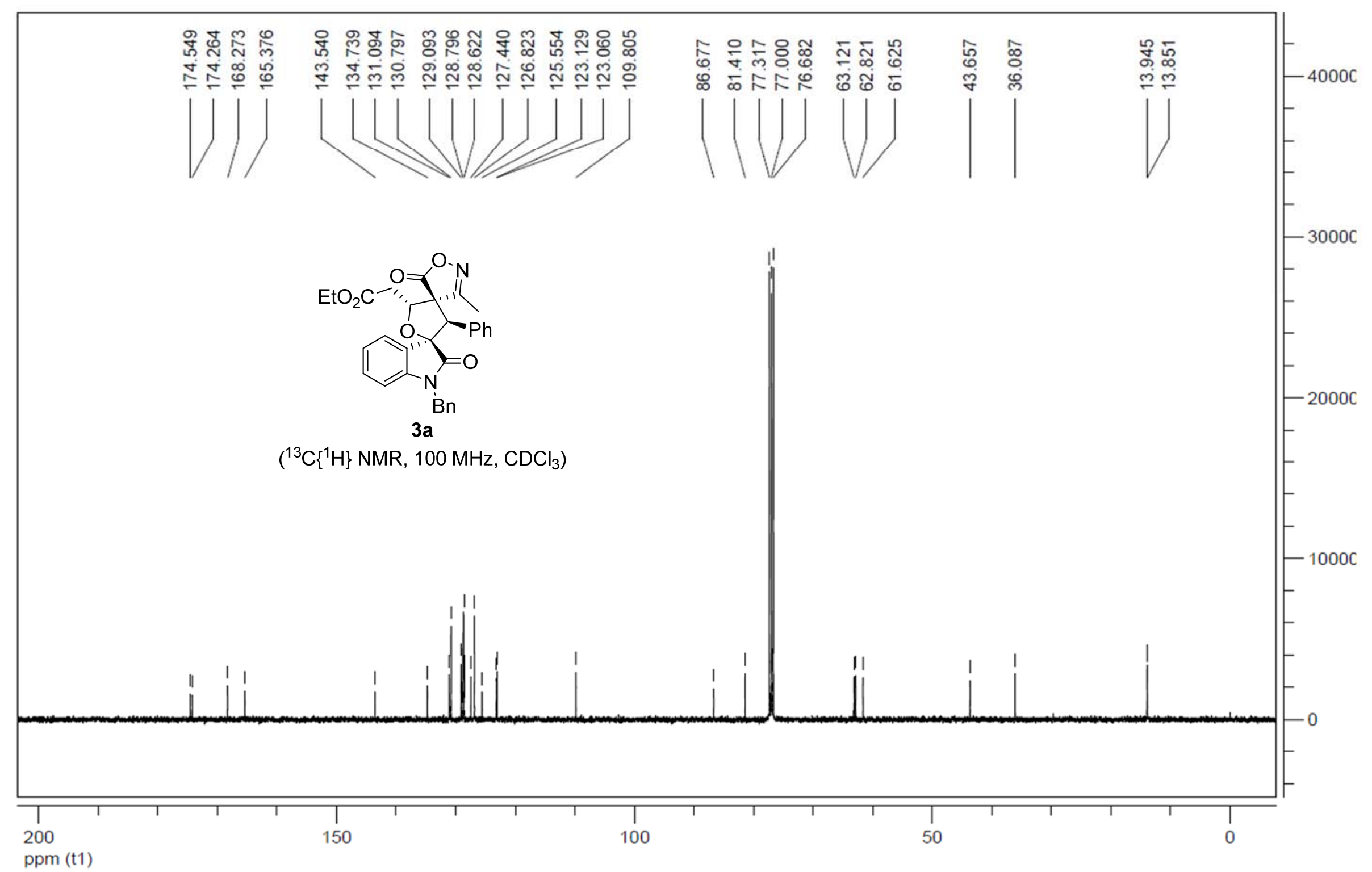




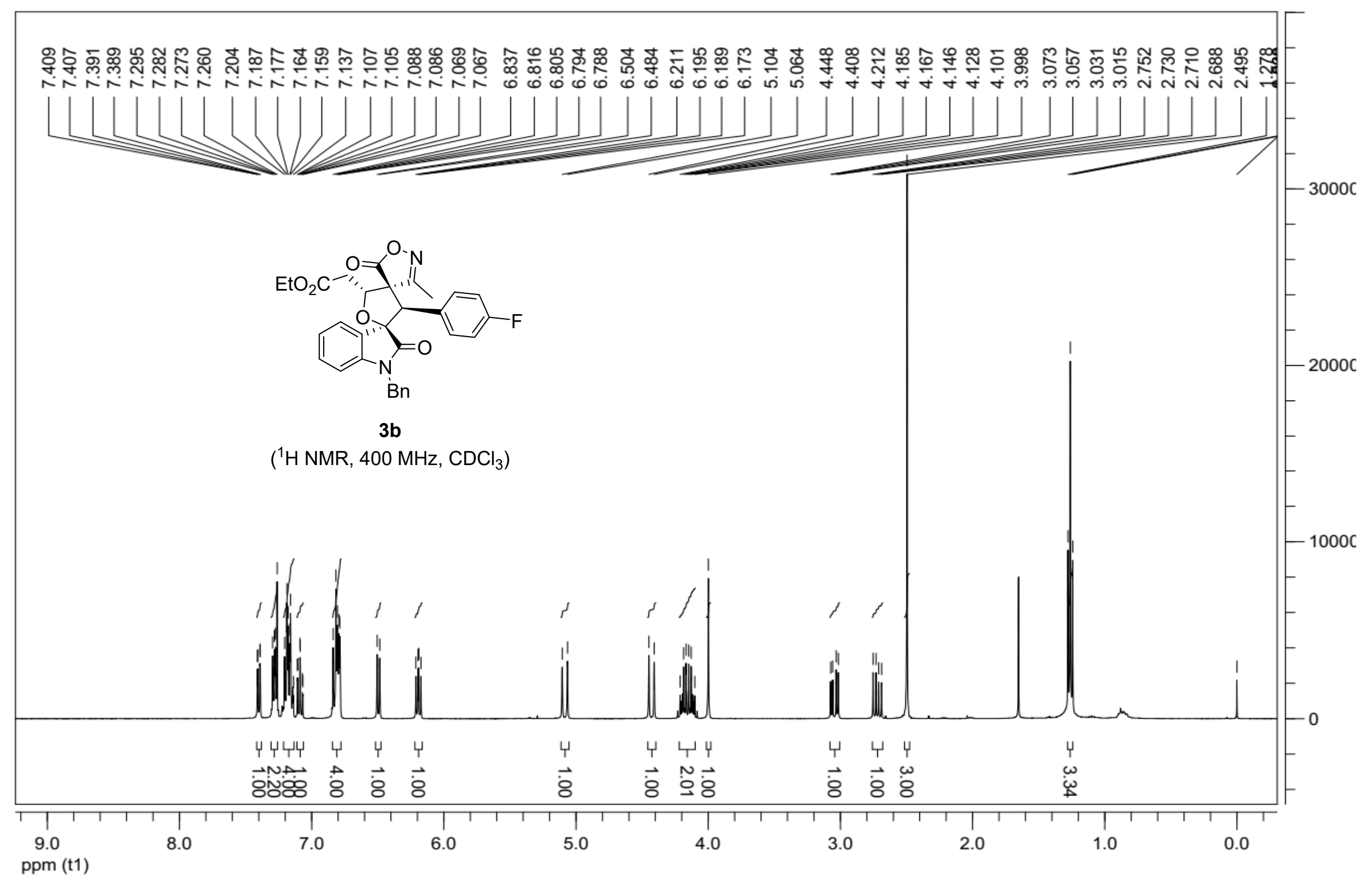




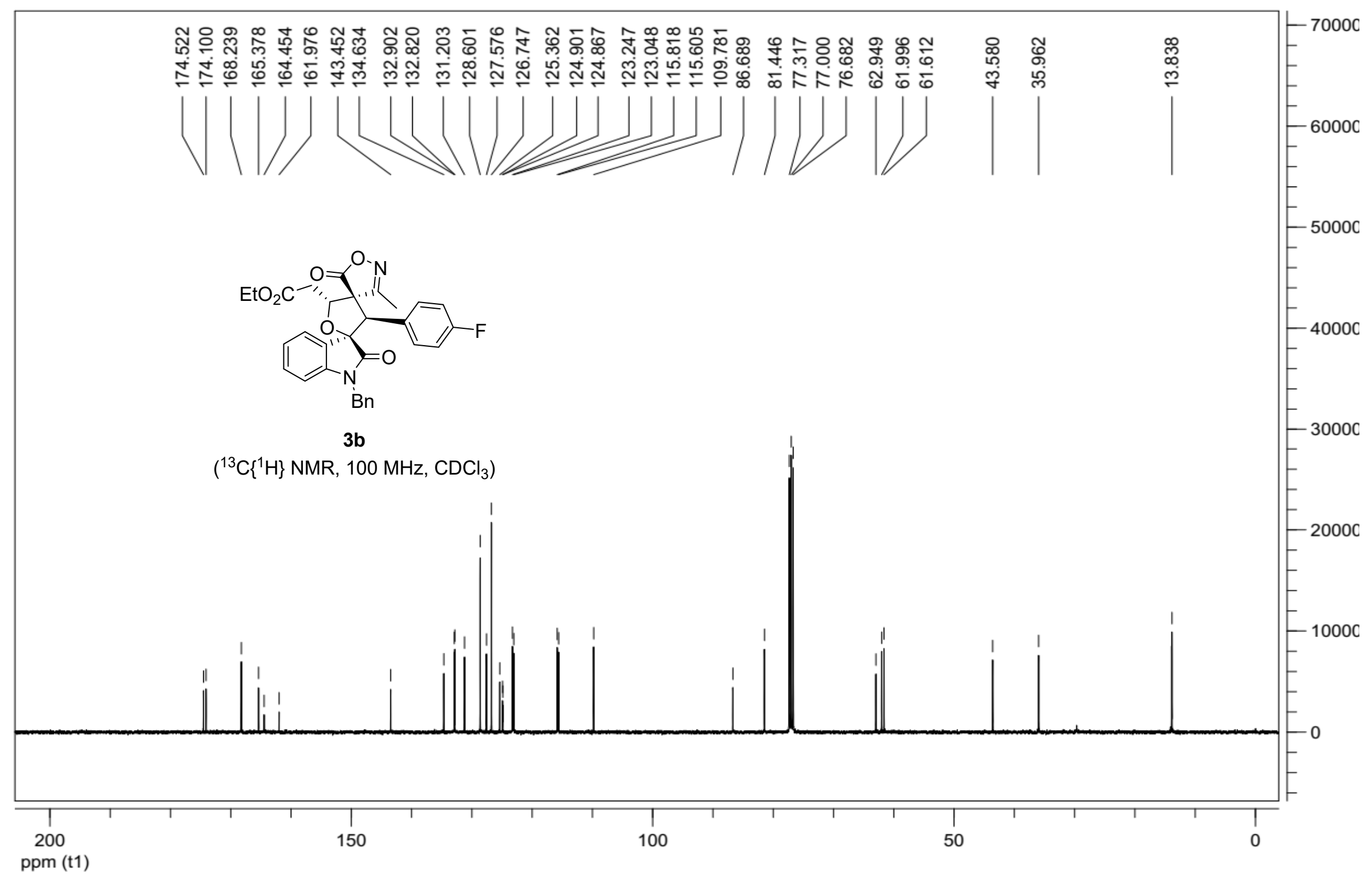




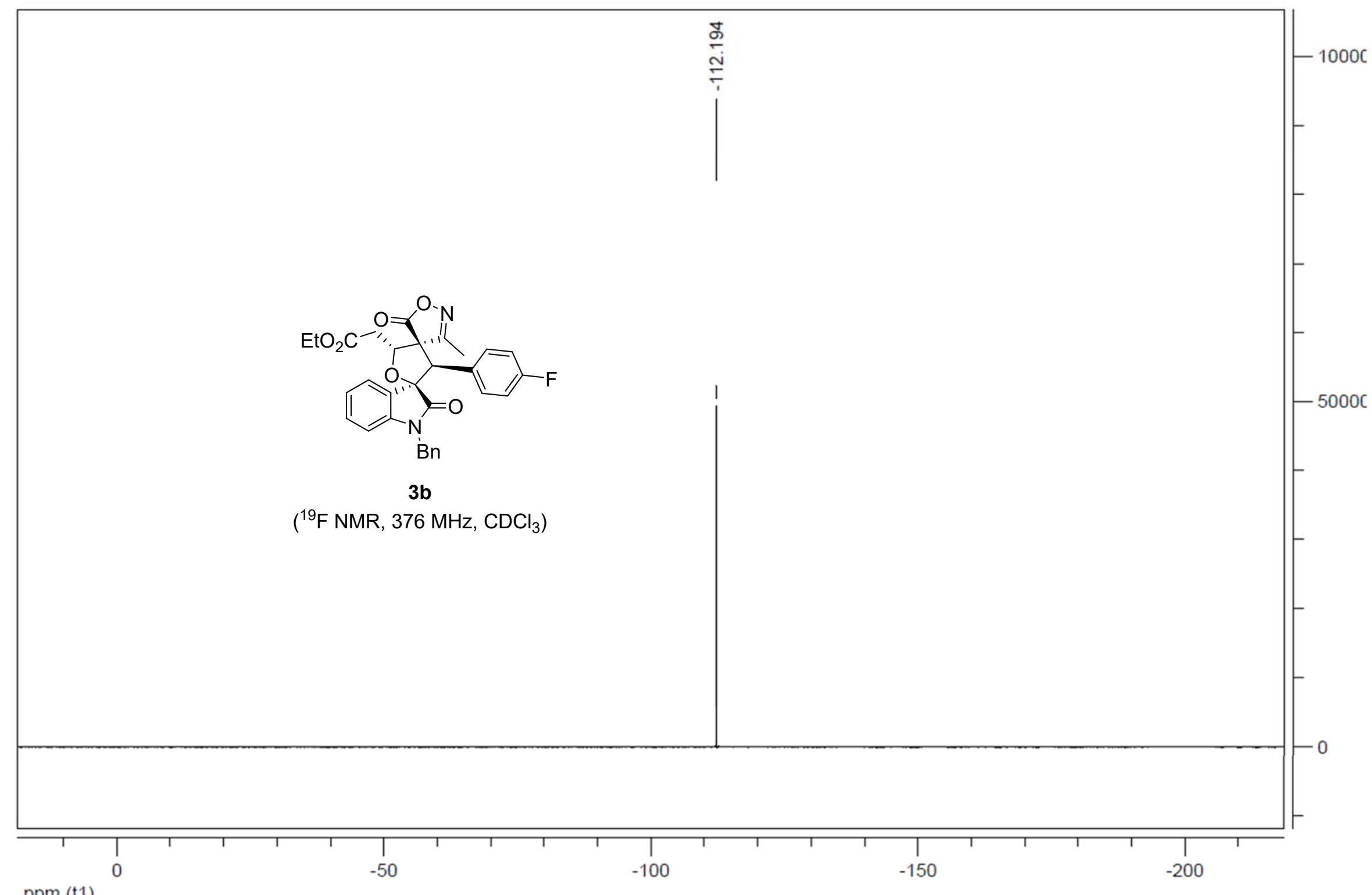

ppm (t1) 


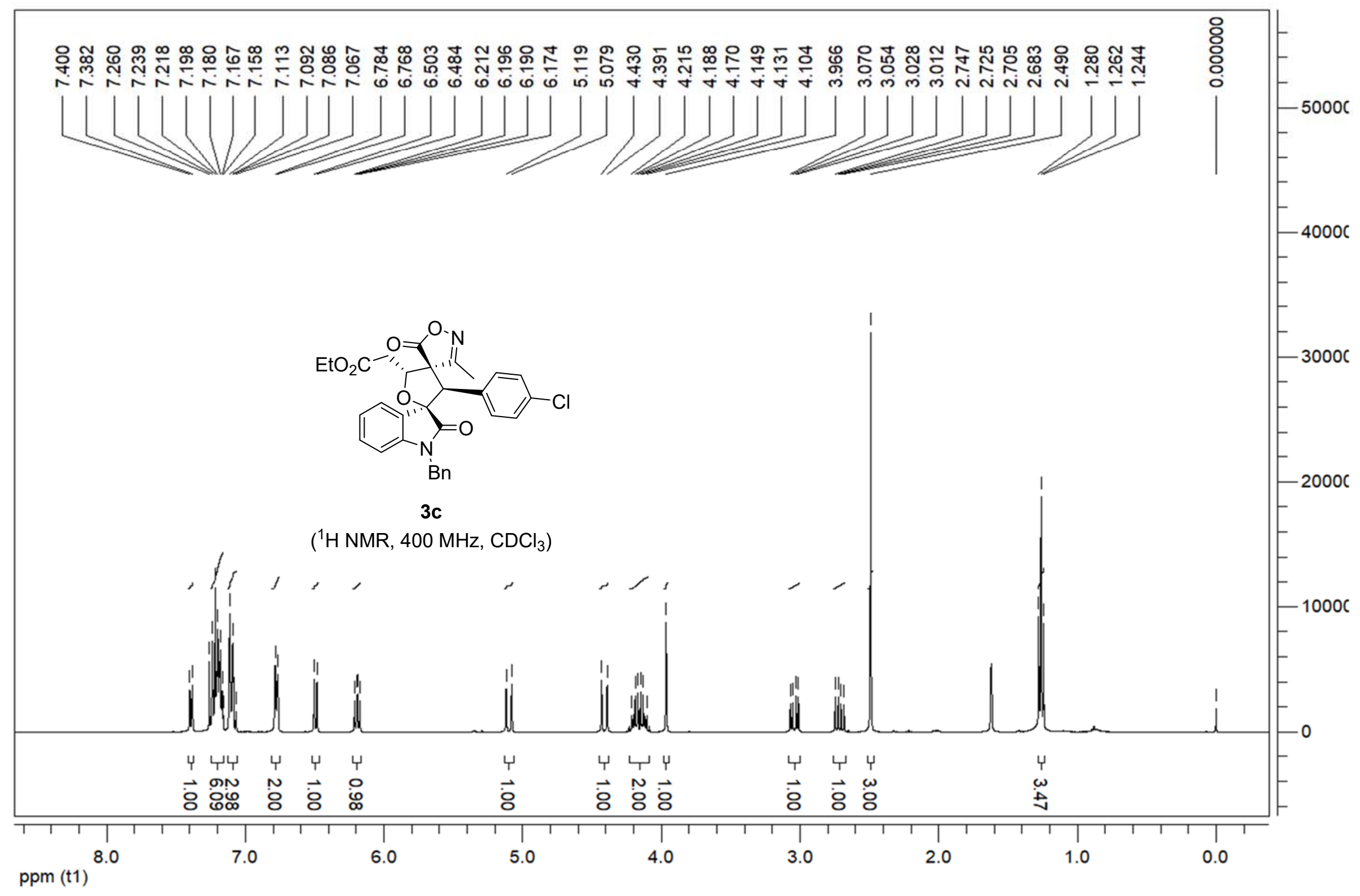




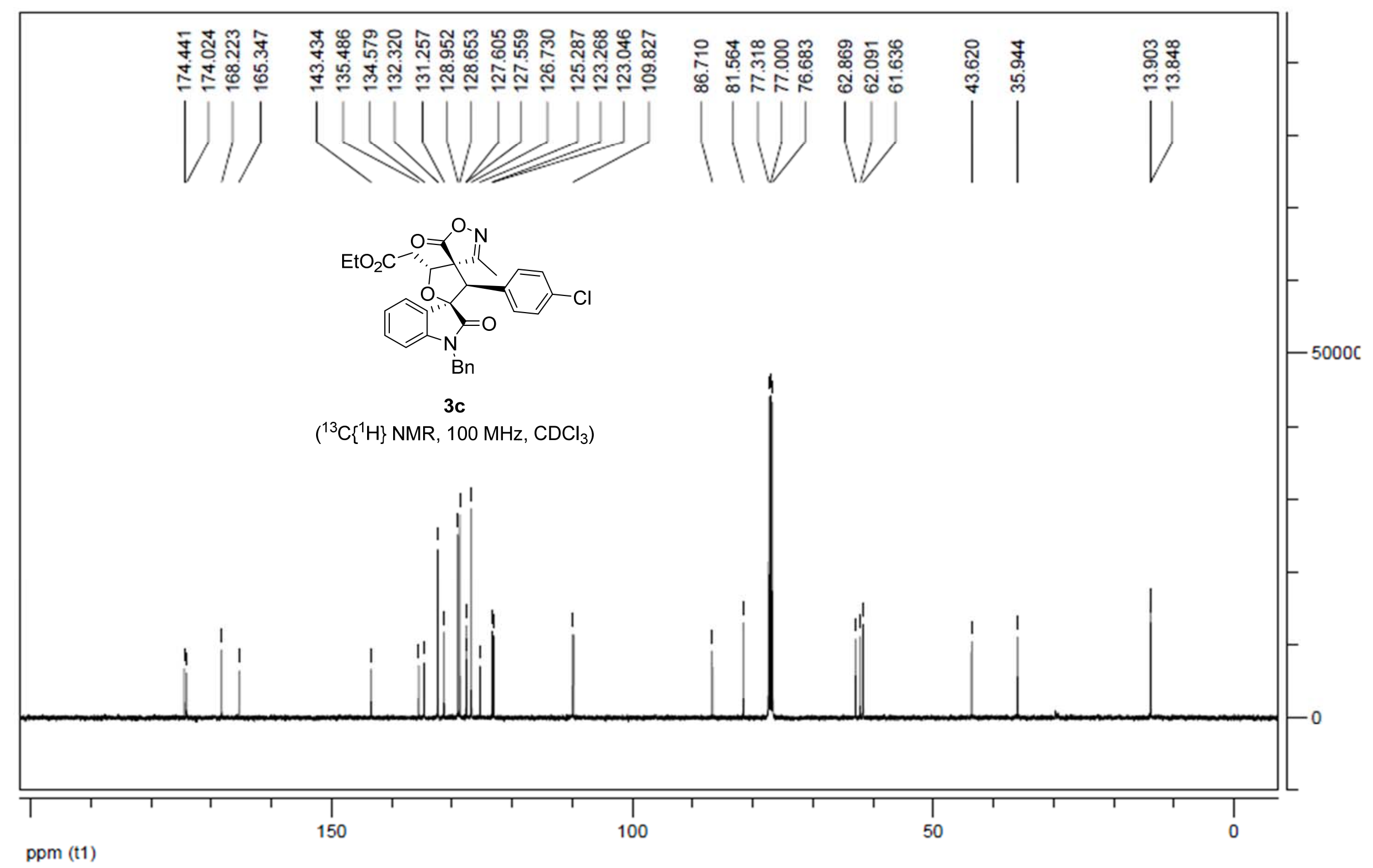




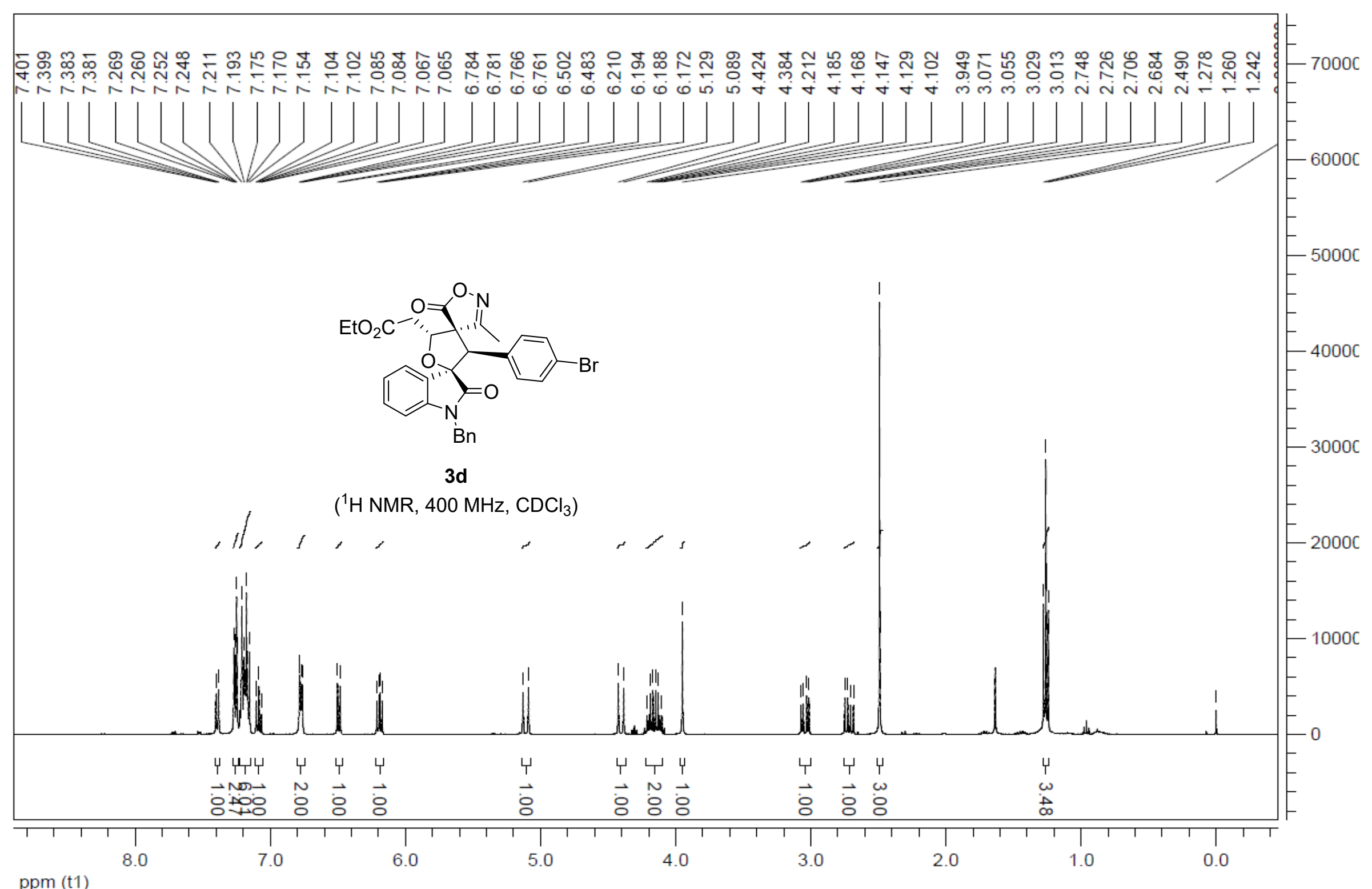




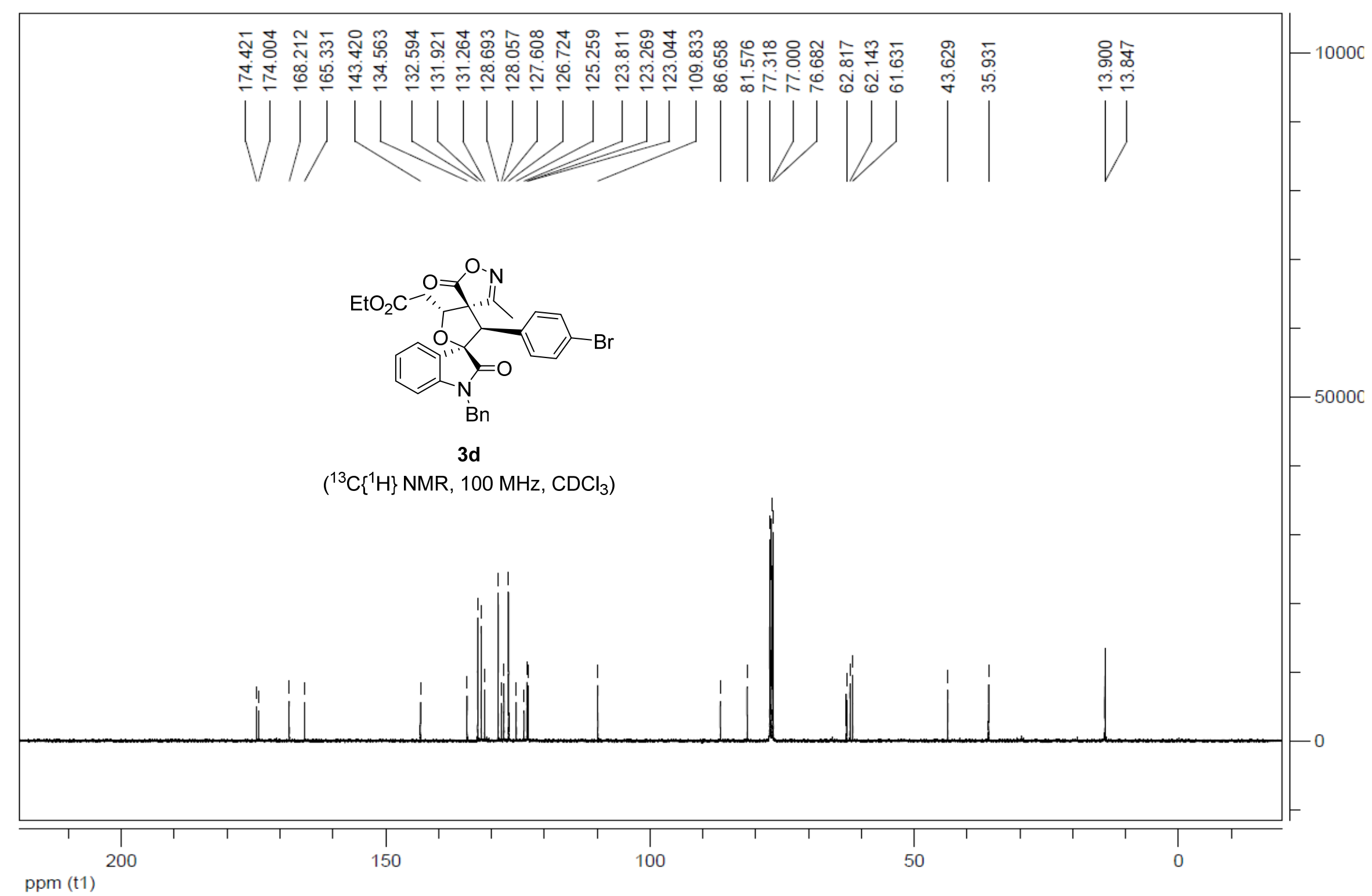




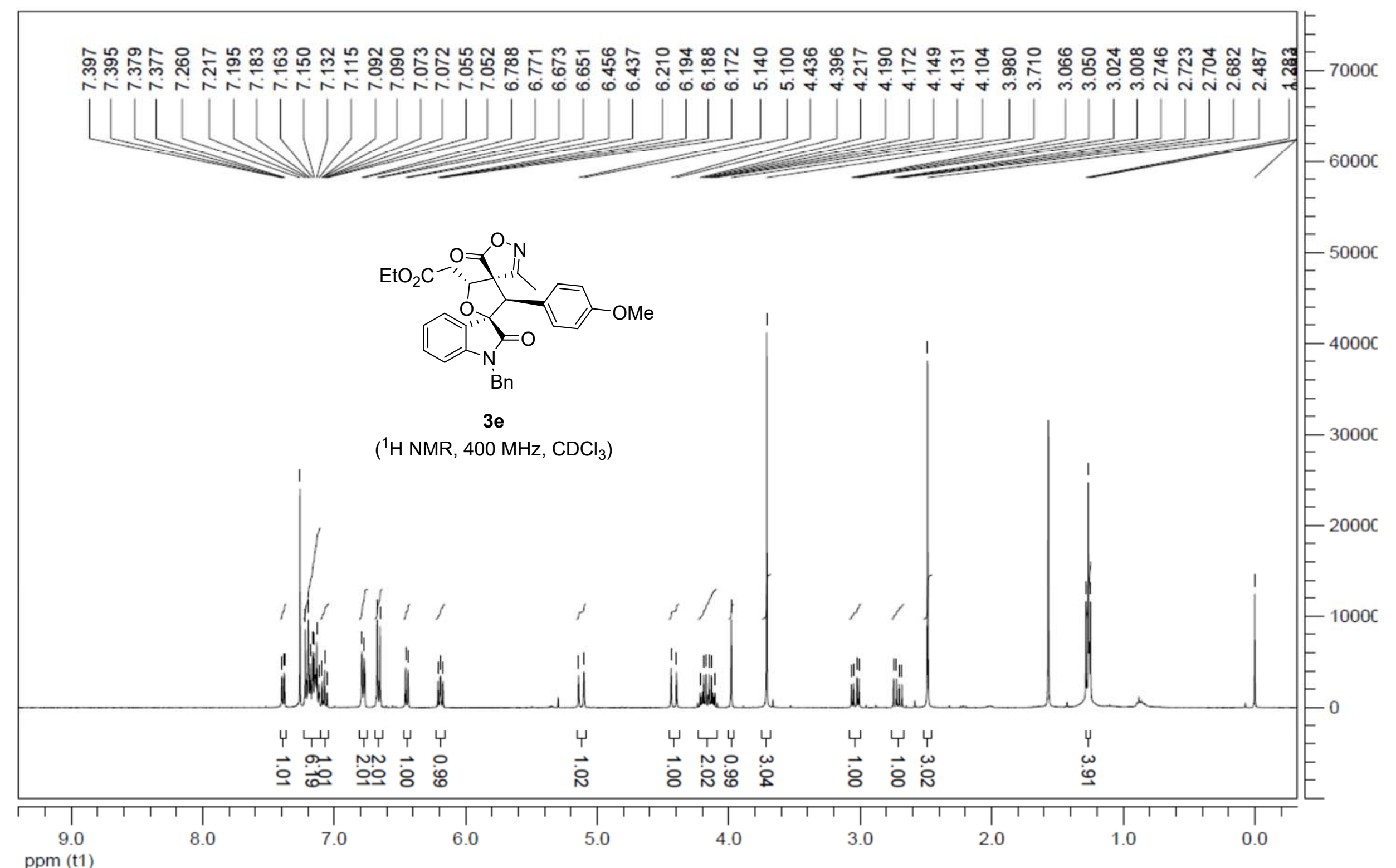




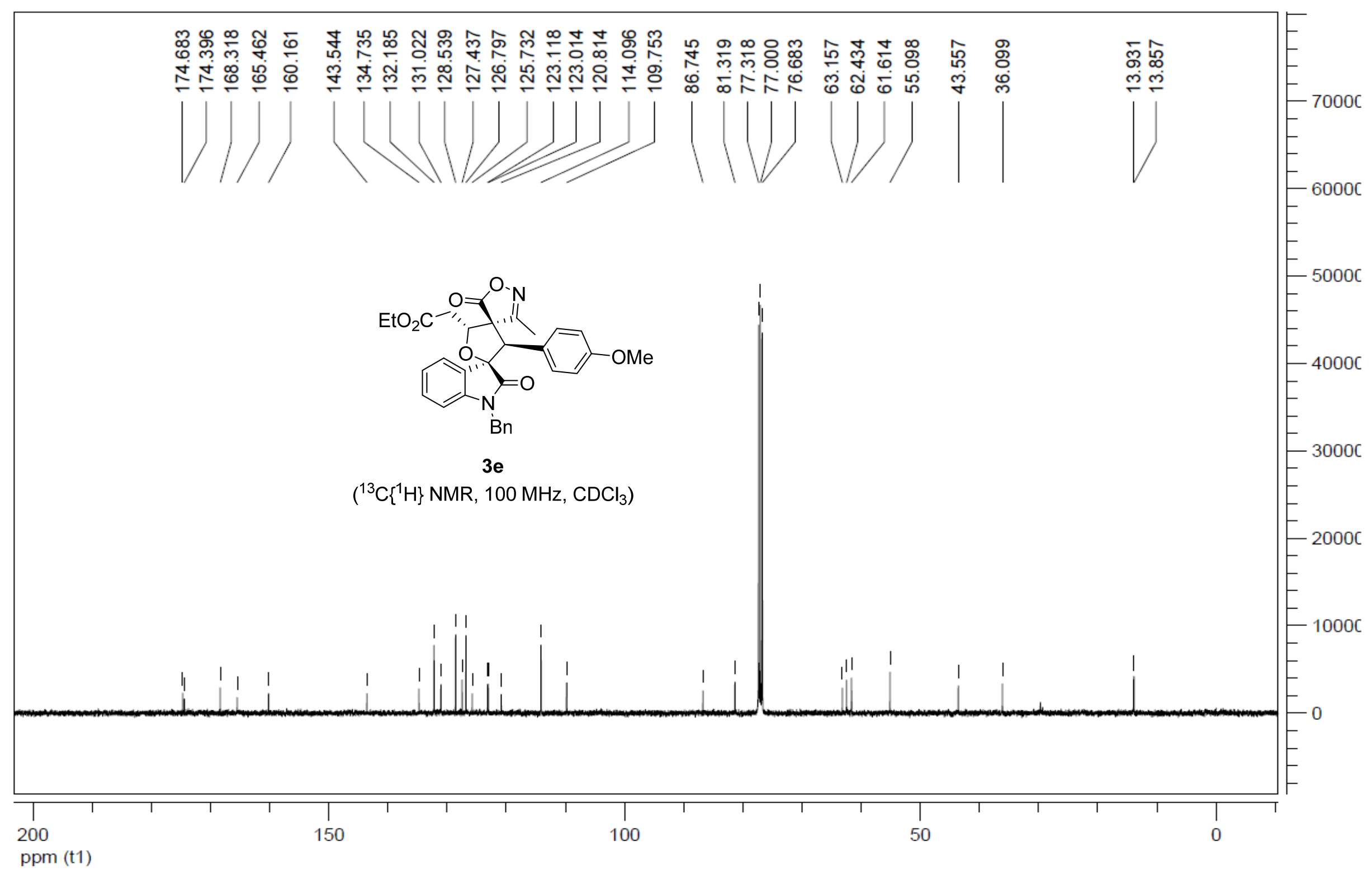




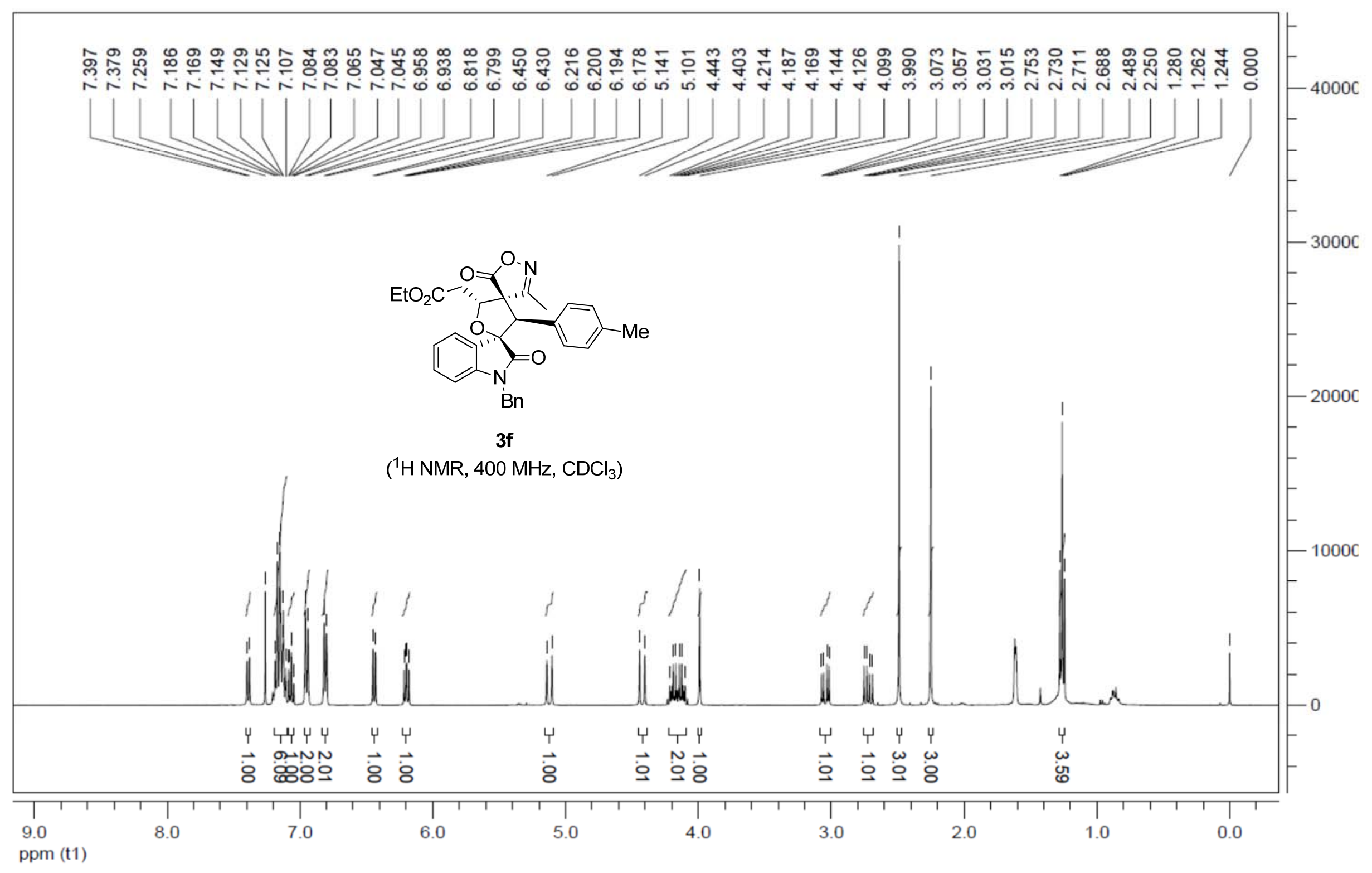




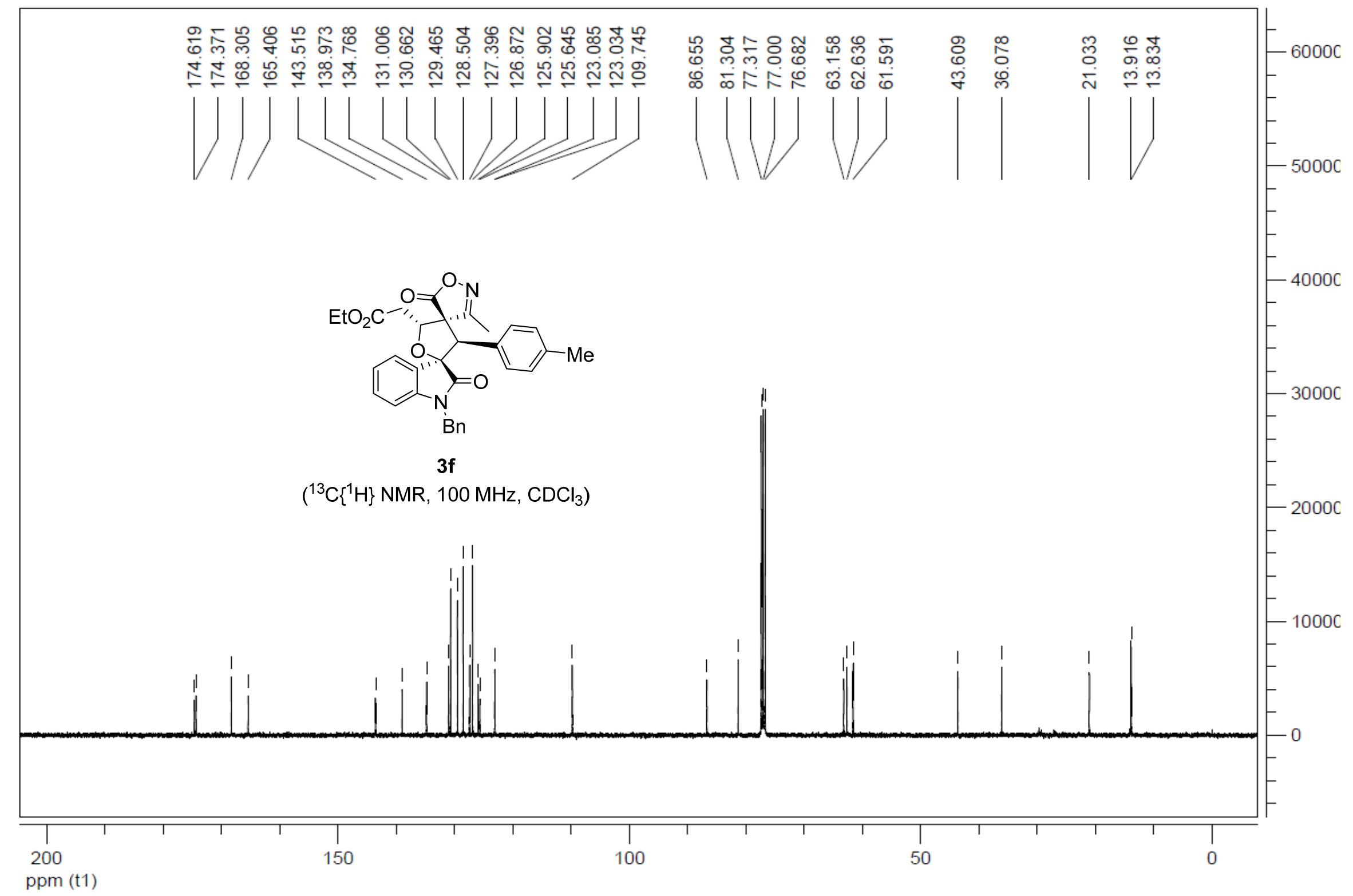




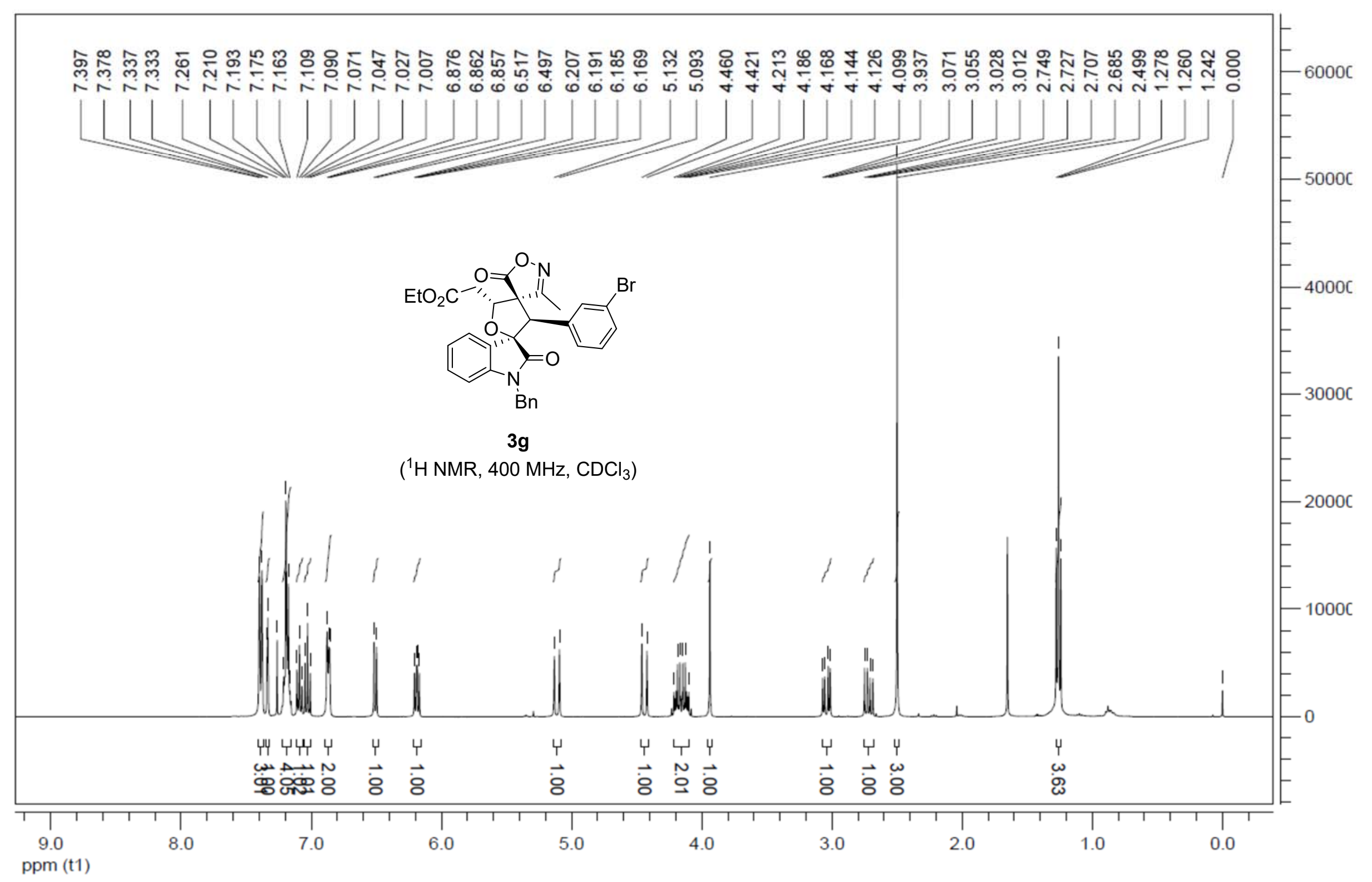




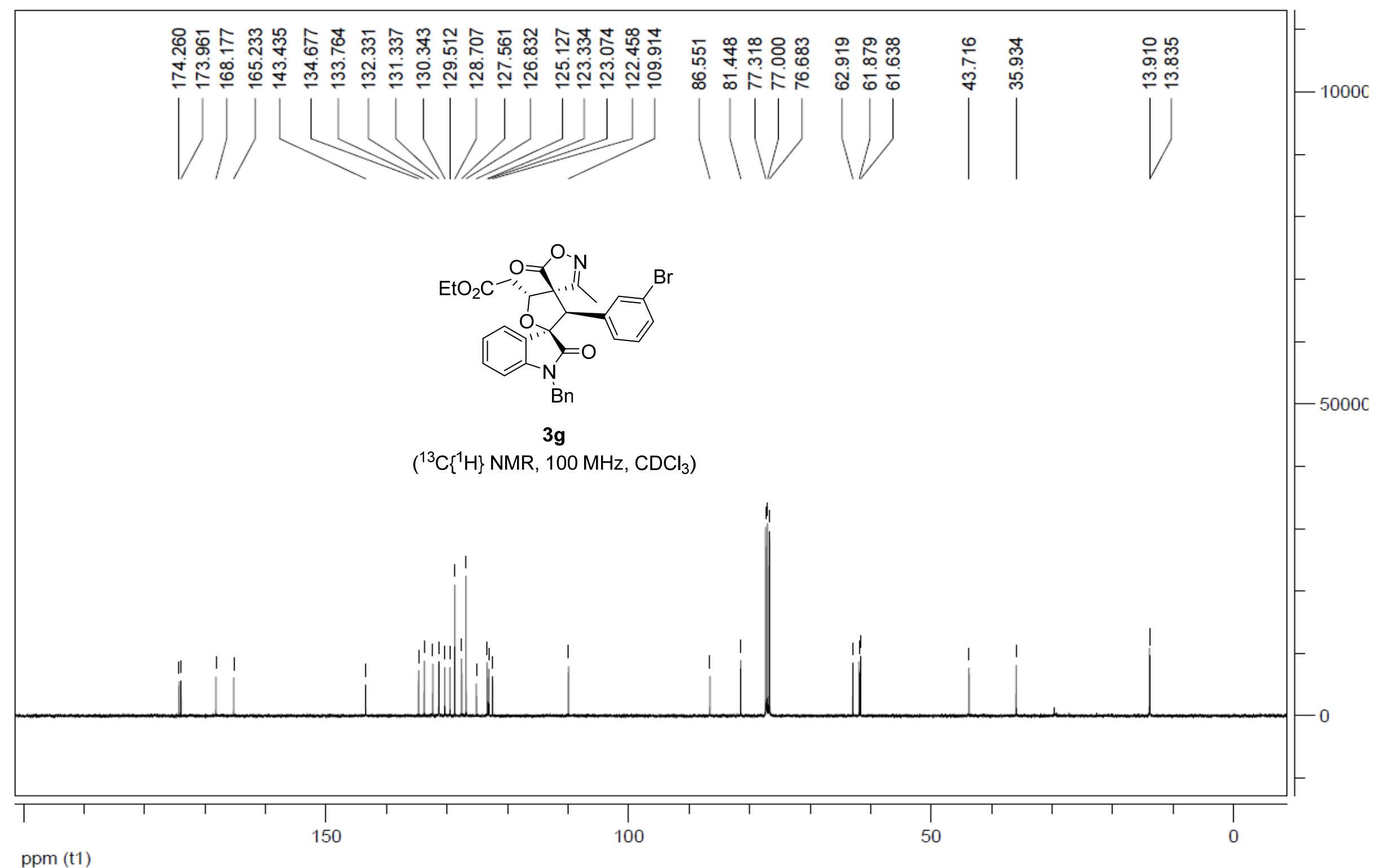




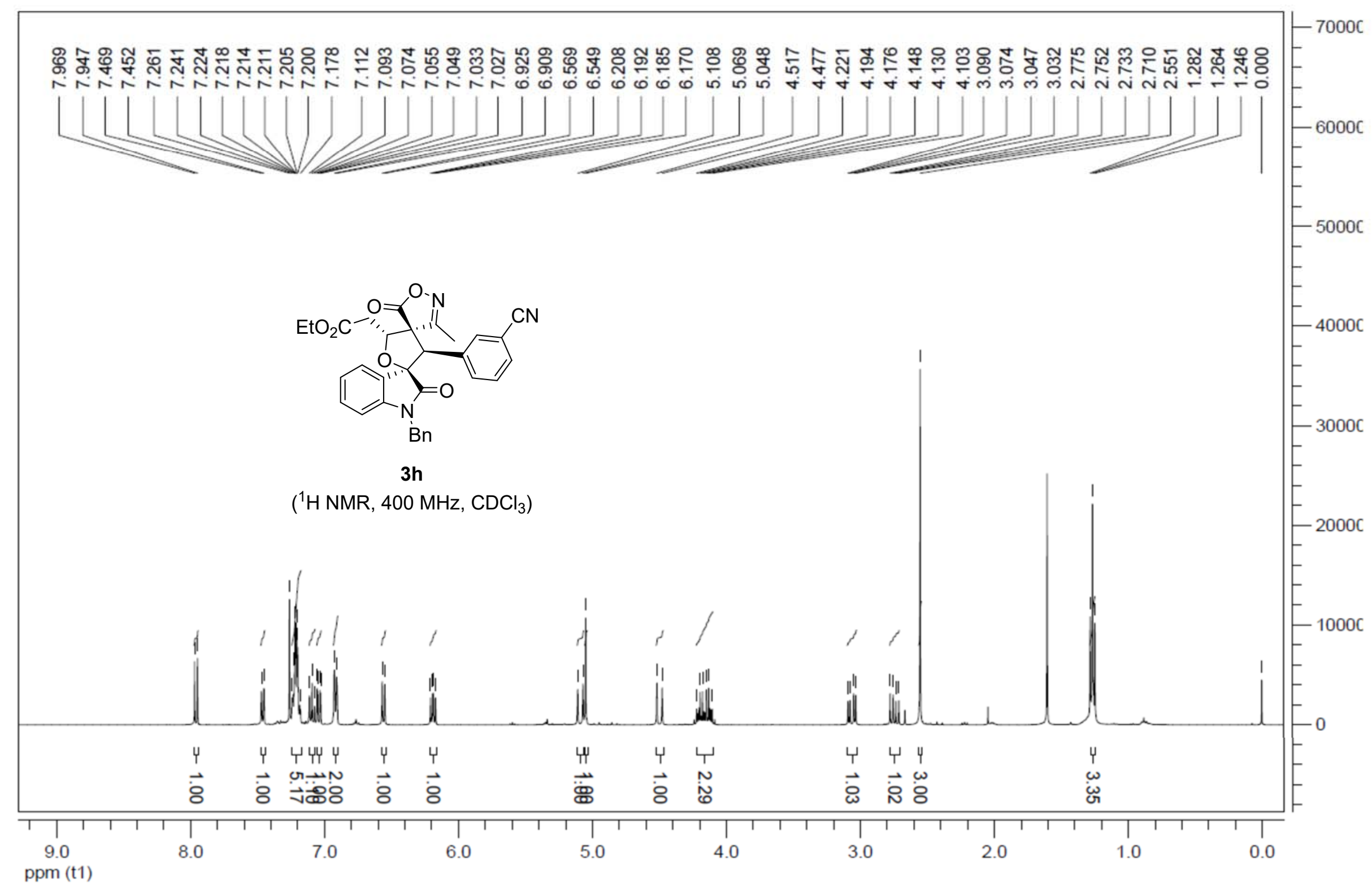




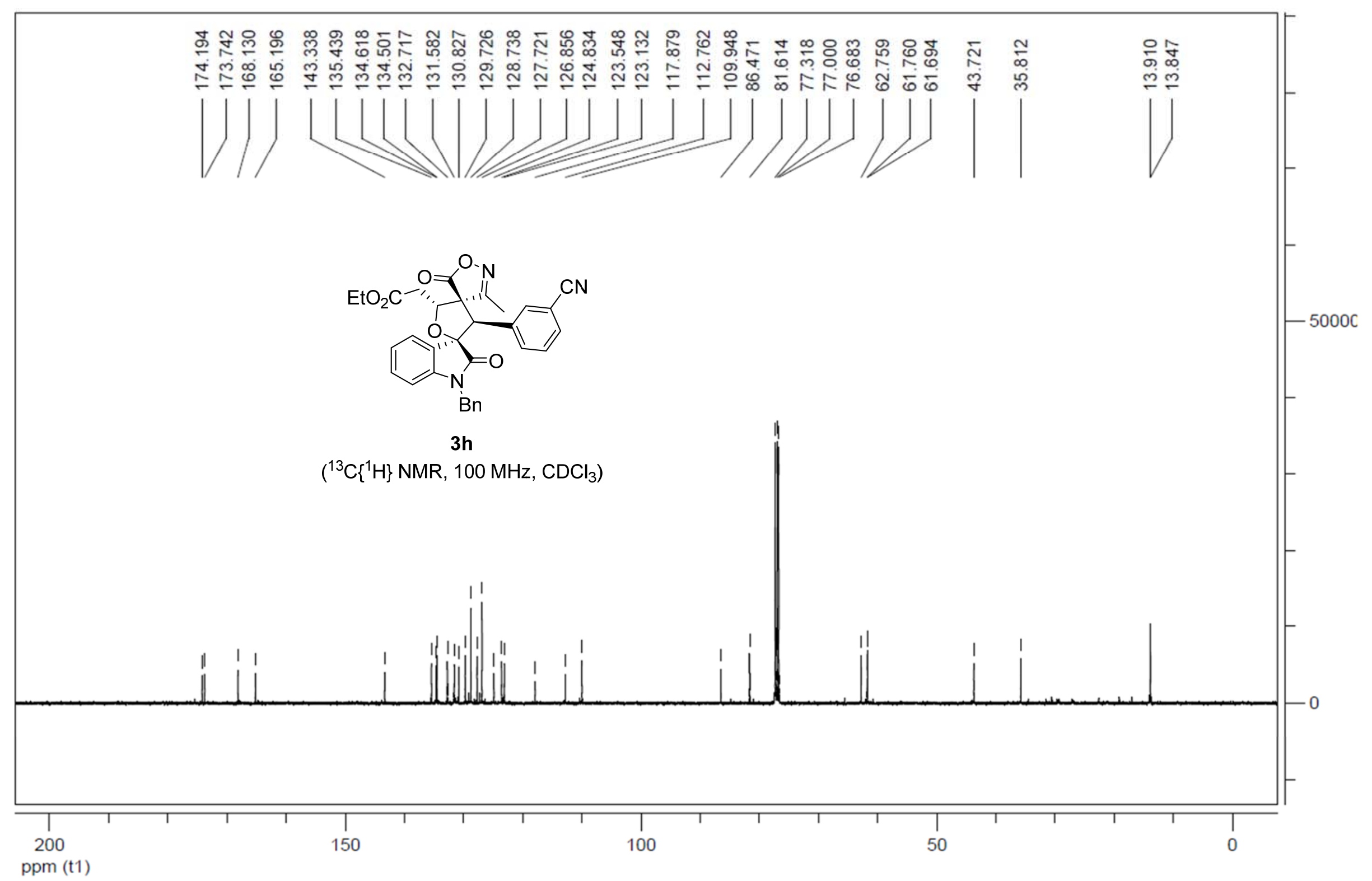




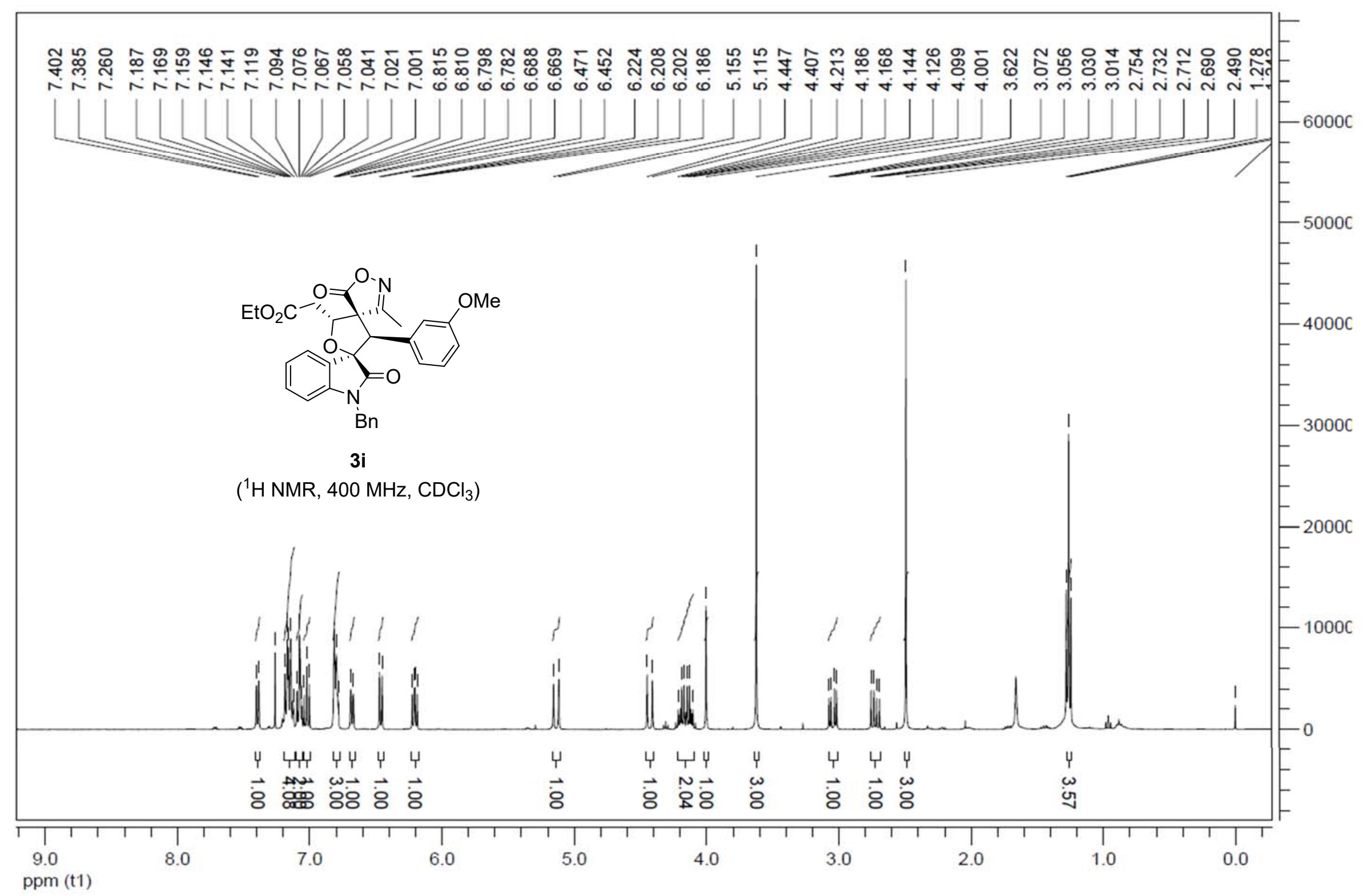




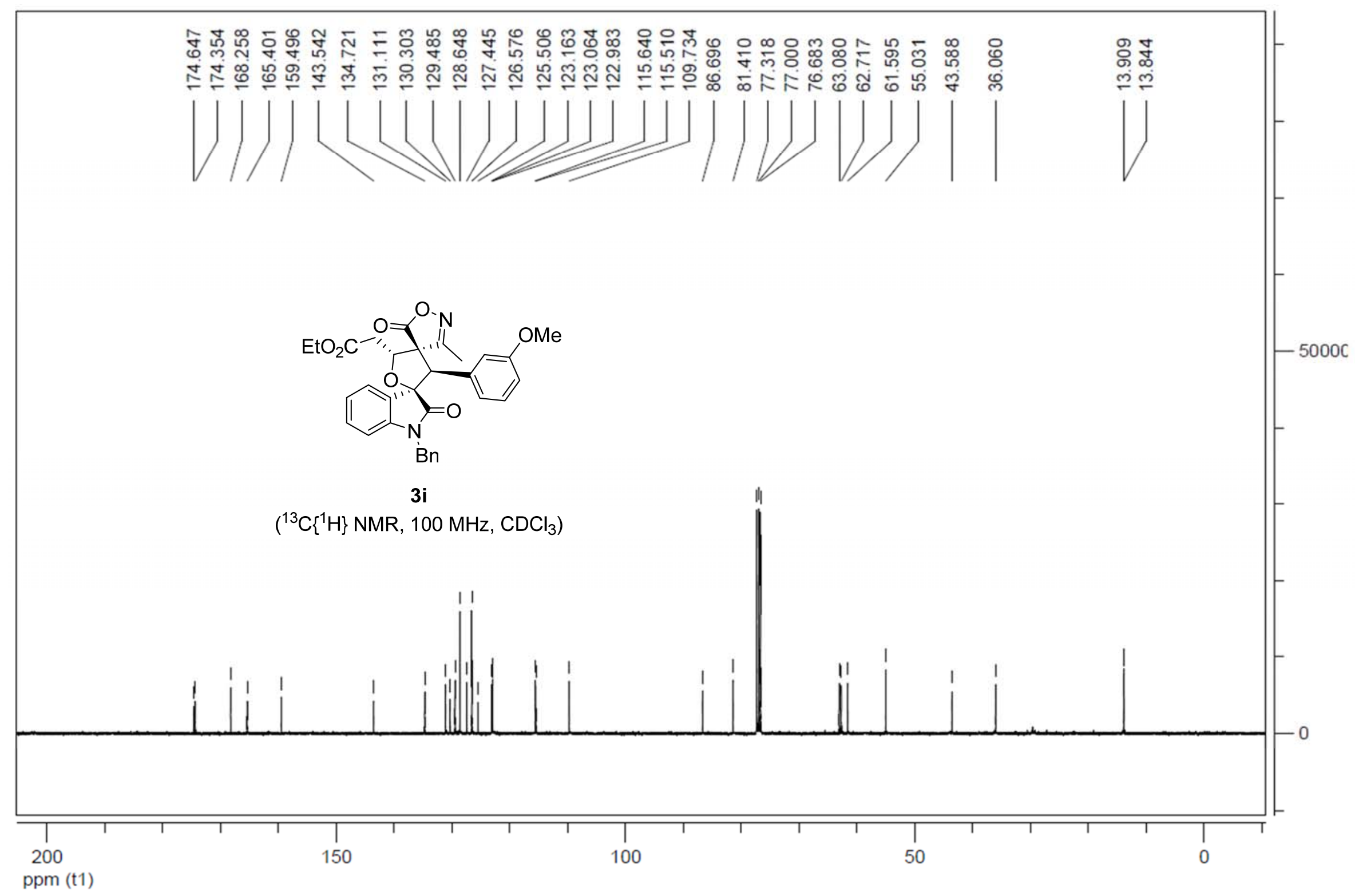




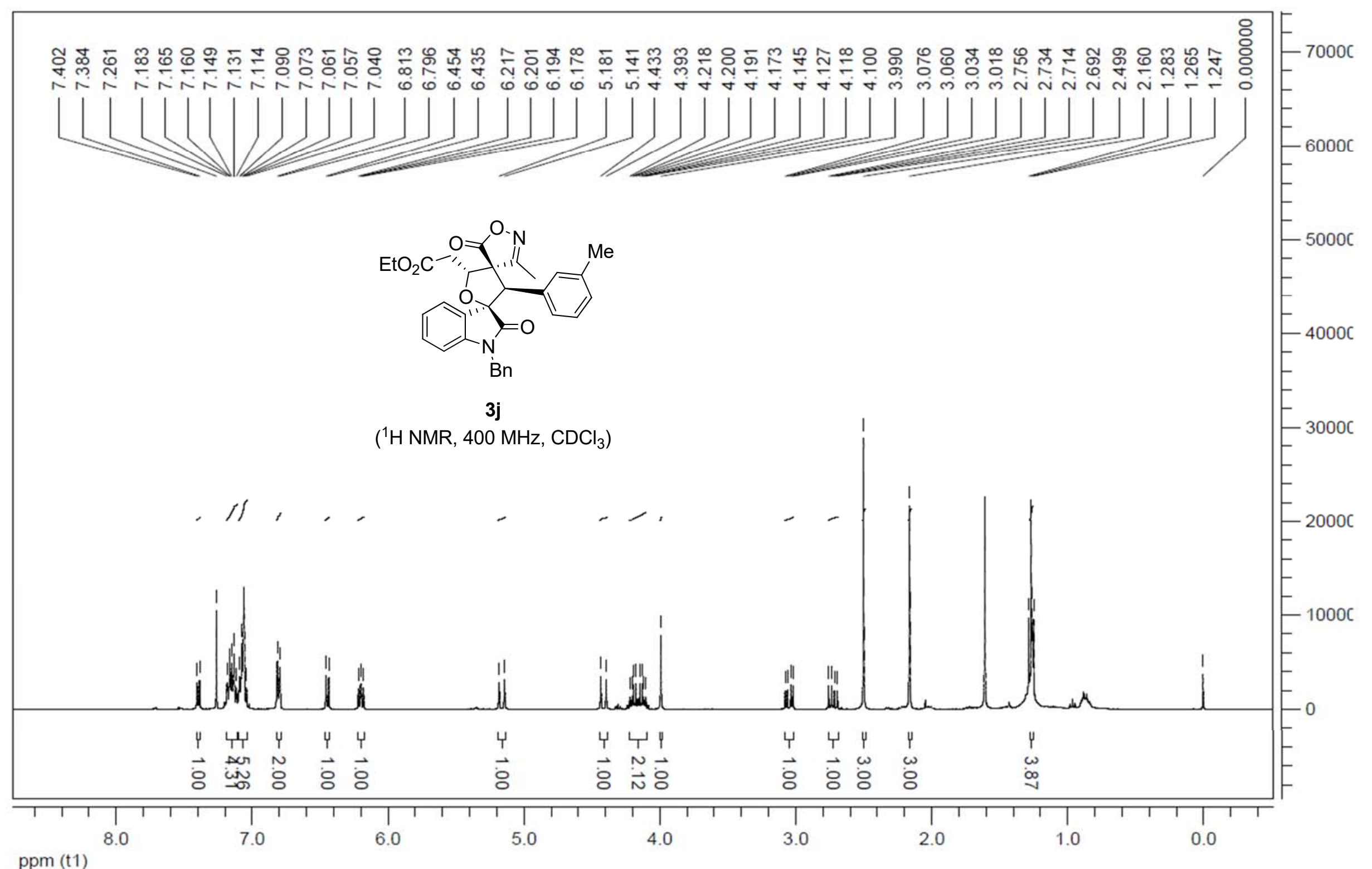




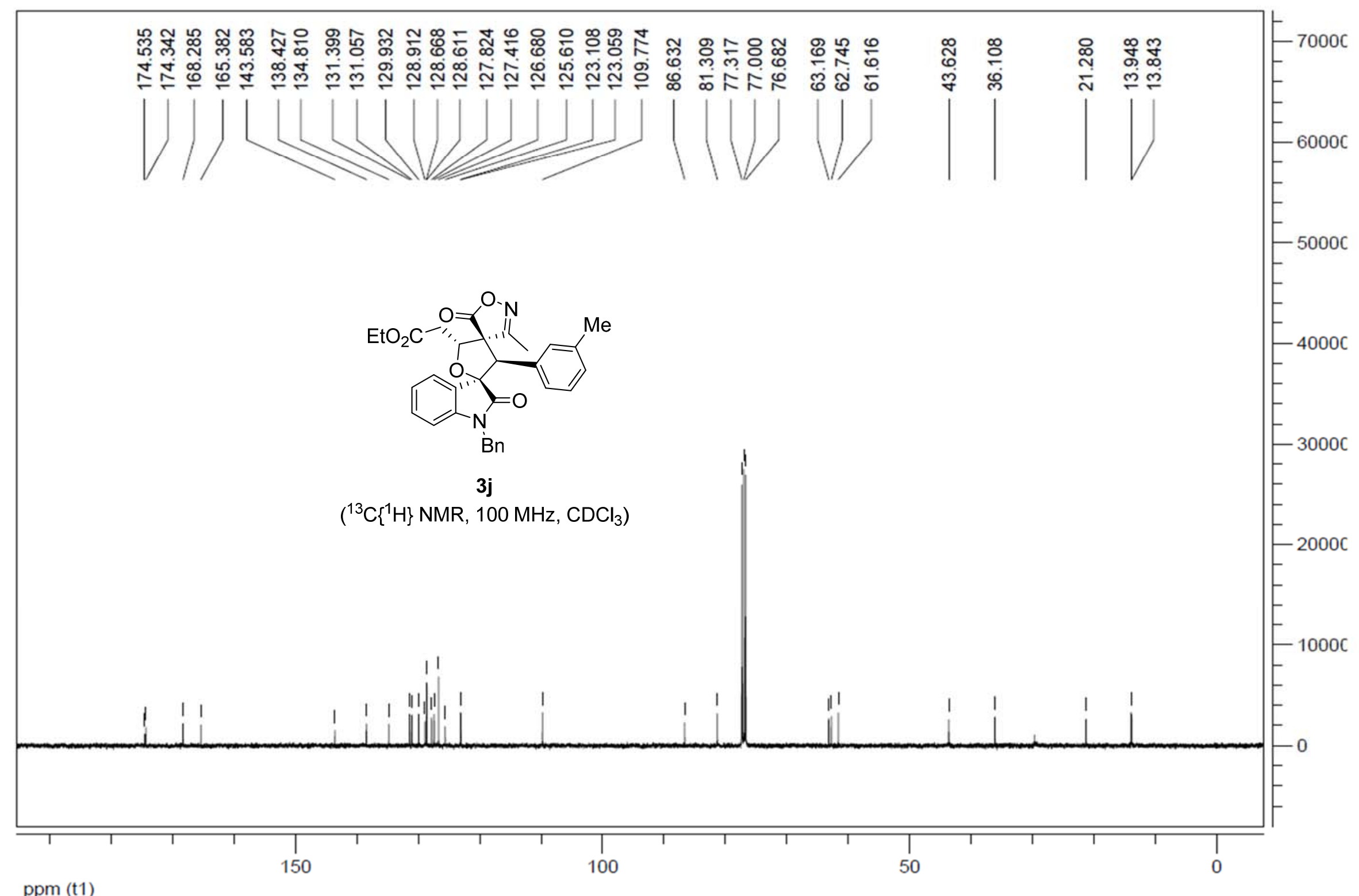




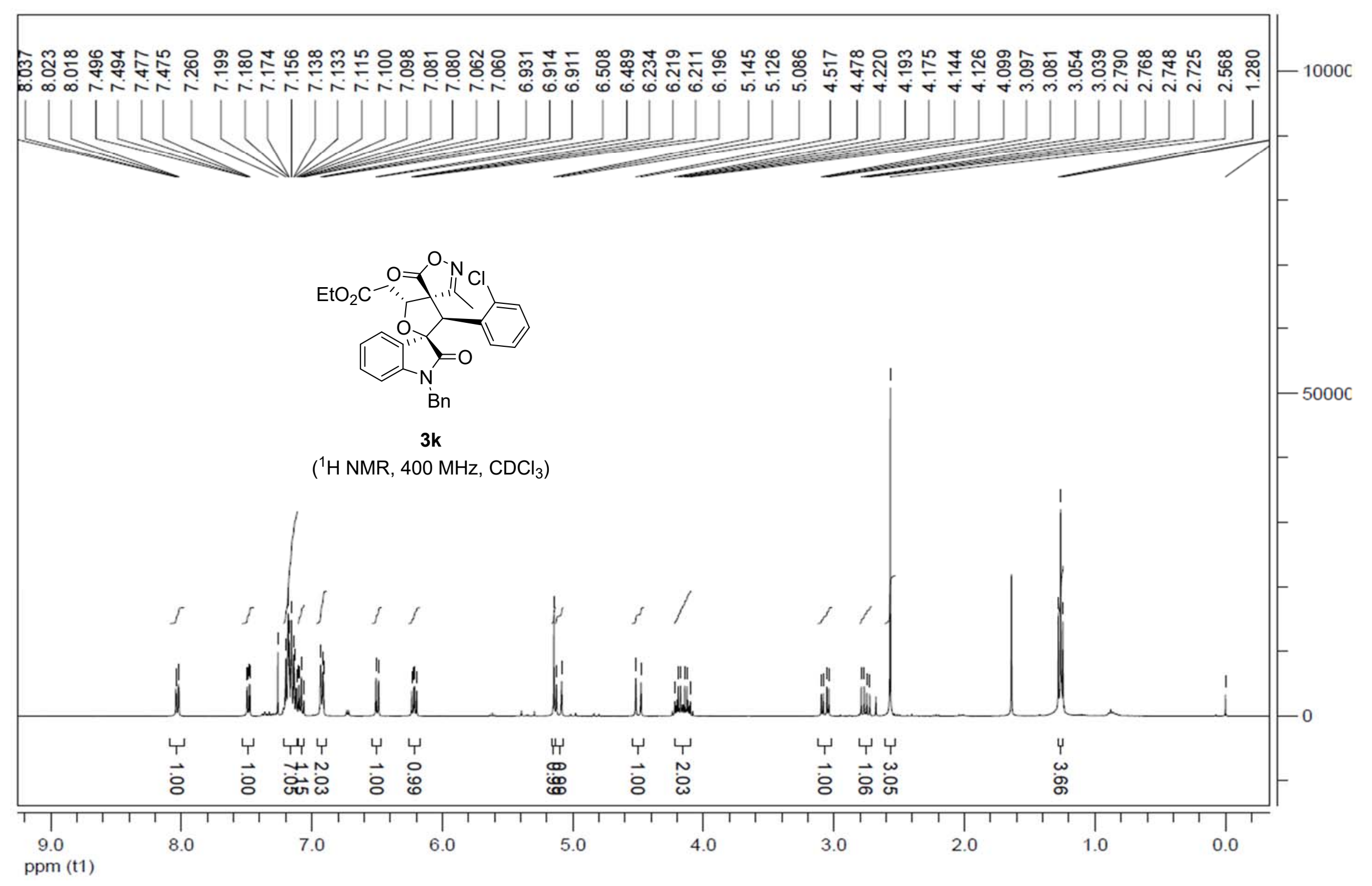




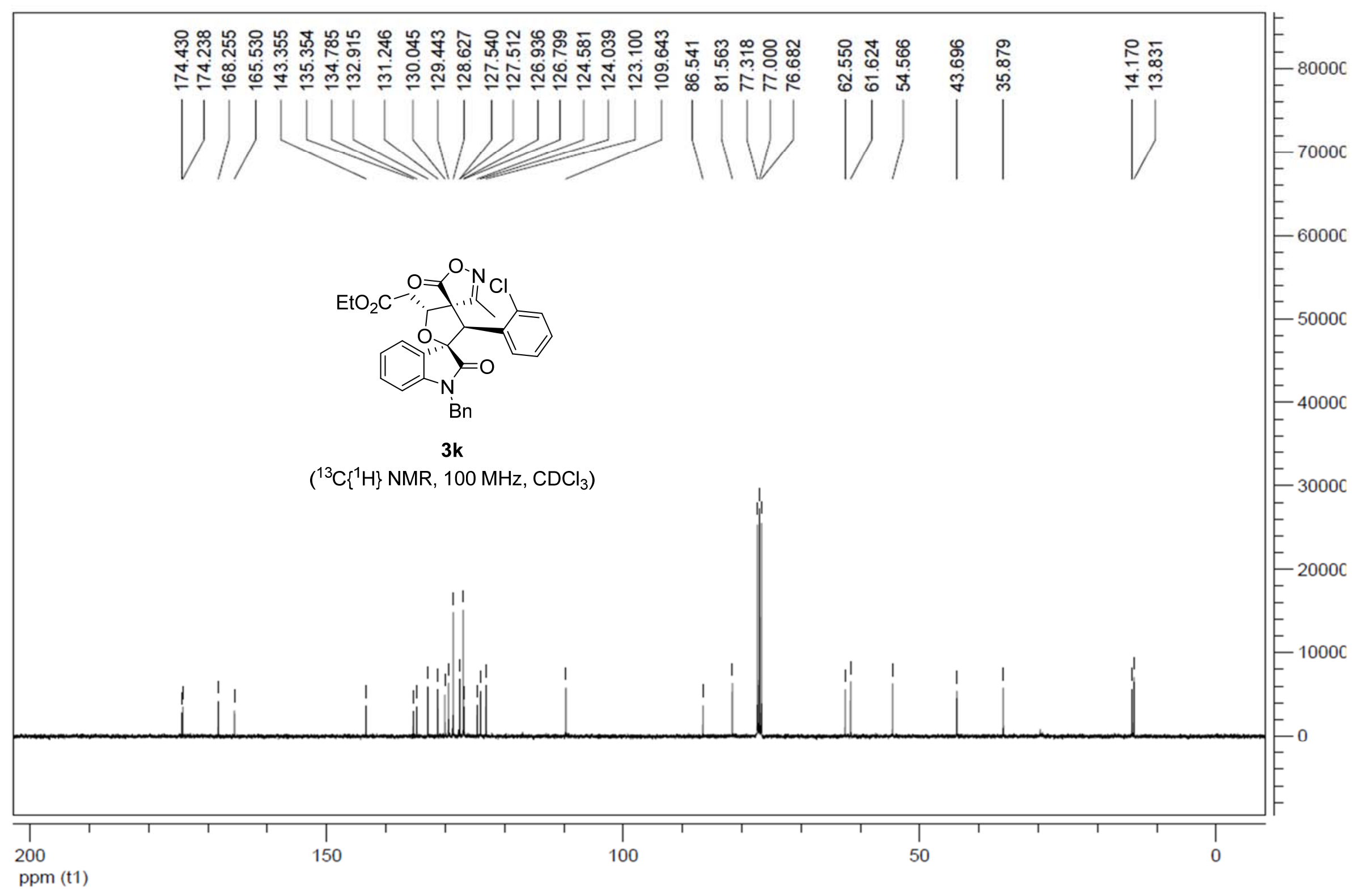




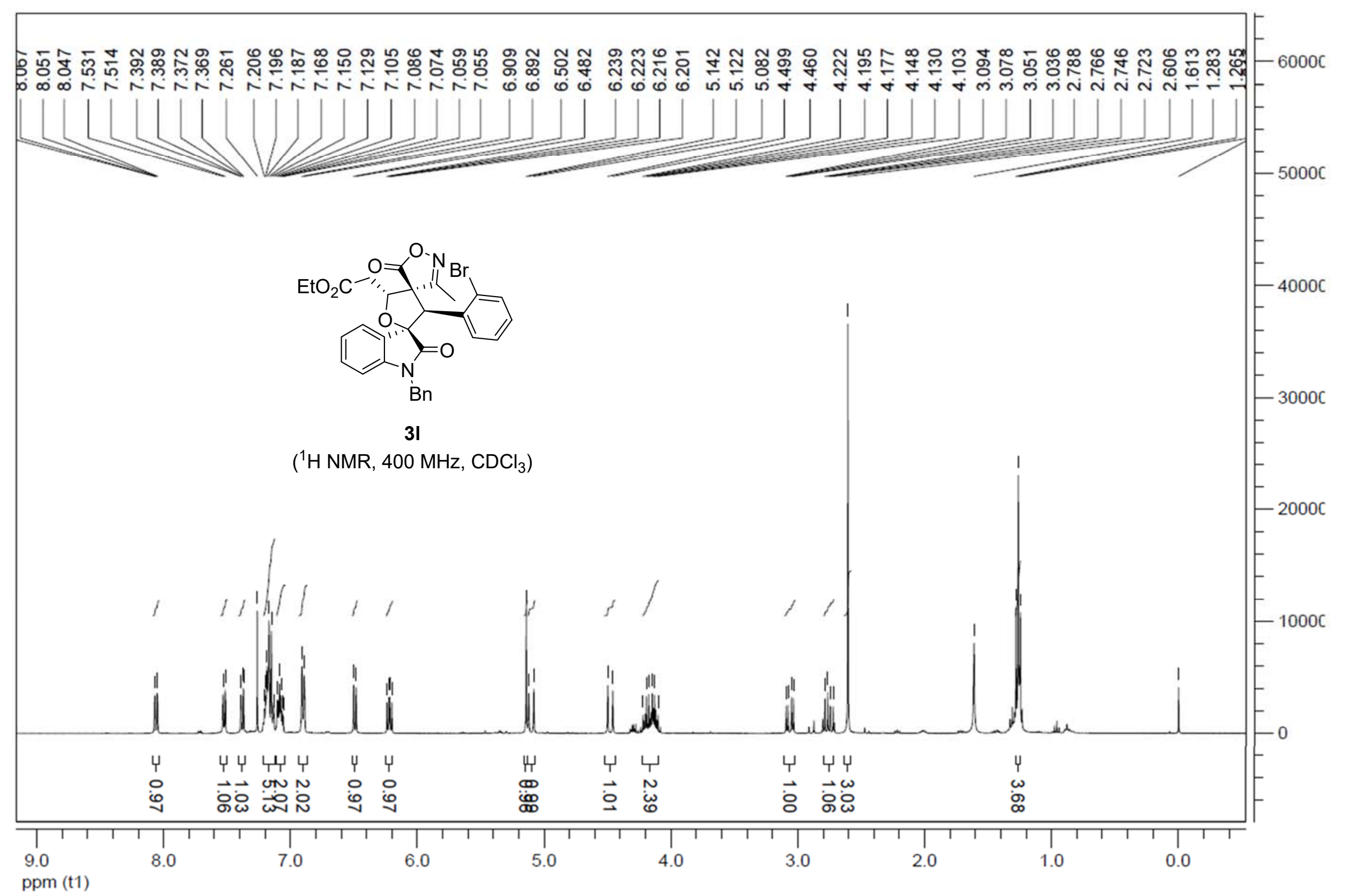




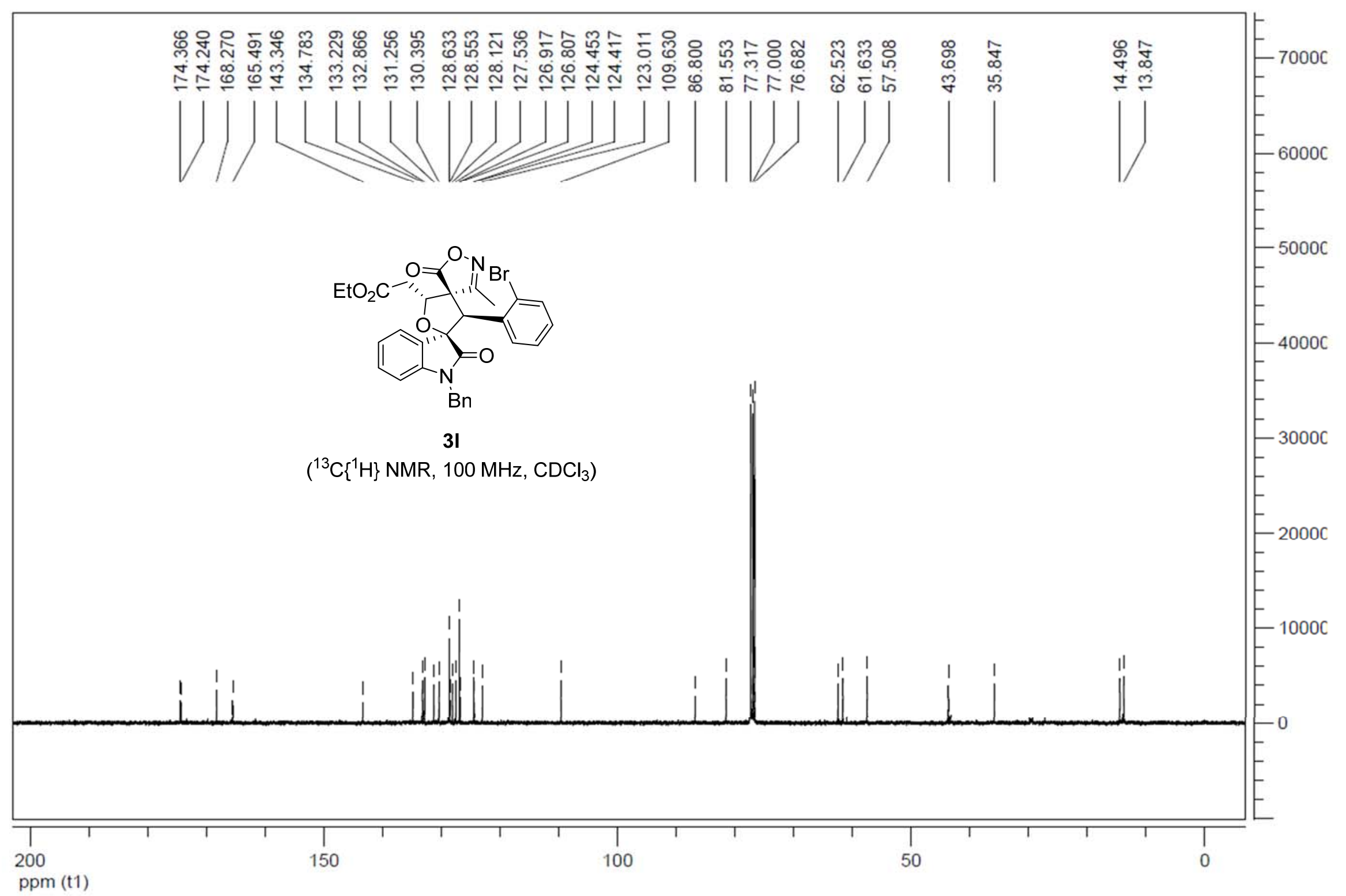




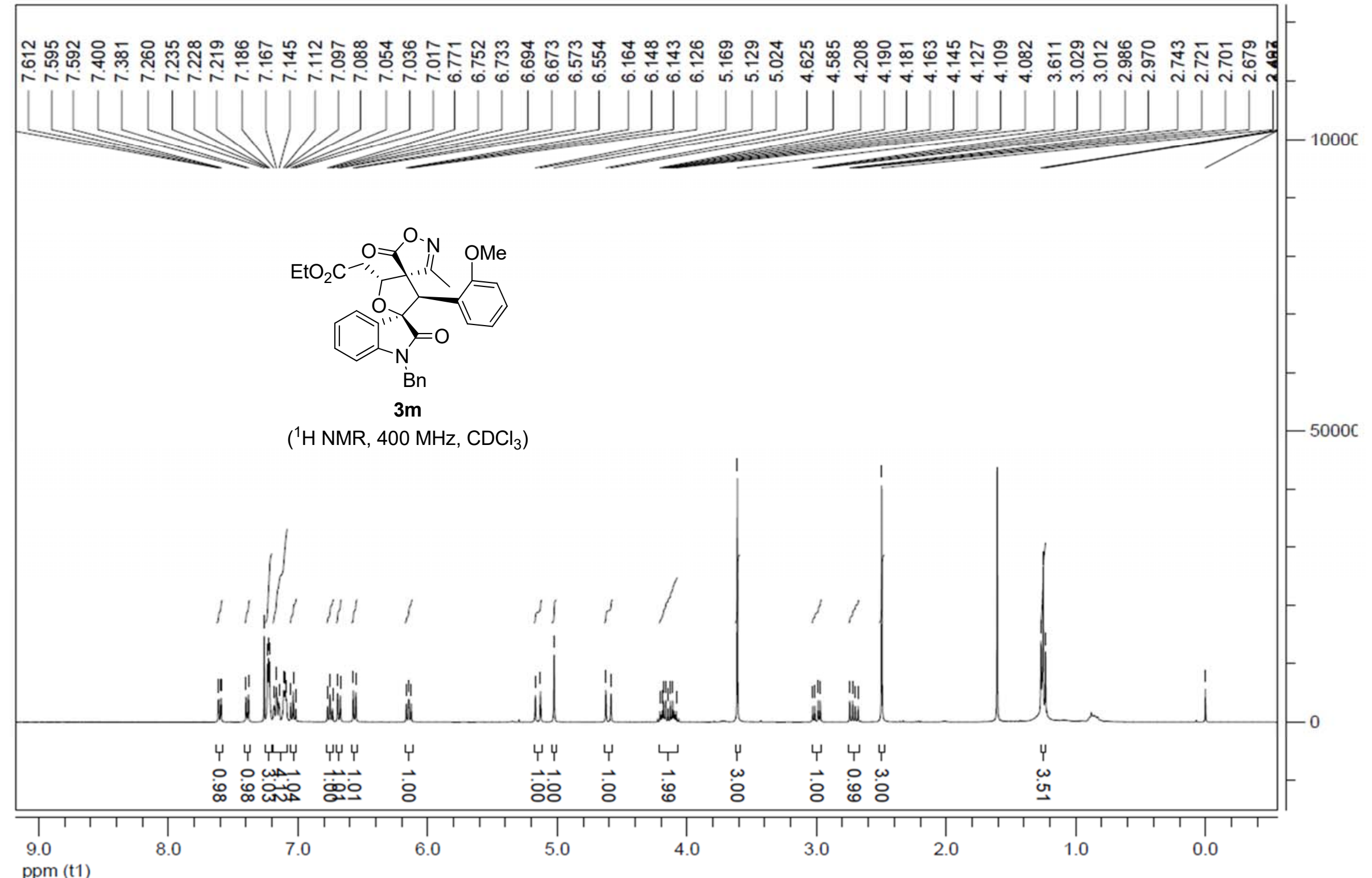




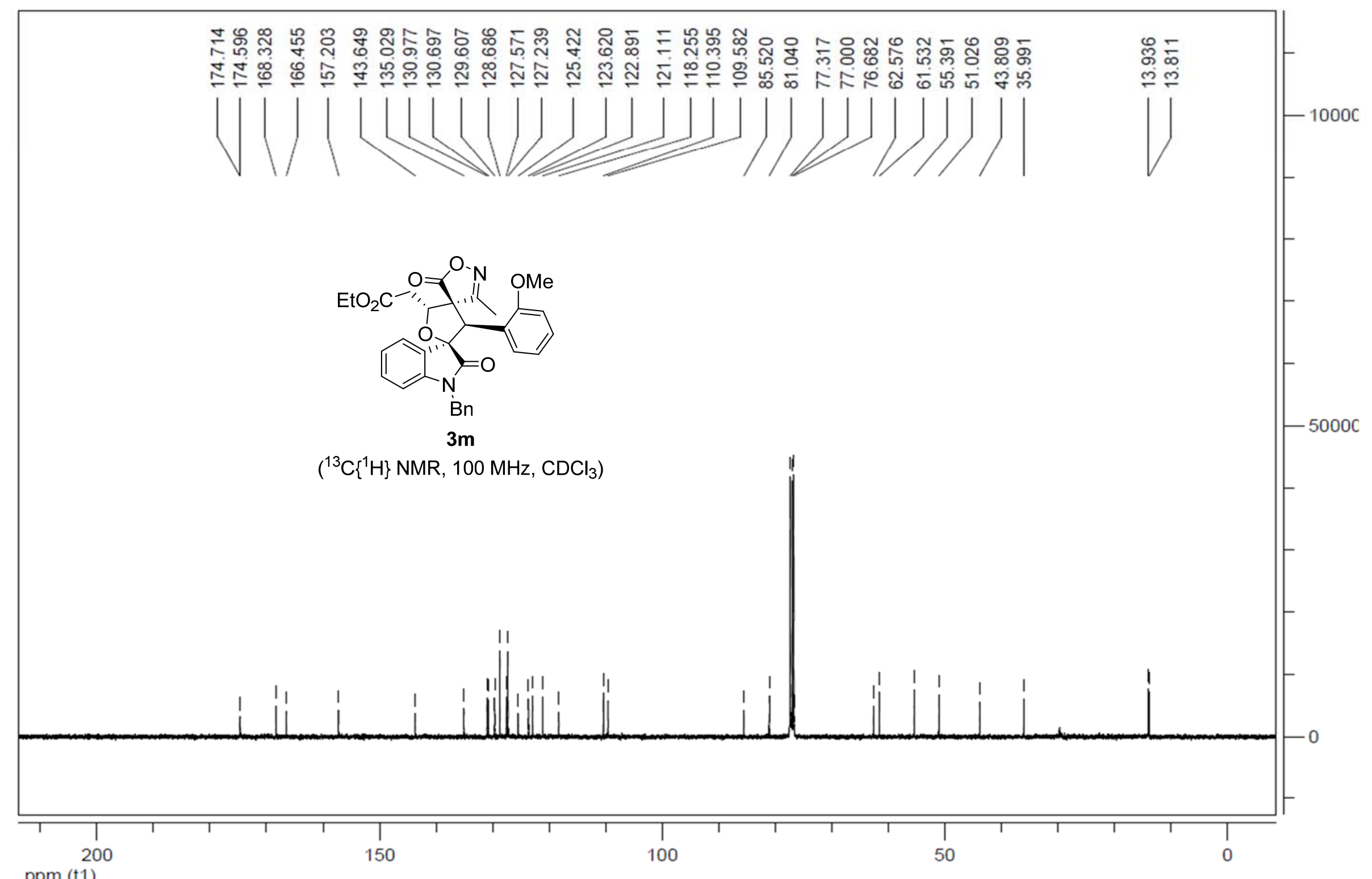




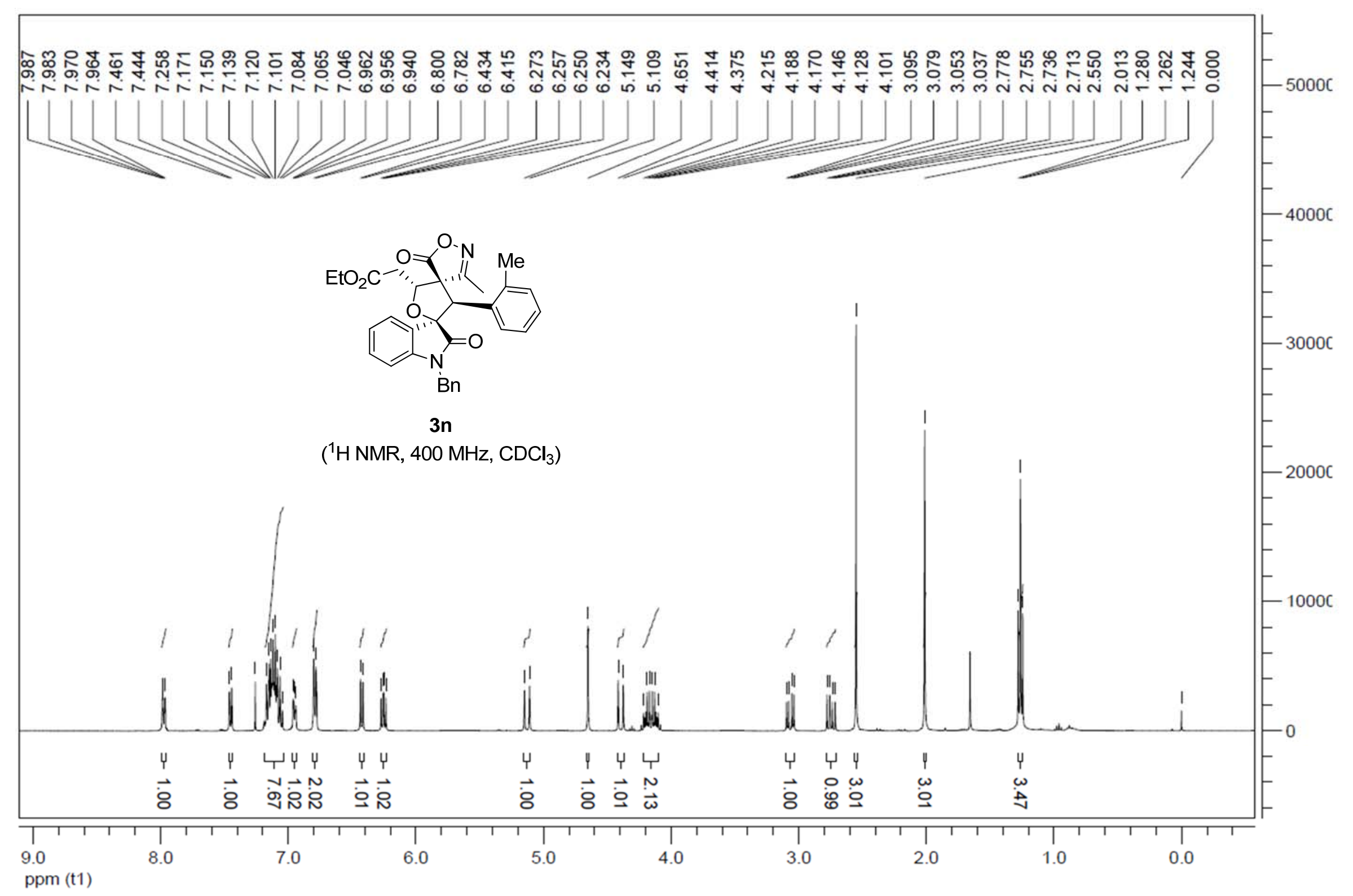




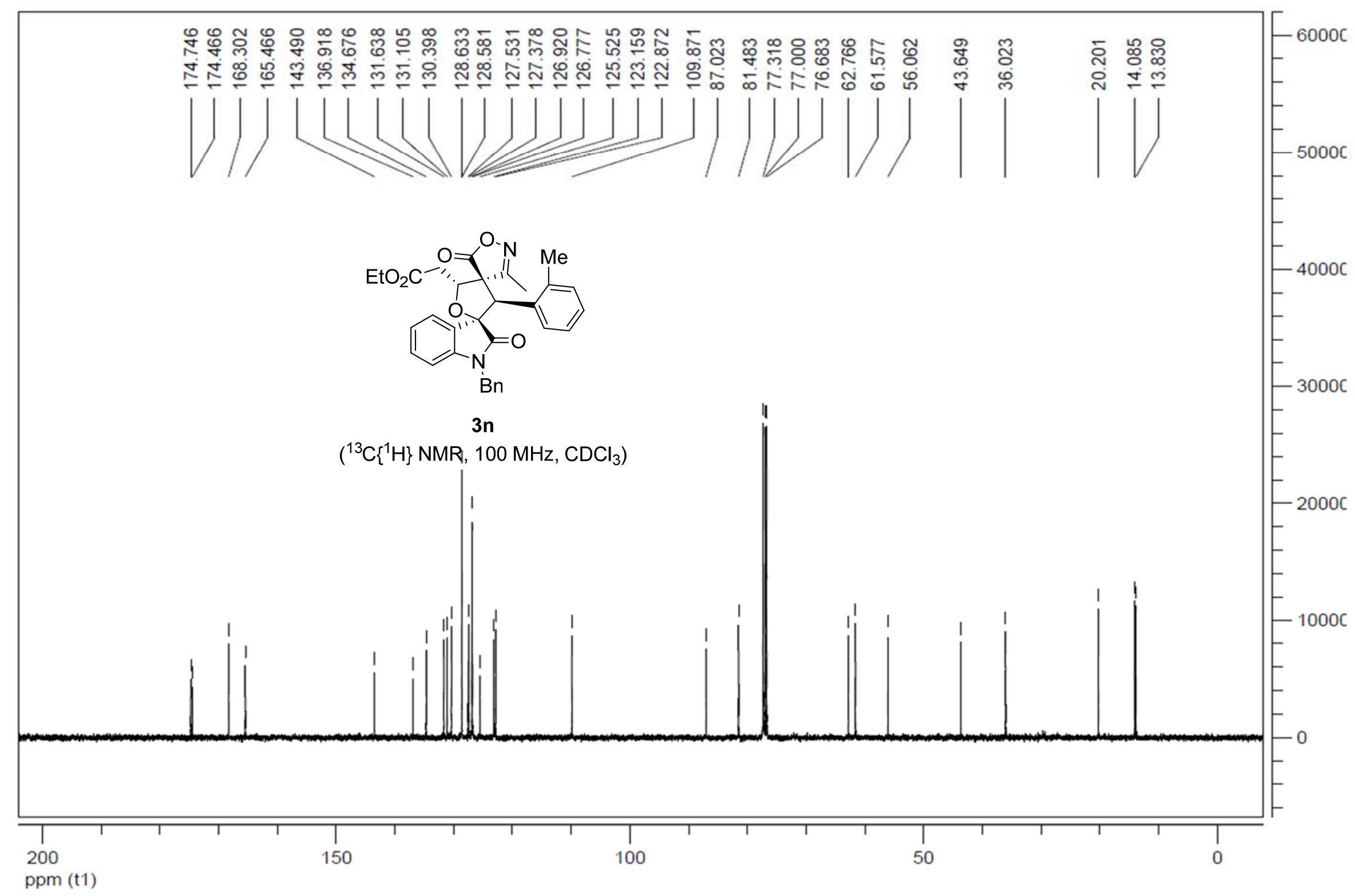




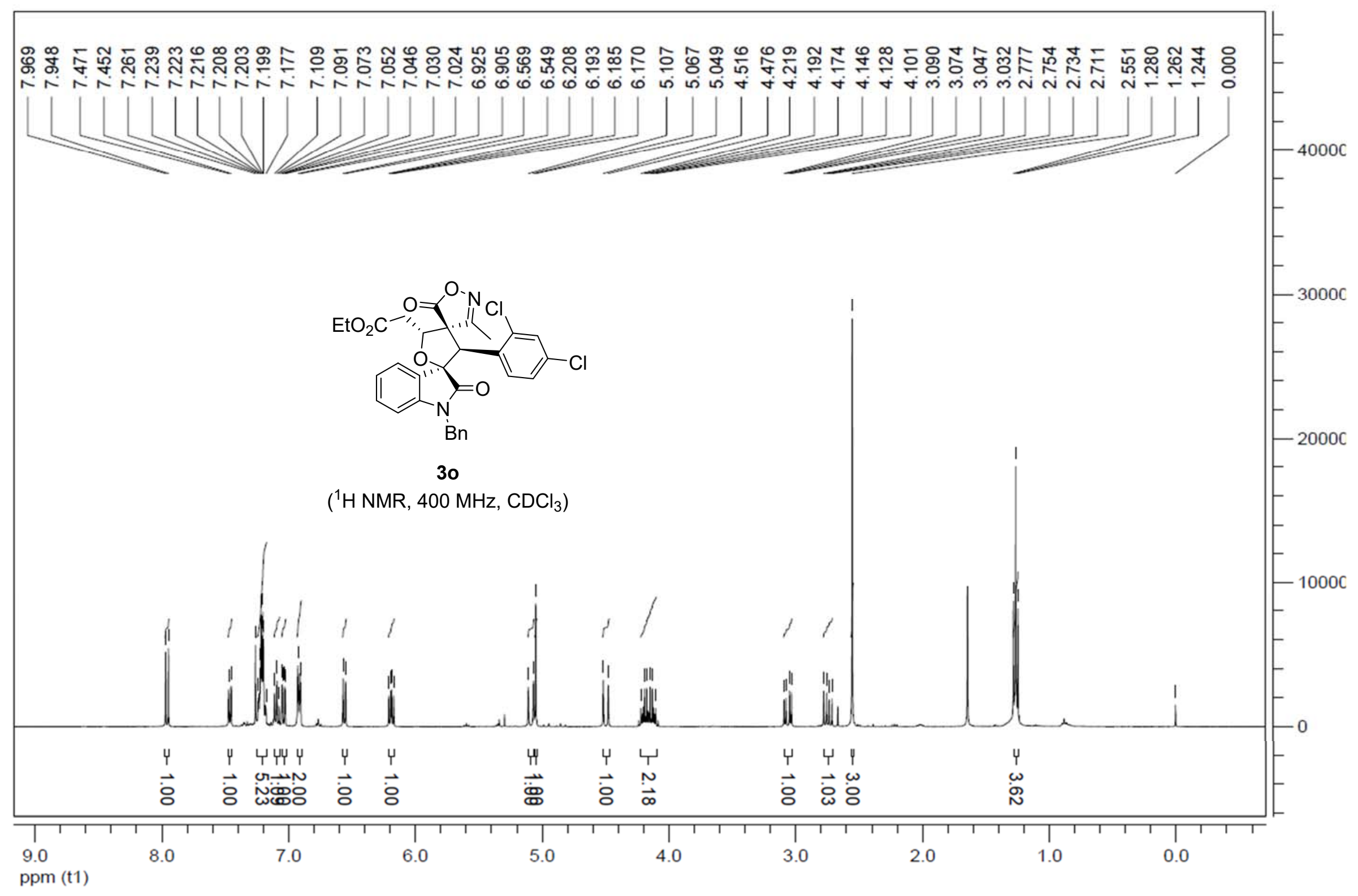




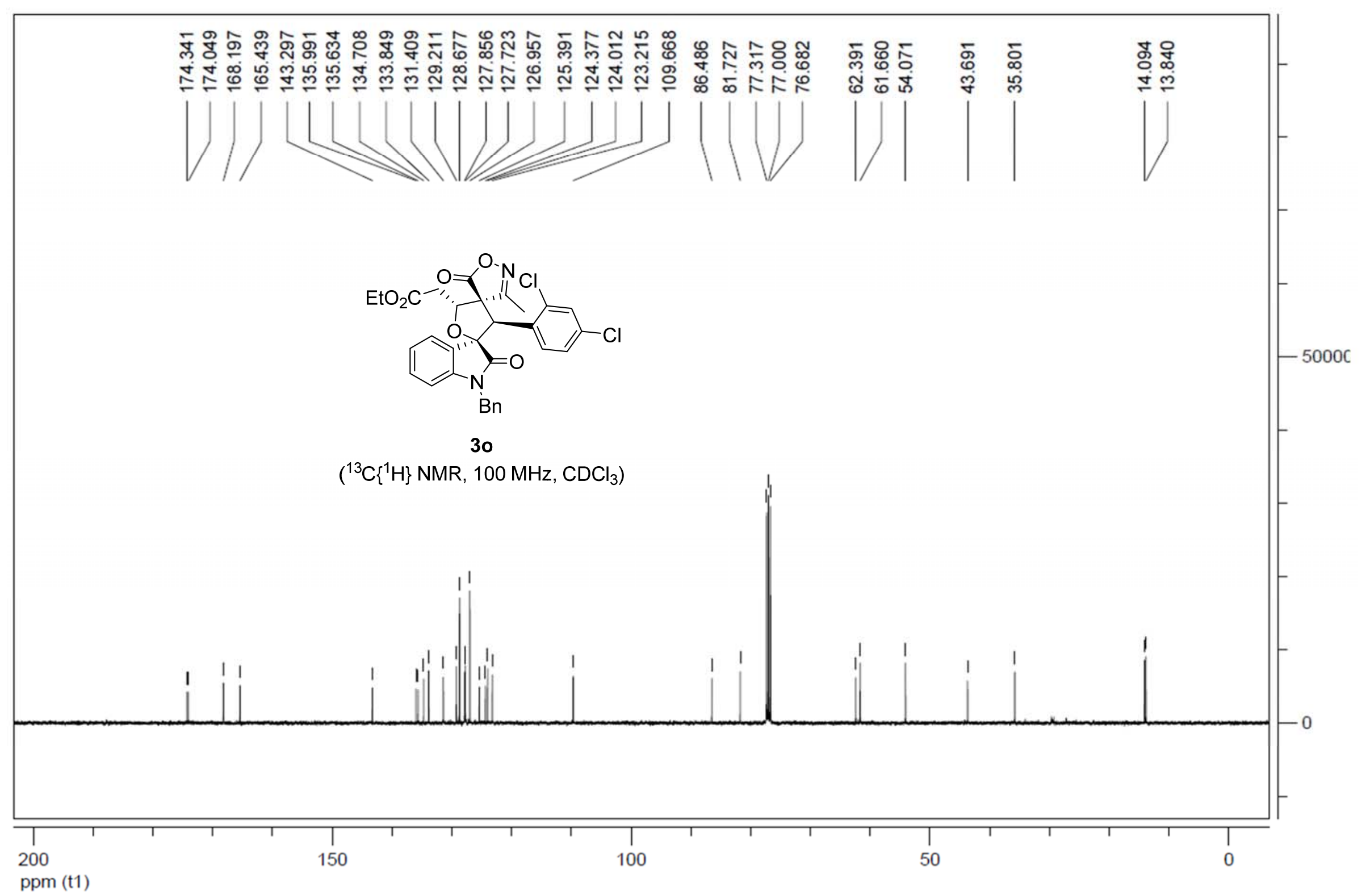




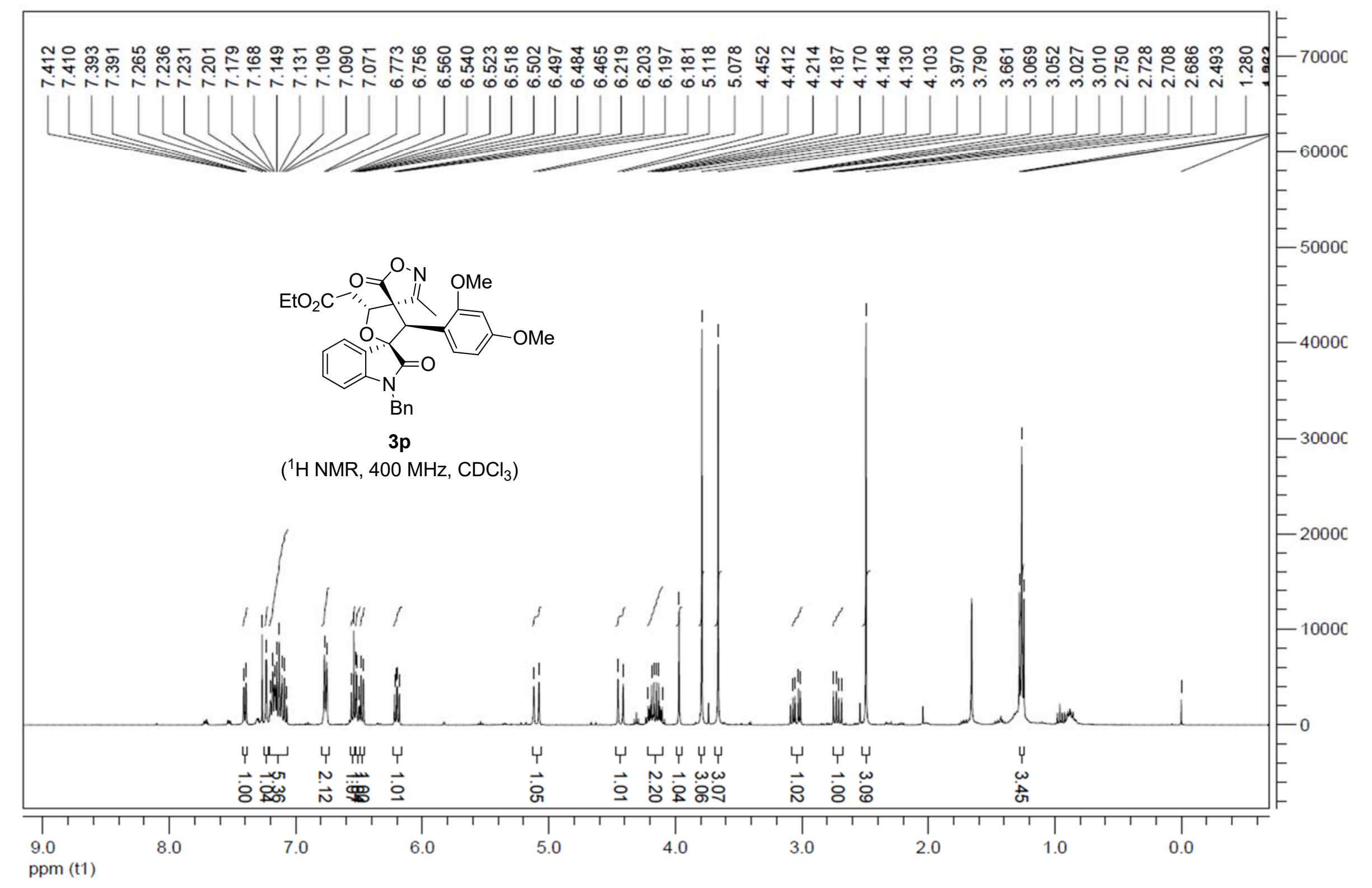




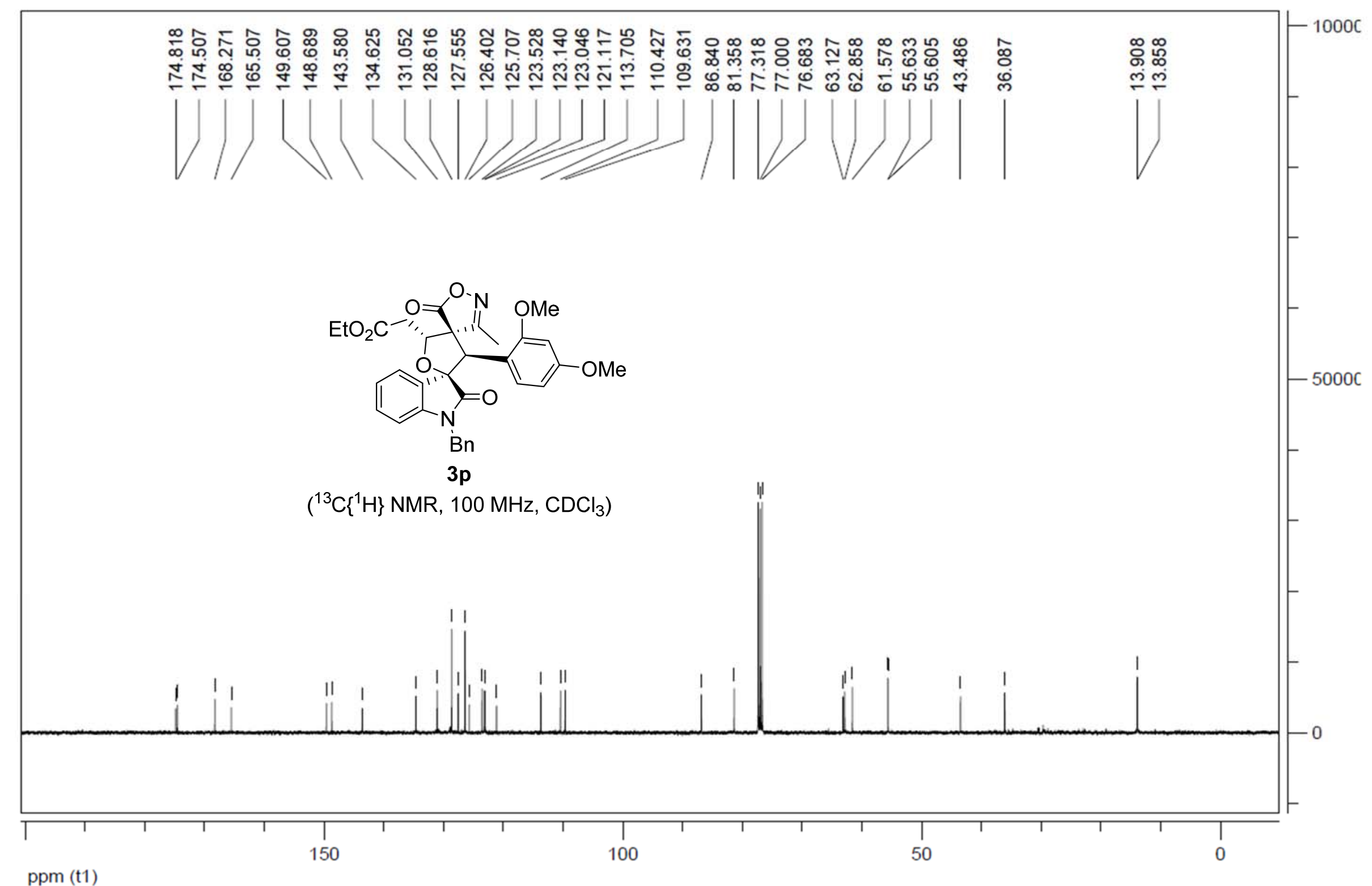




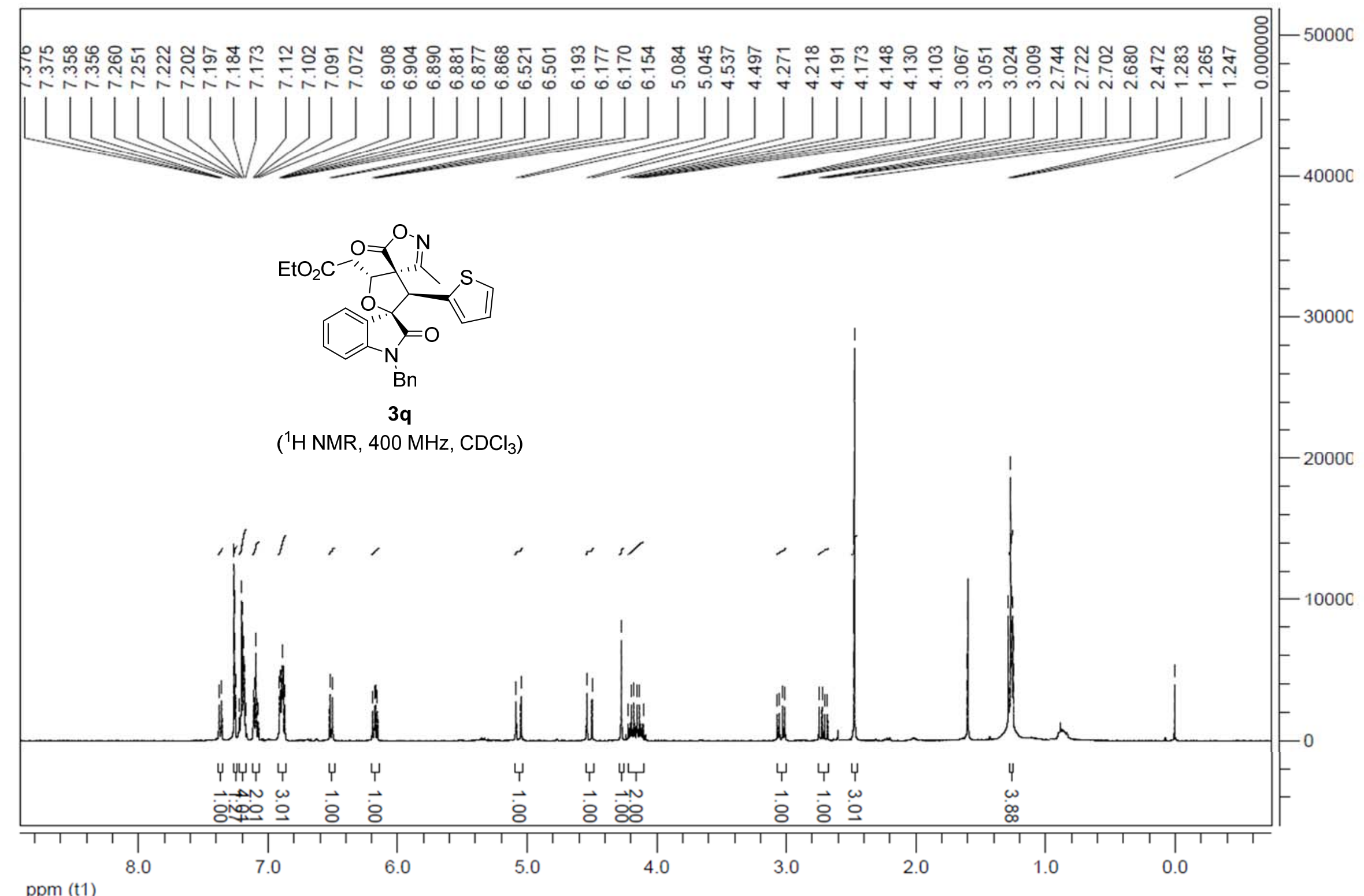




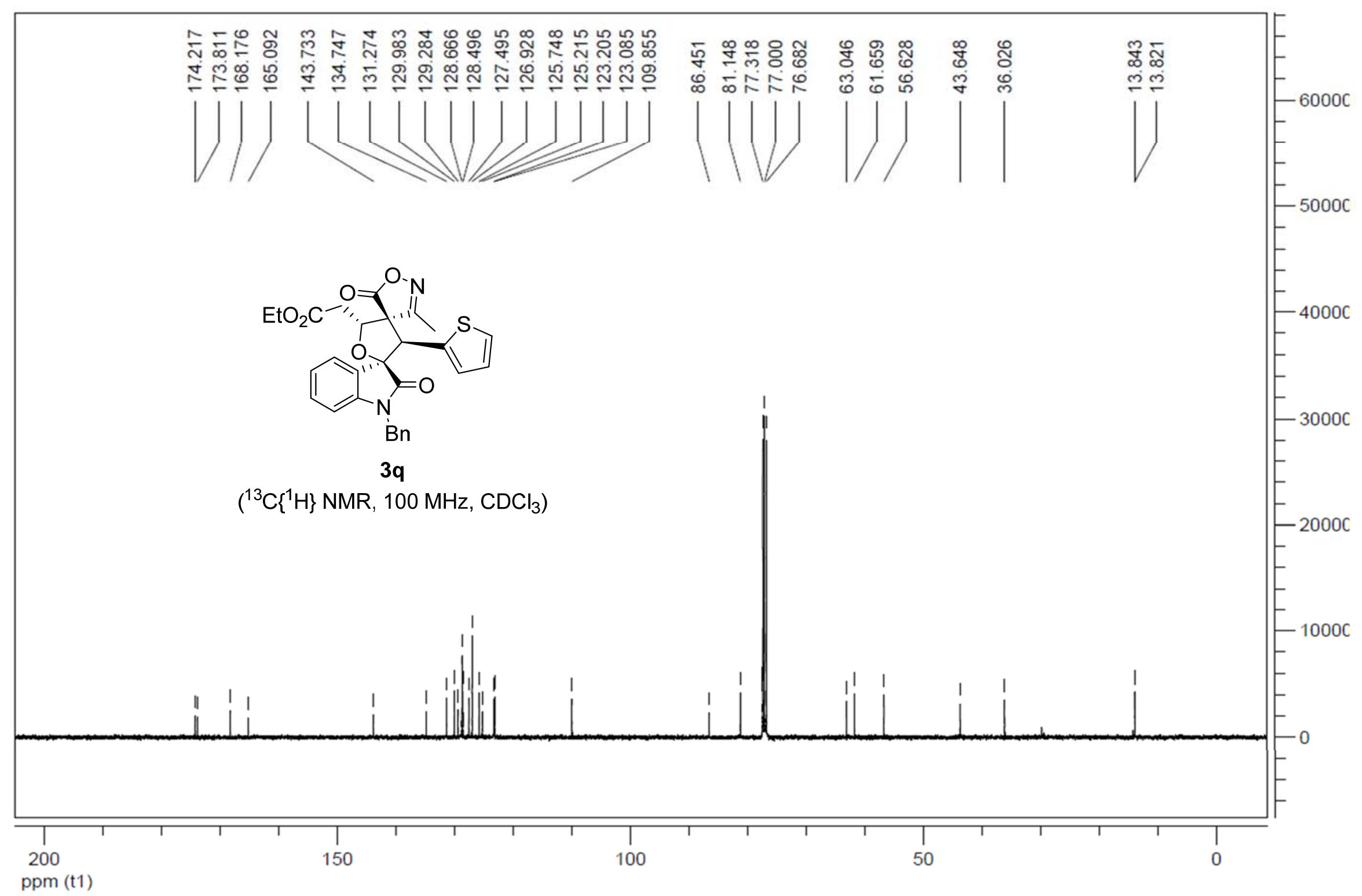




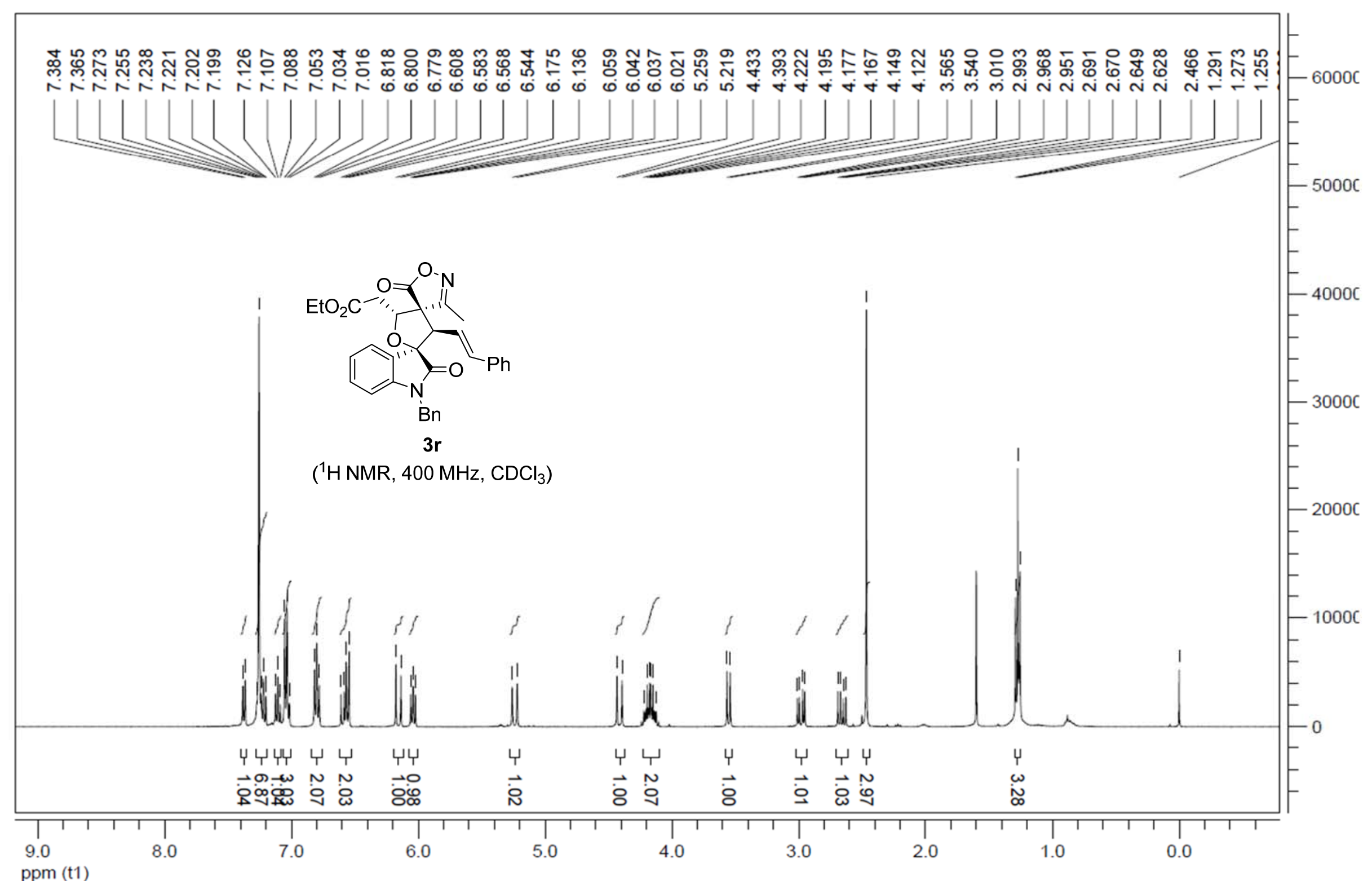




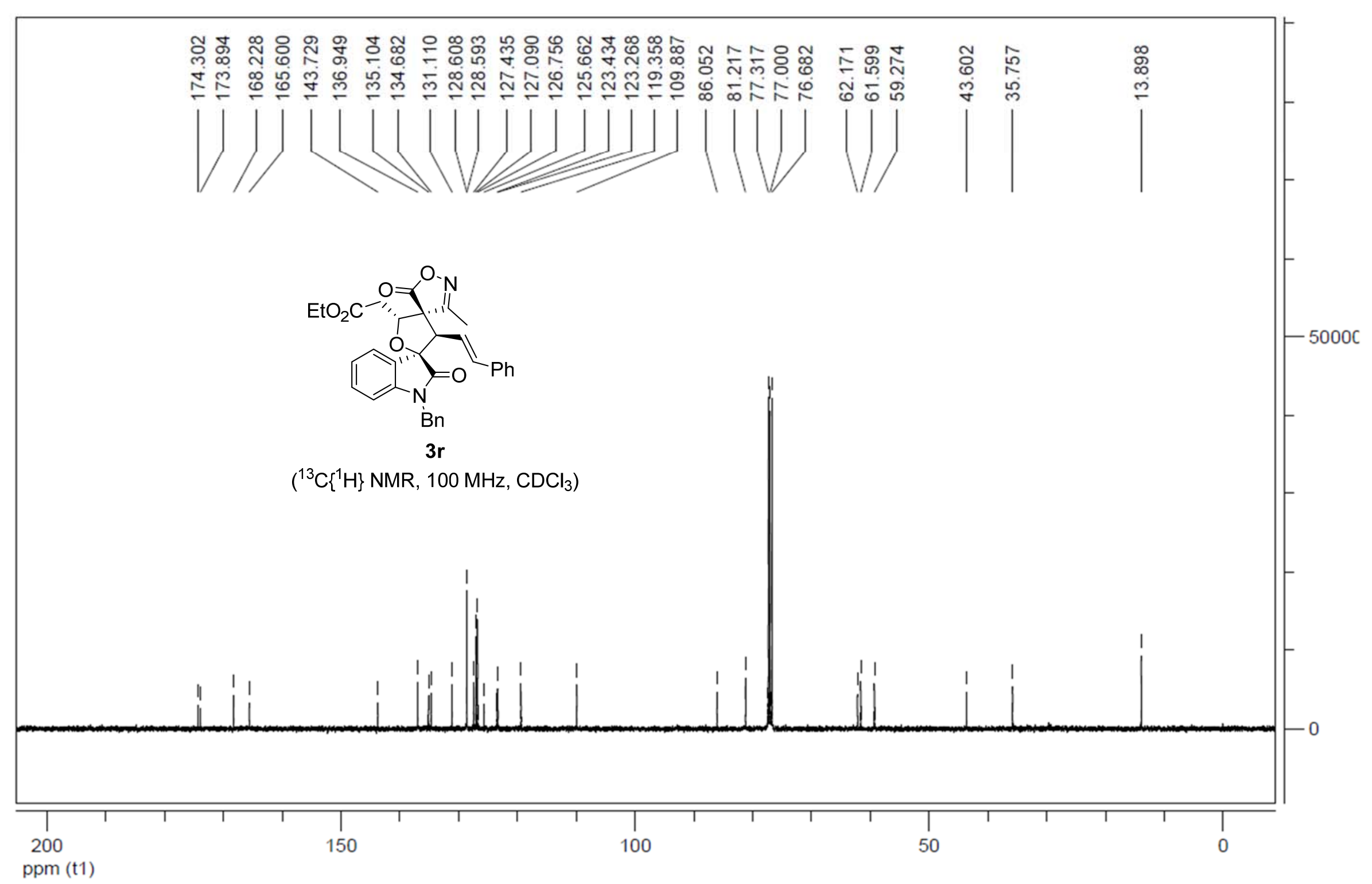




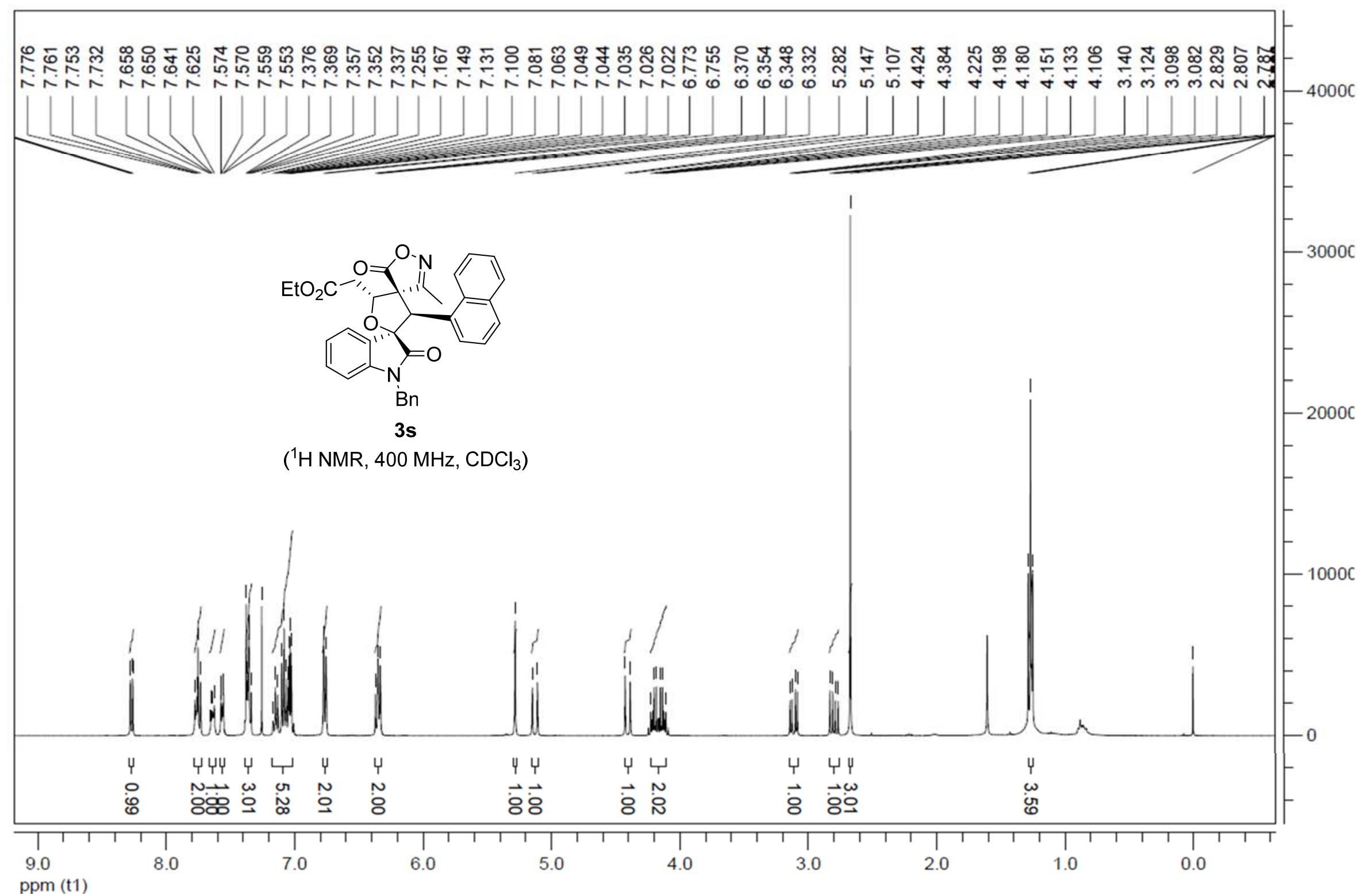




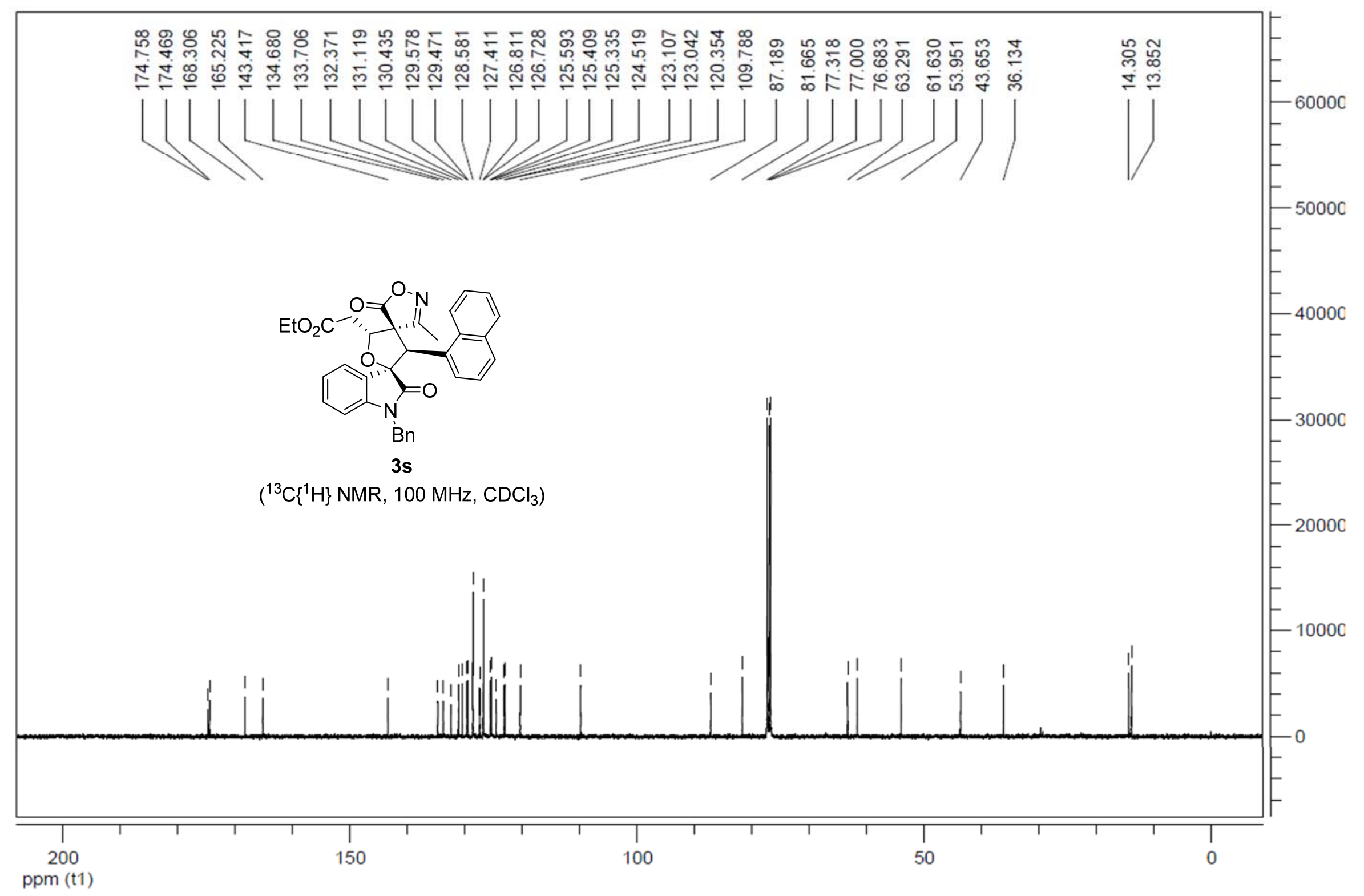




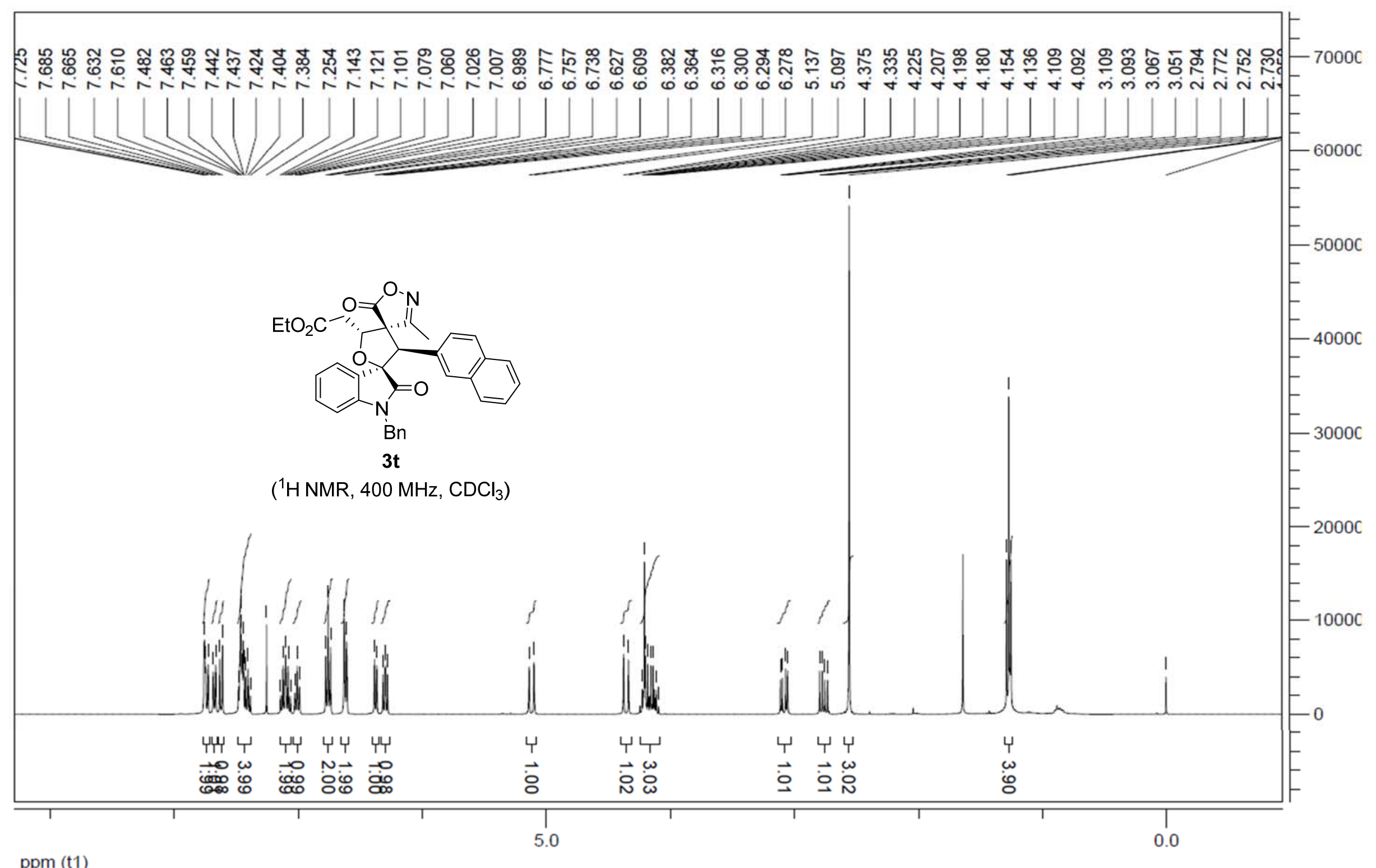

ppm (t1) 


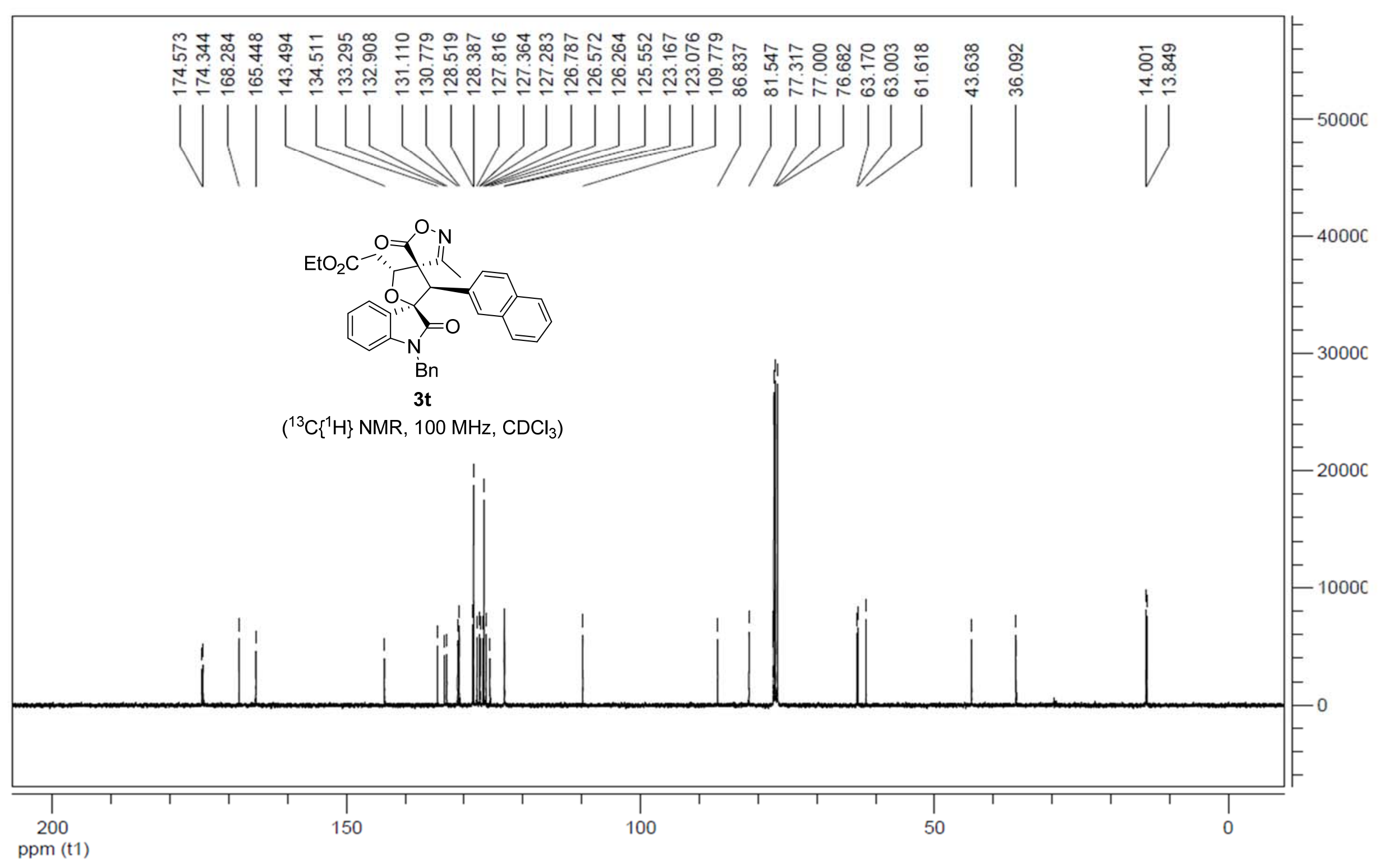




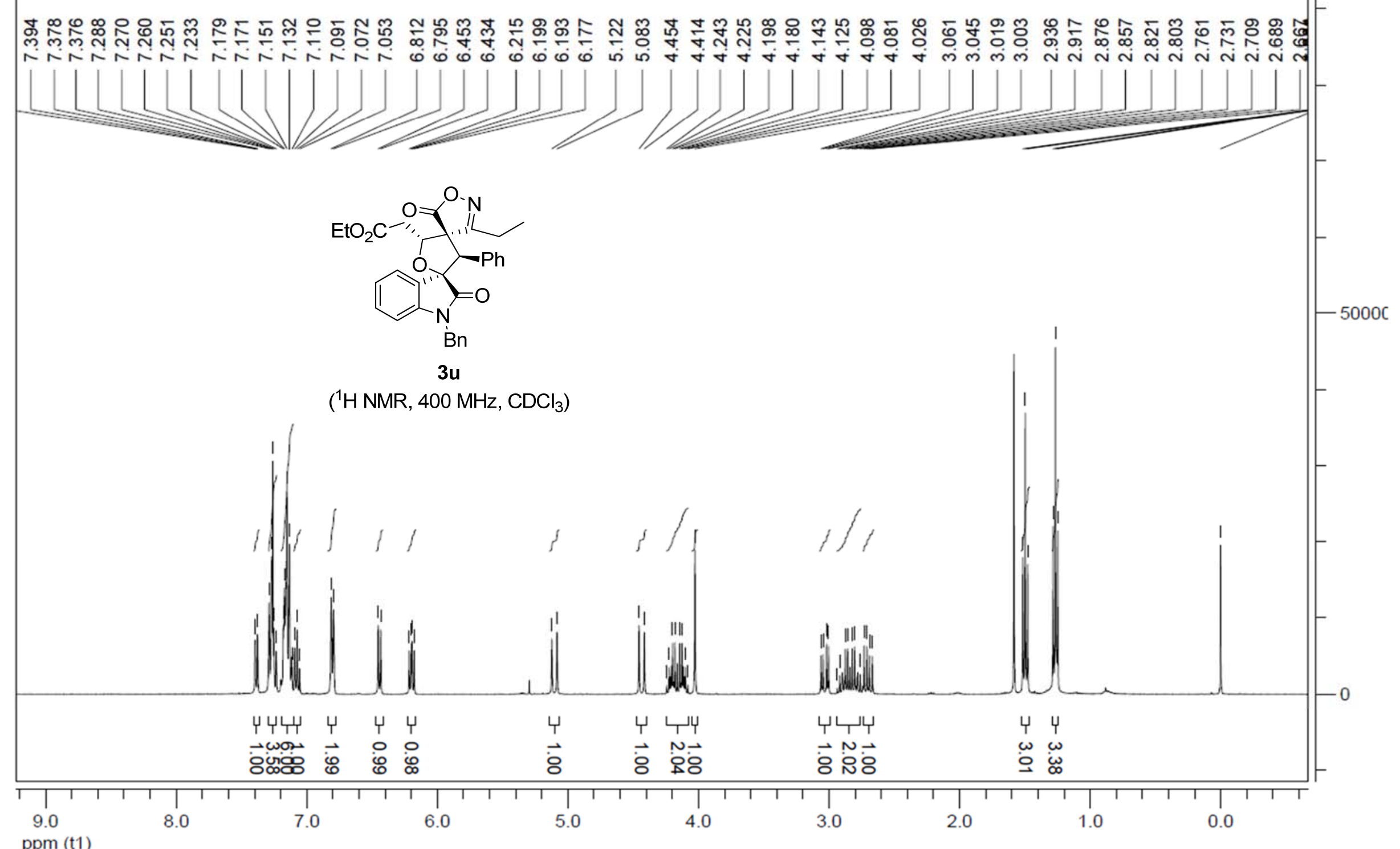




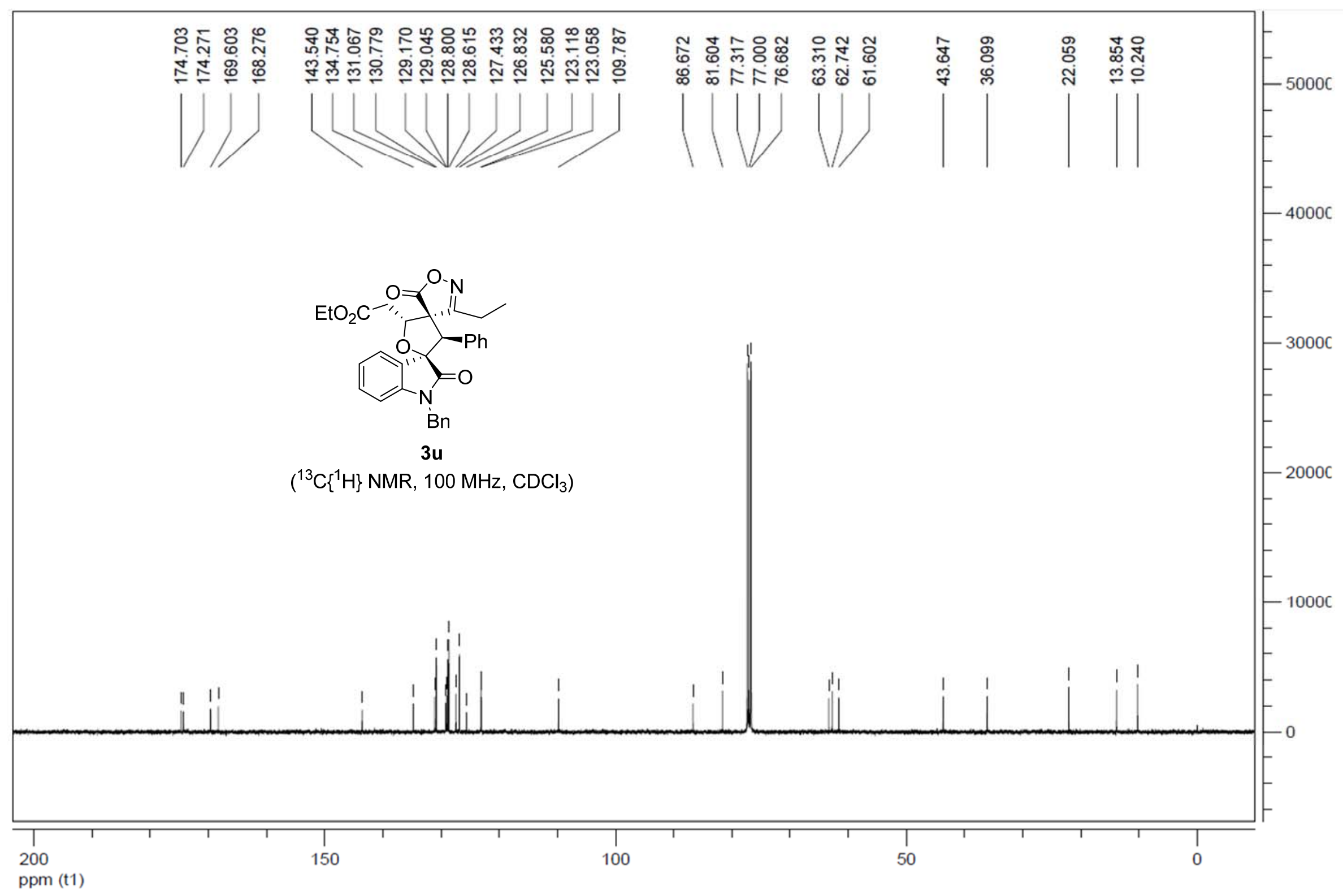




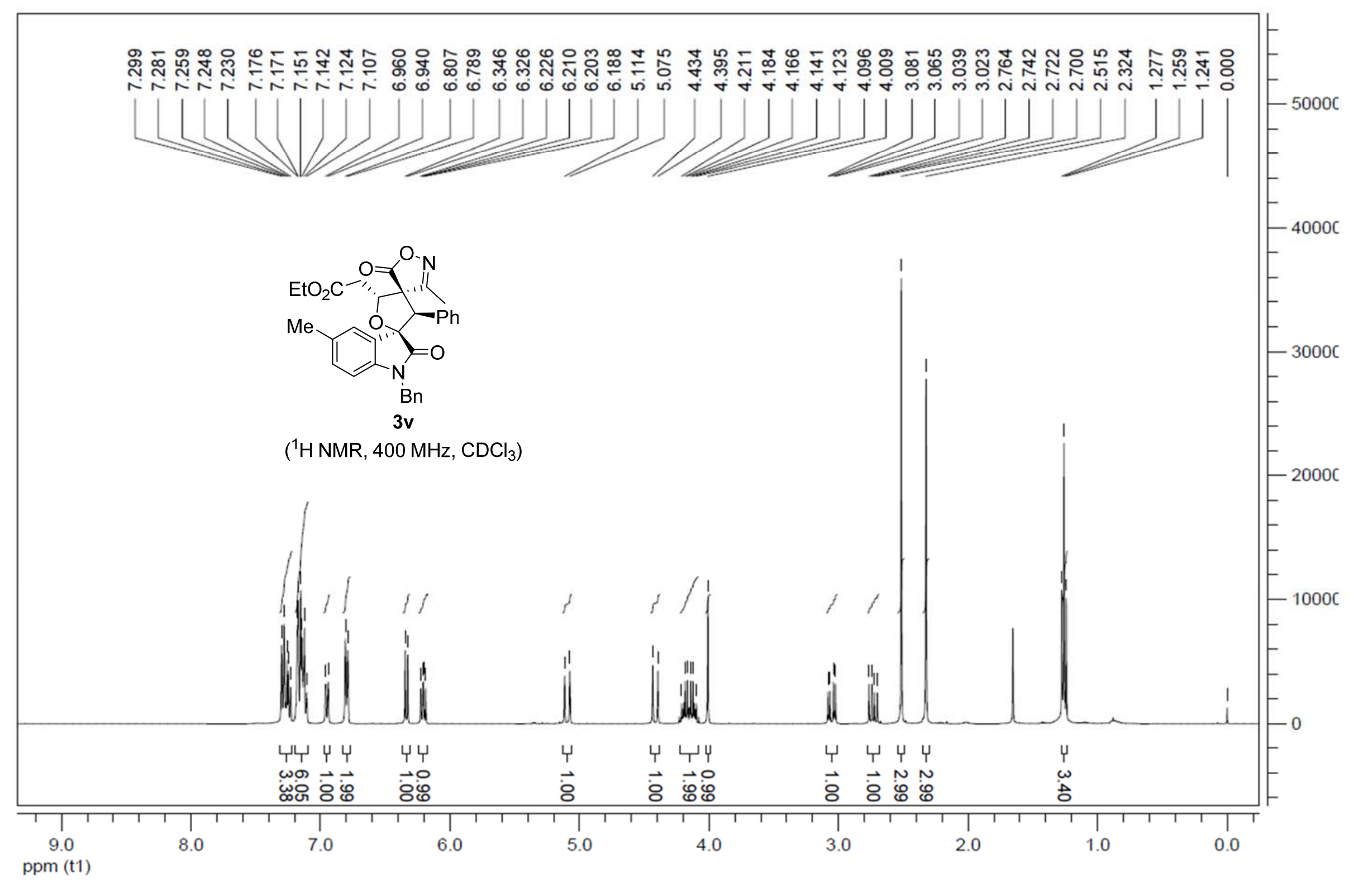




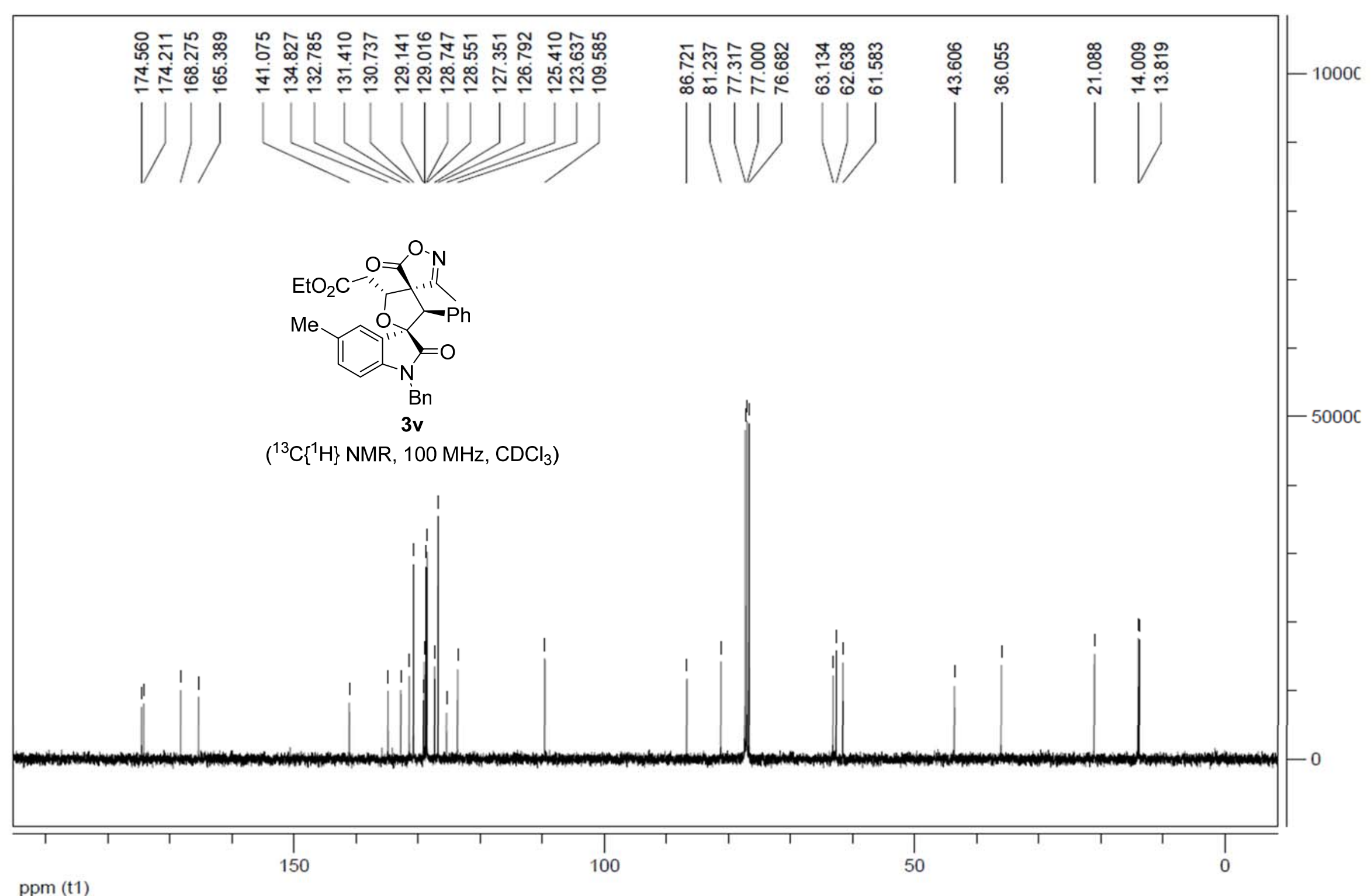




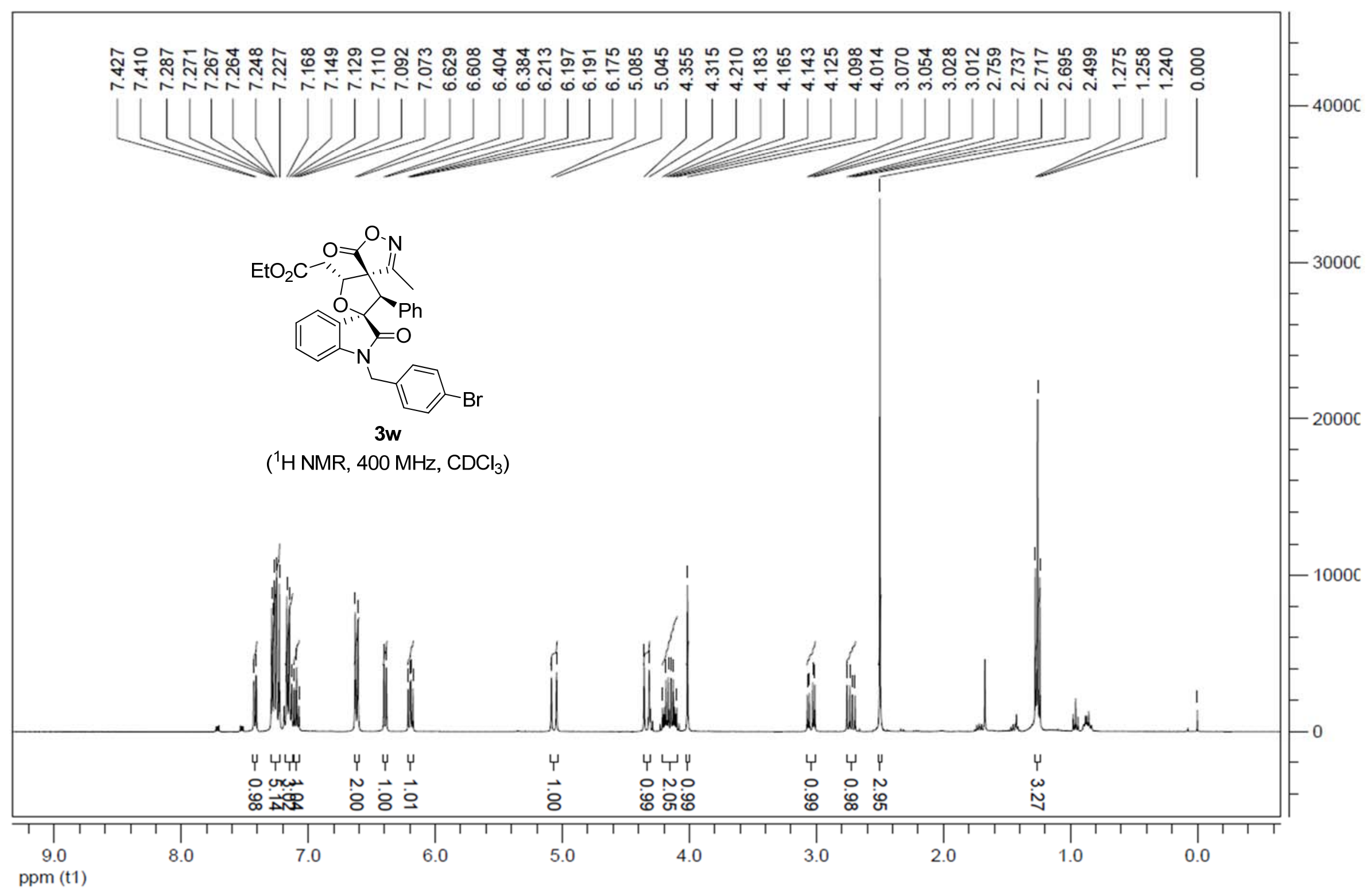




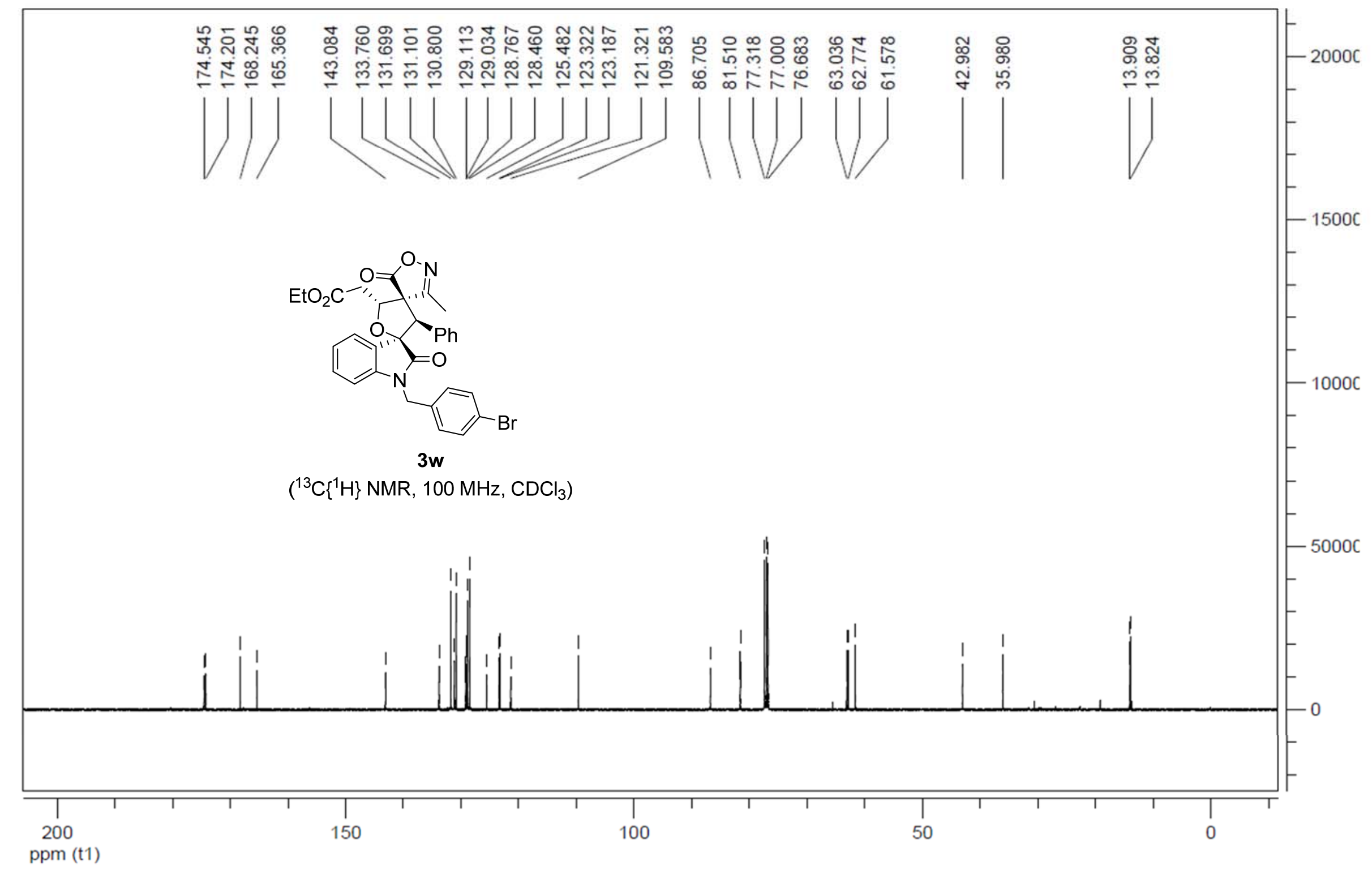




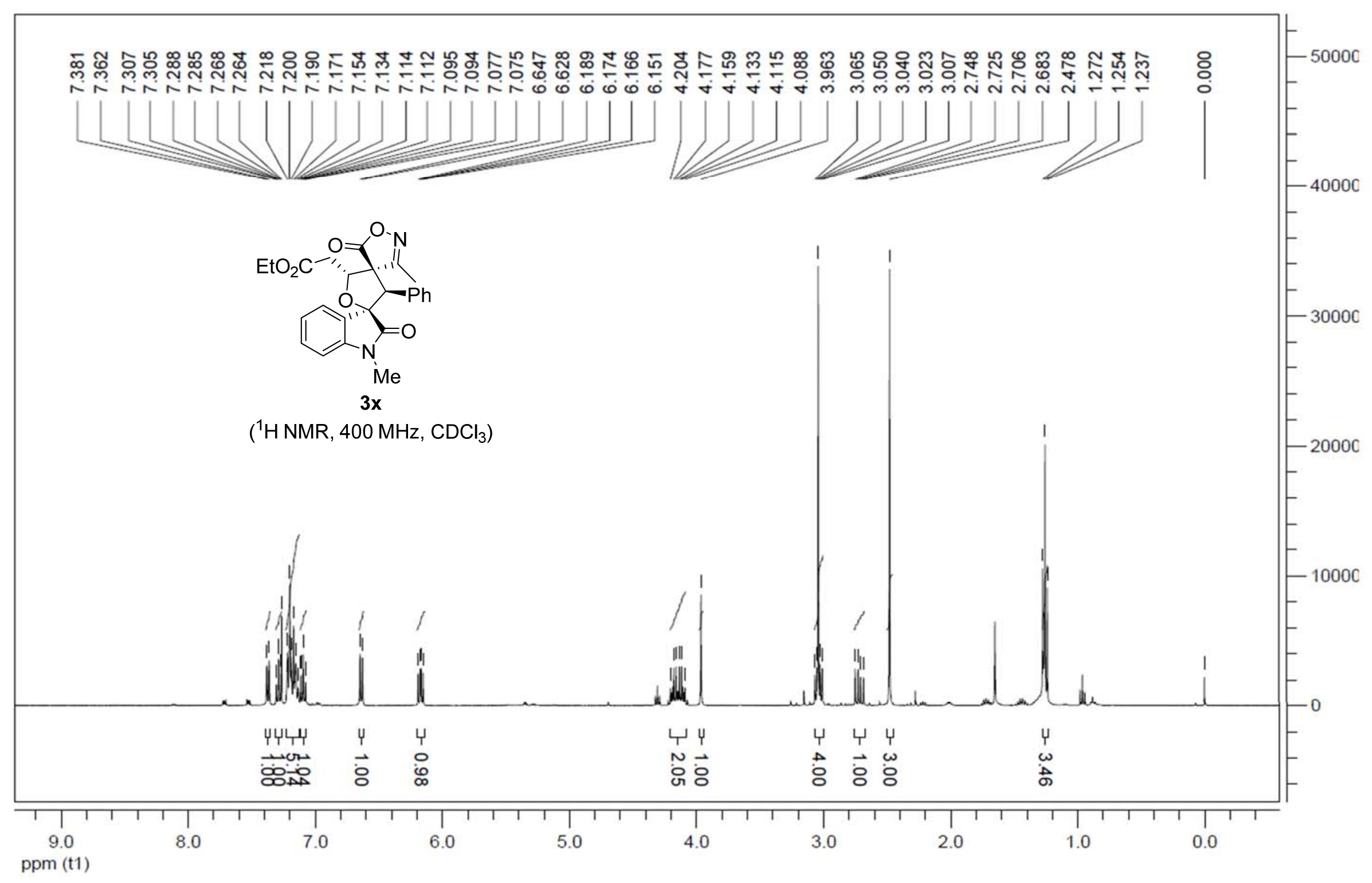




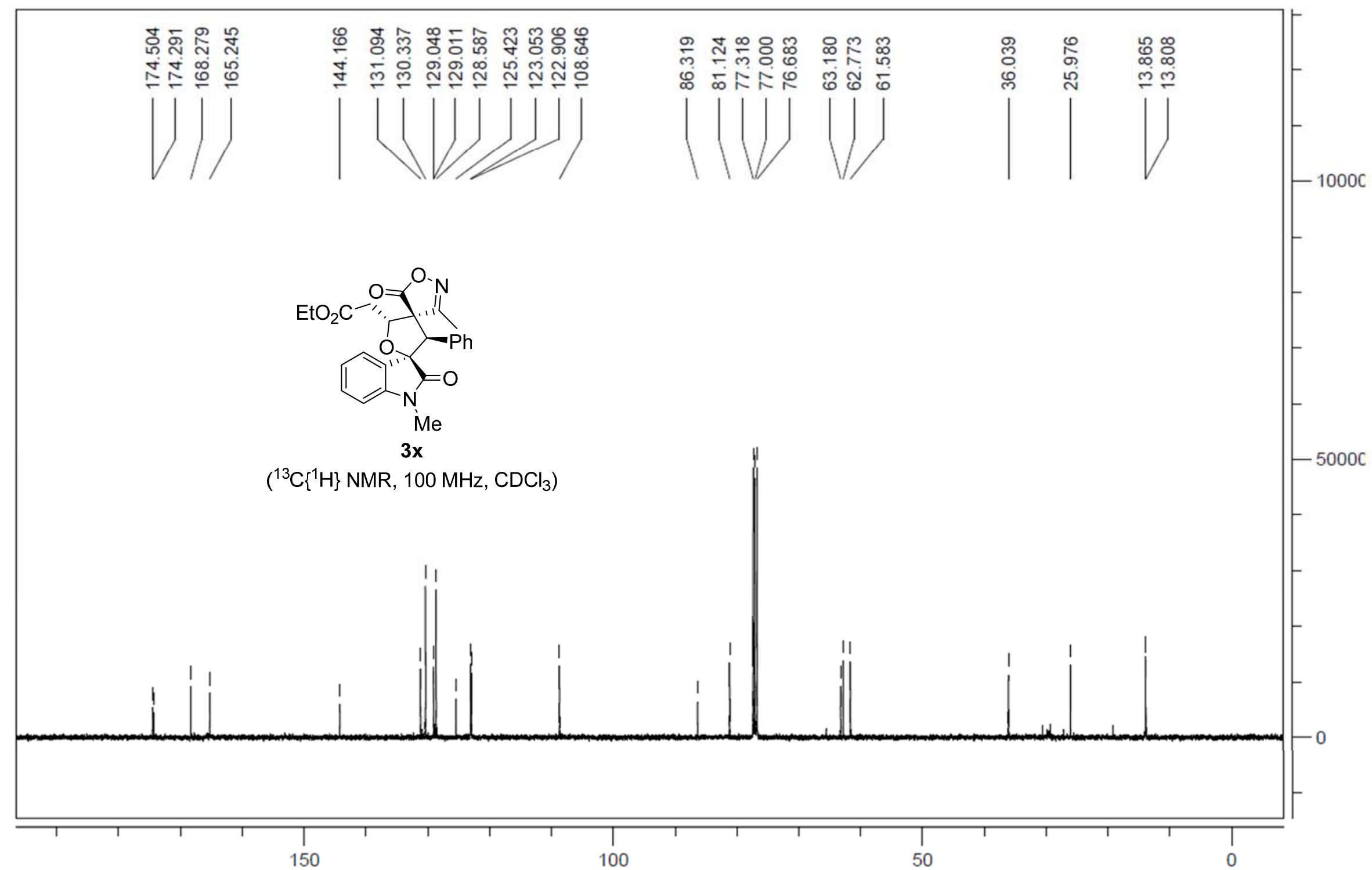

ppm (t1) 


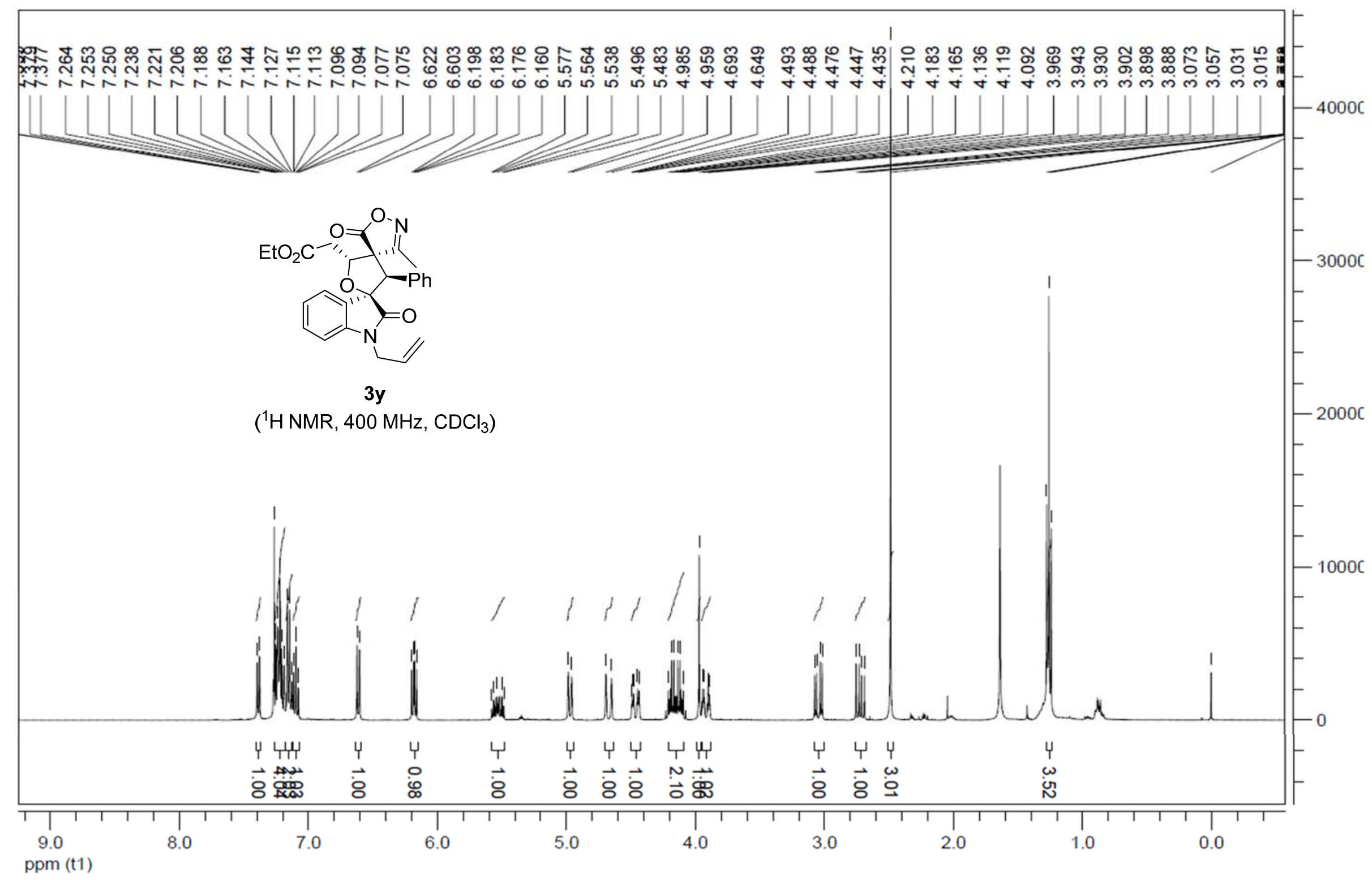




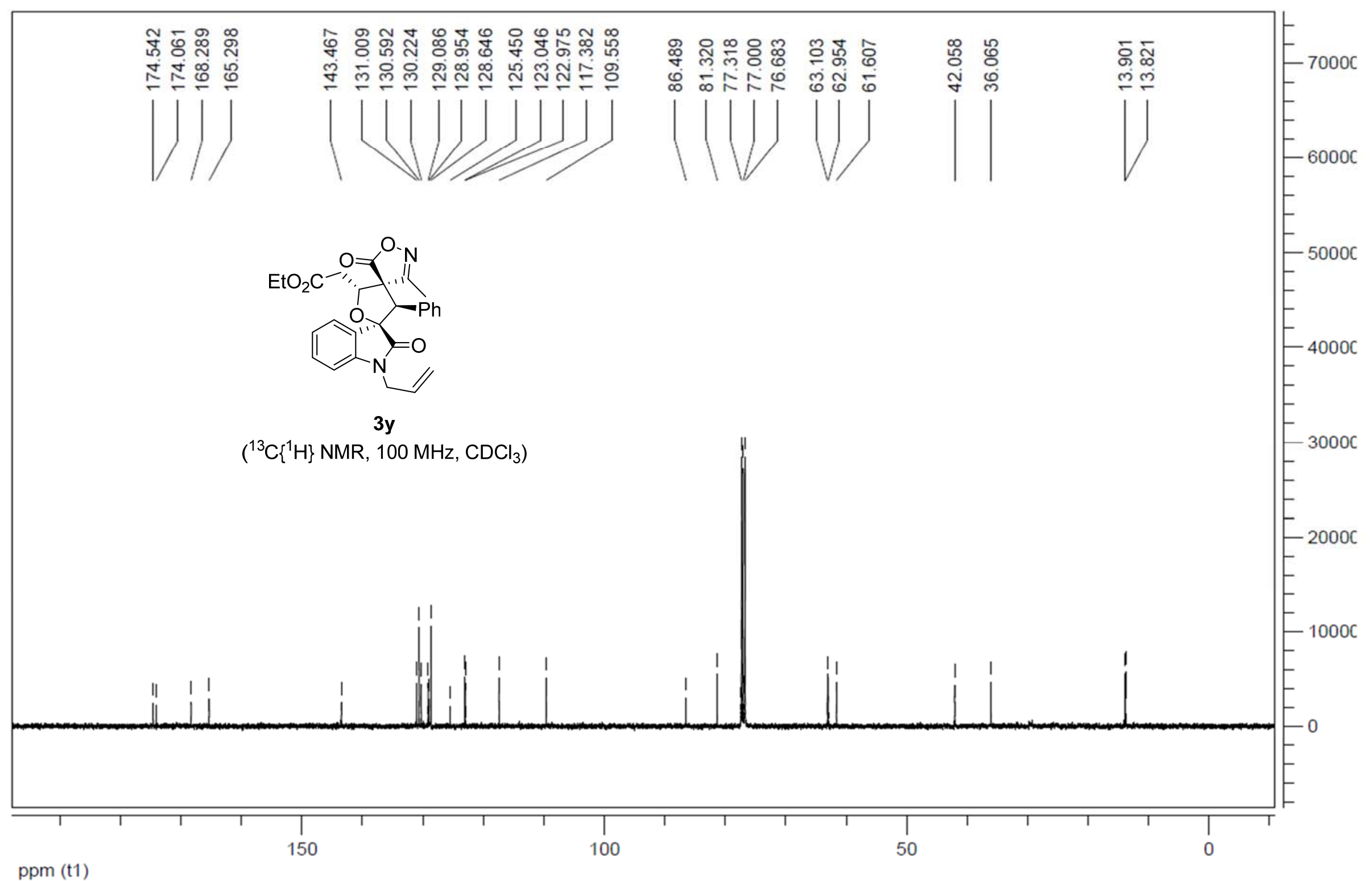




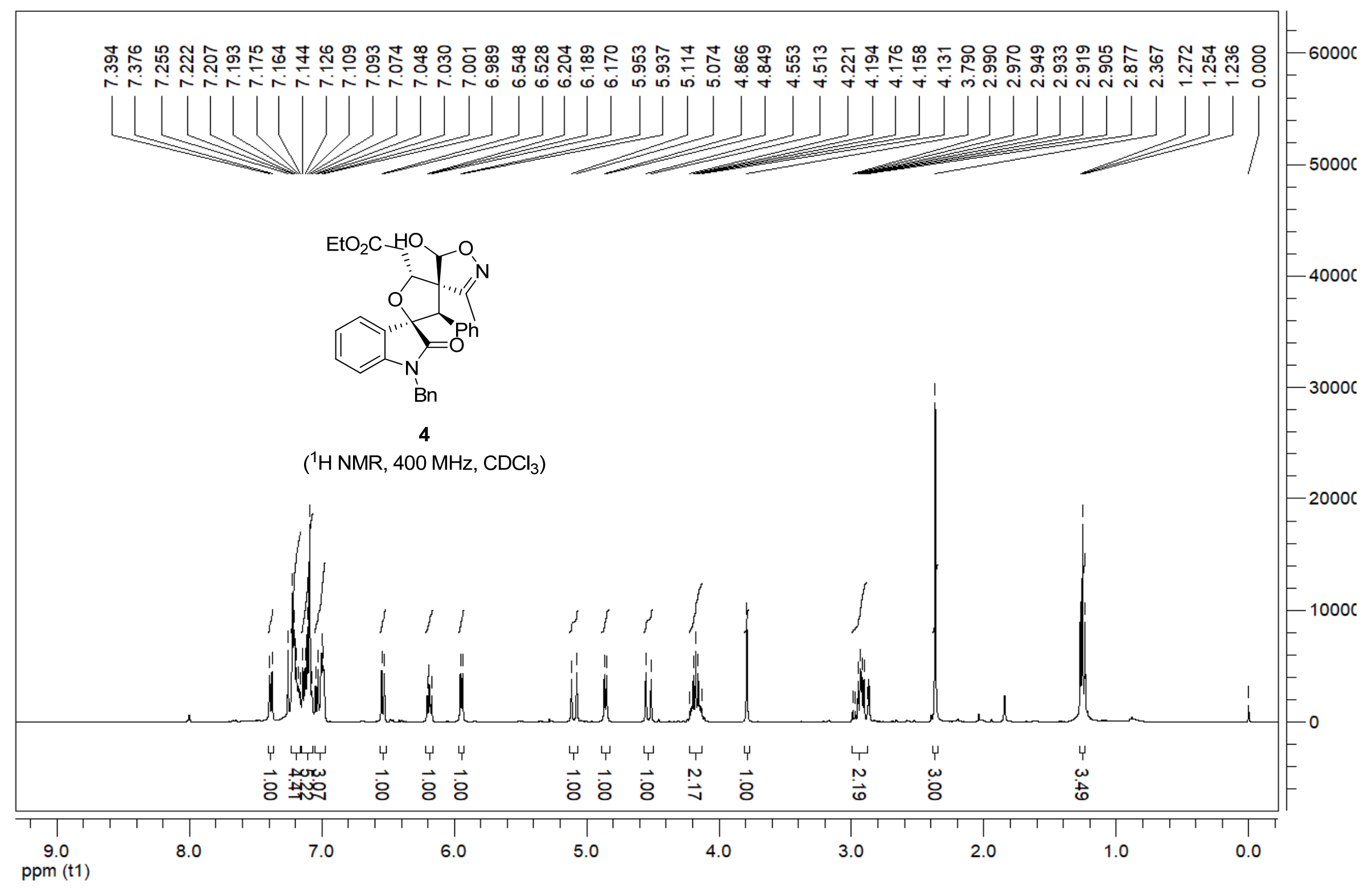




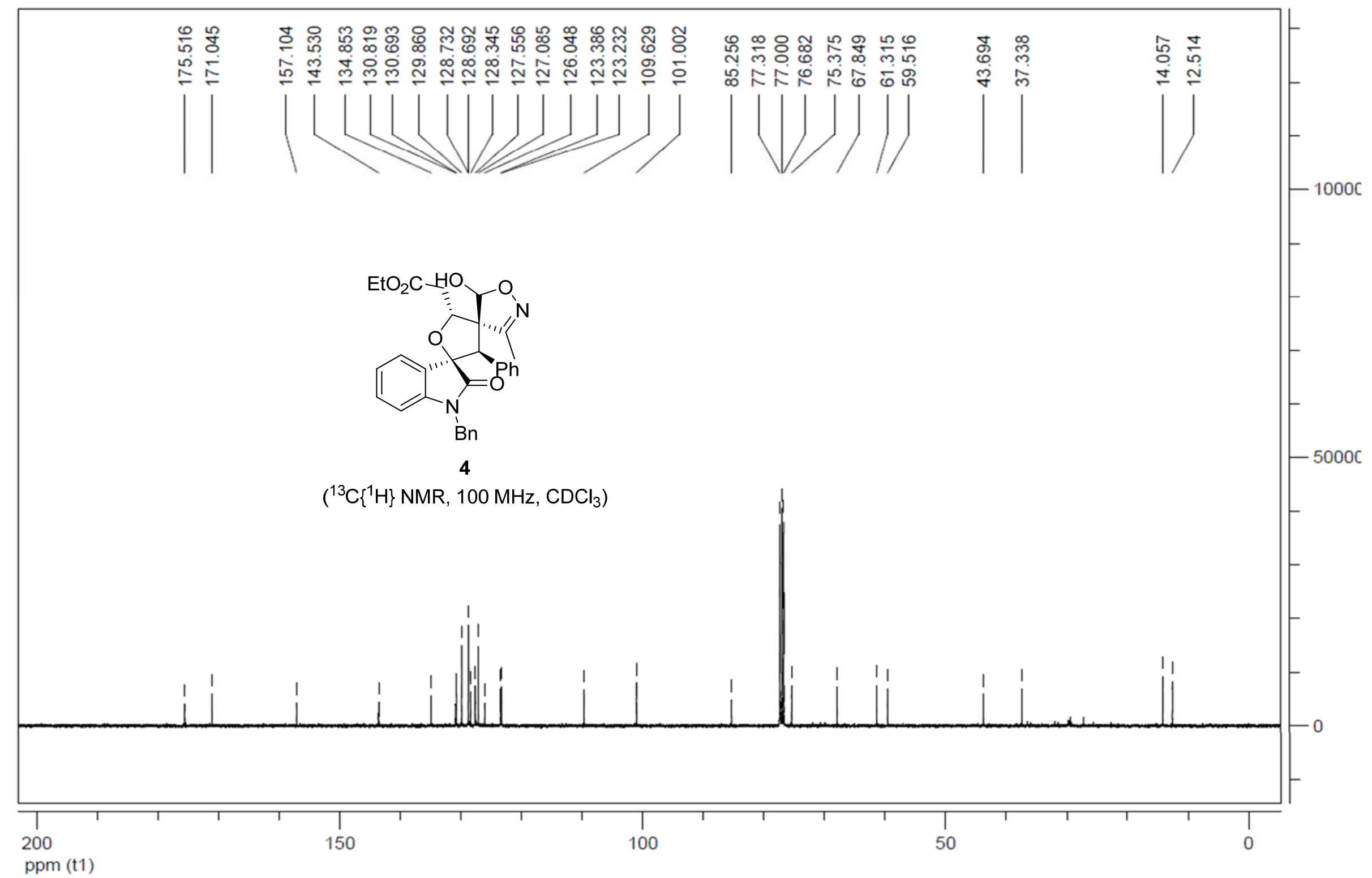




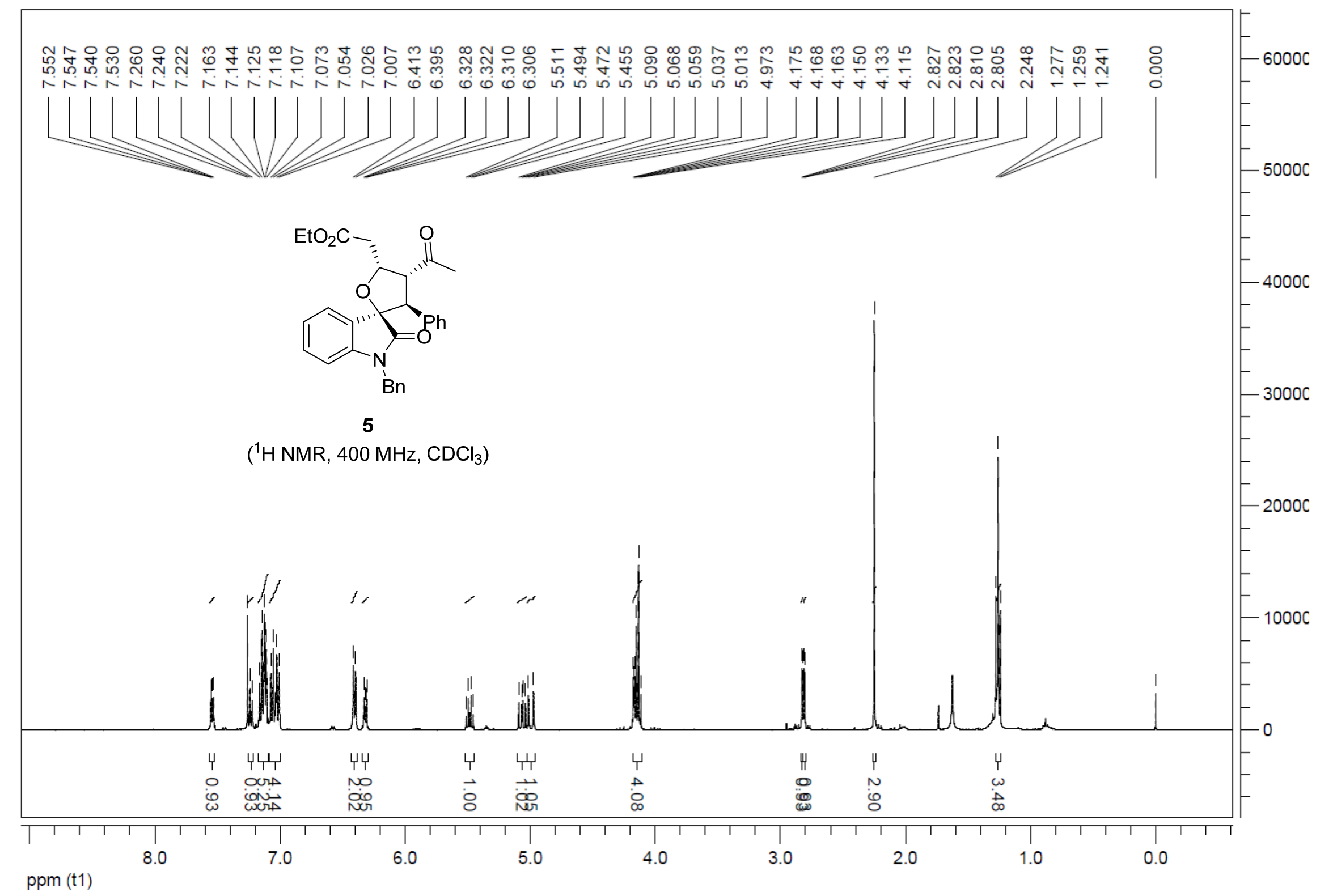




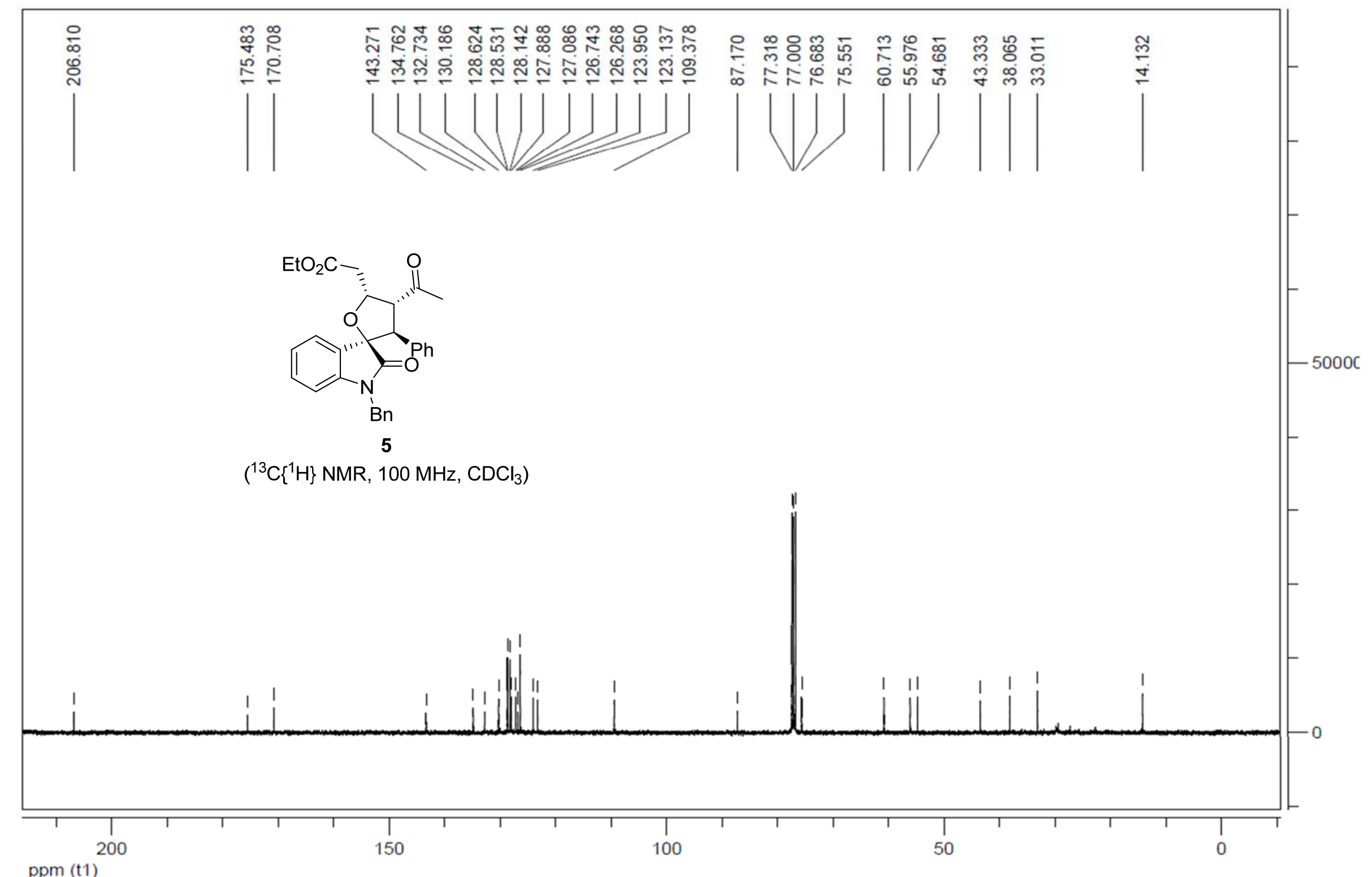


3. Copies of HPLC chromatograms of products
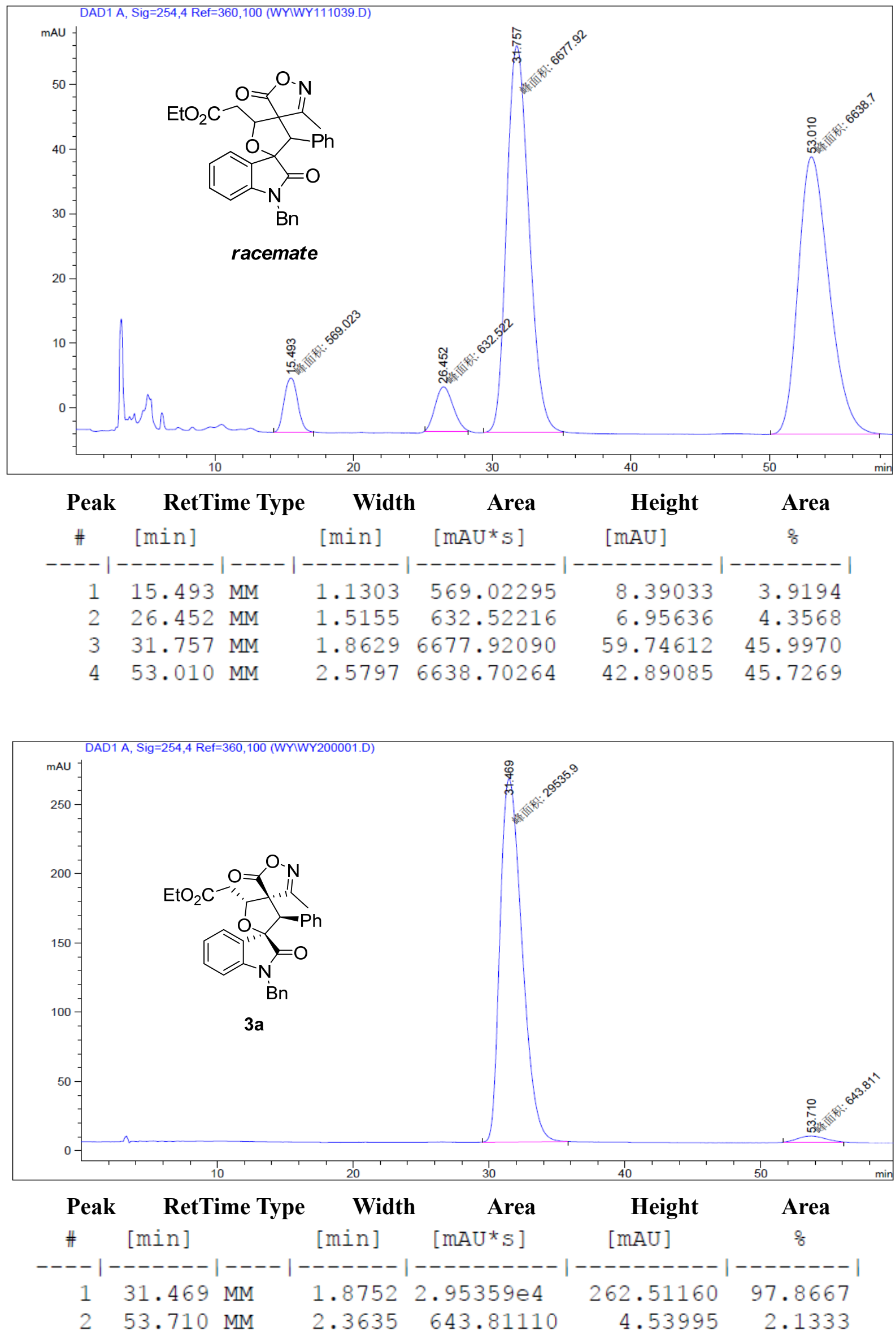

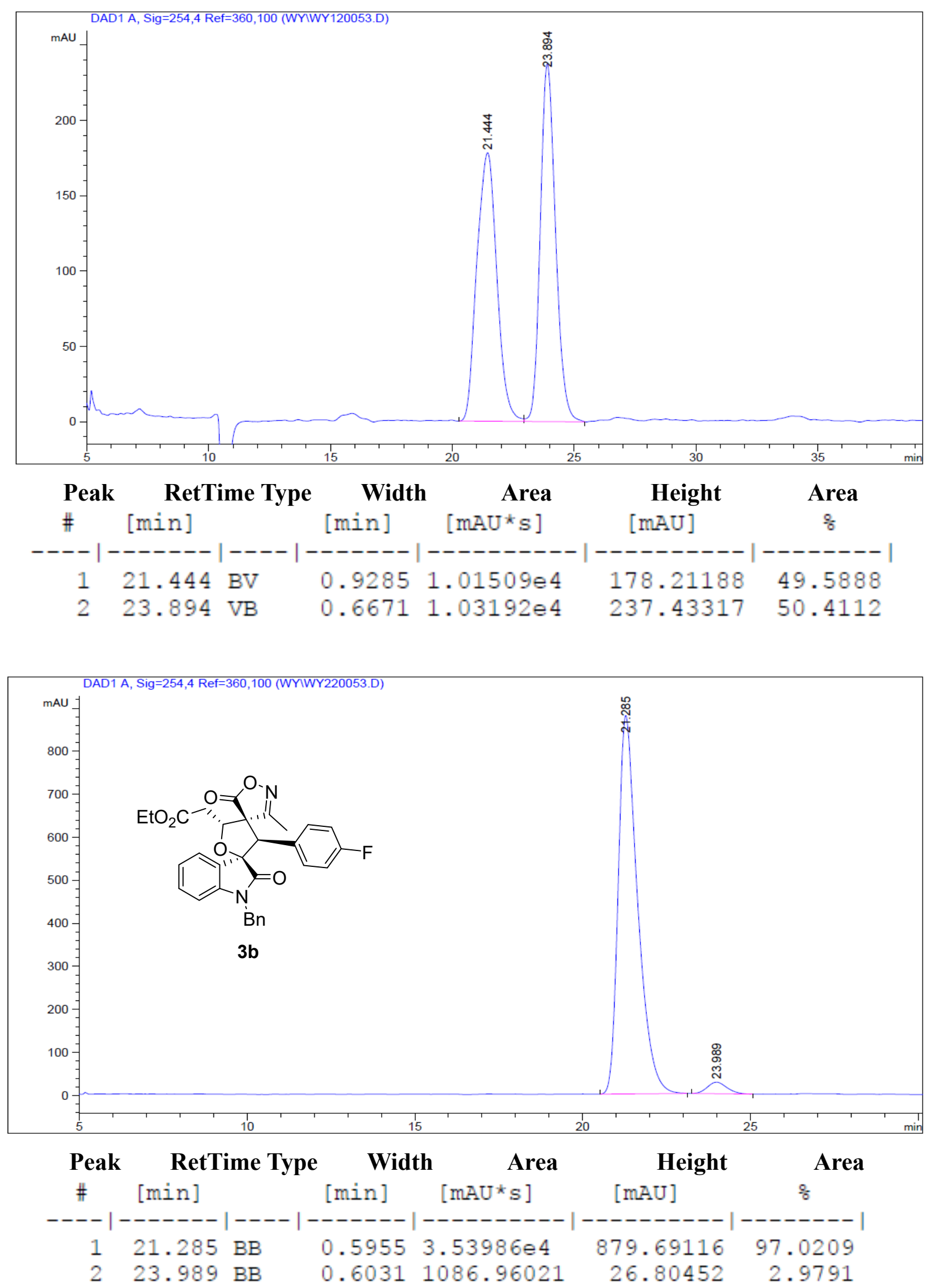

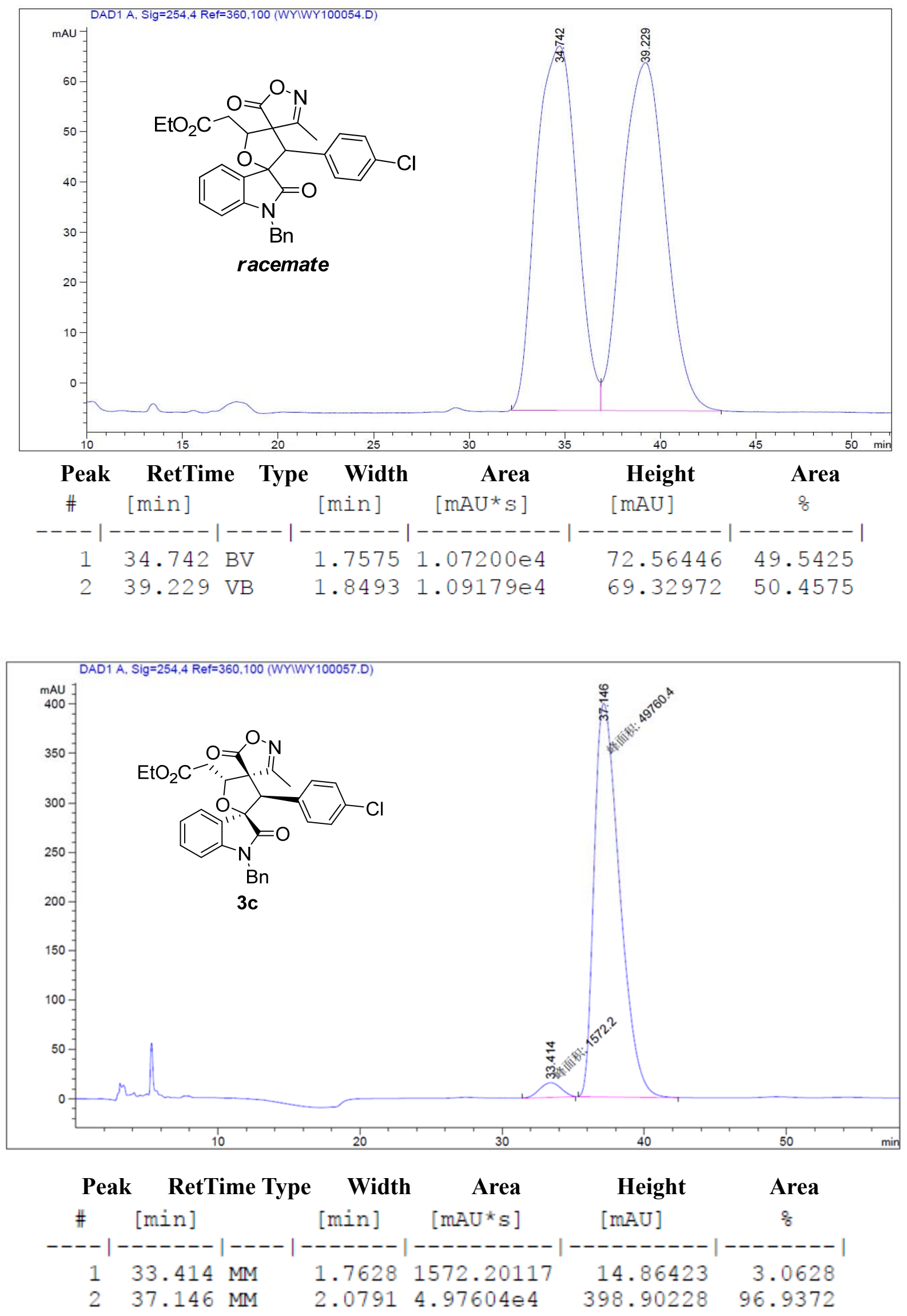

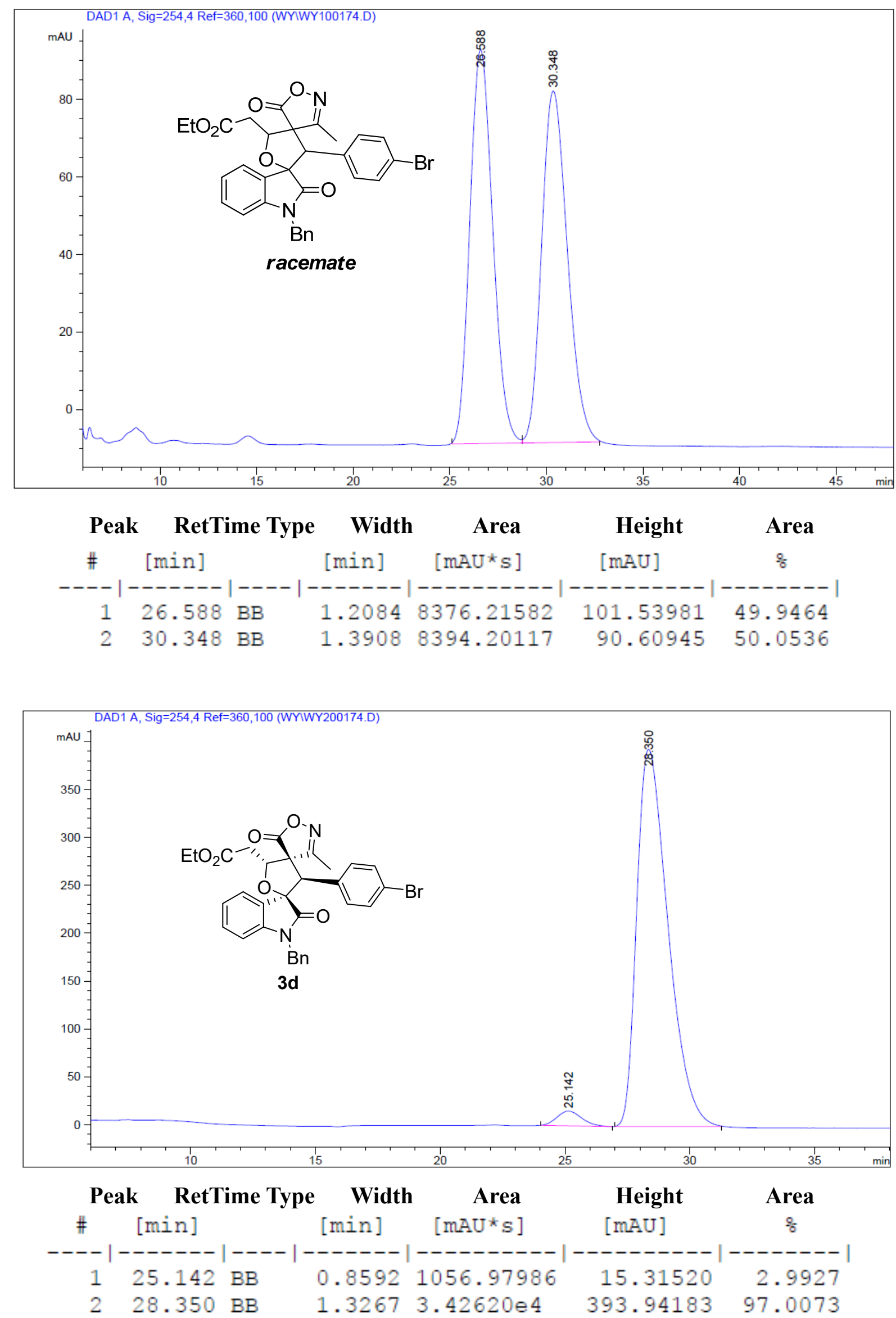

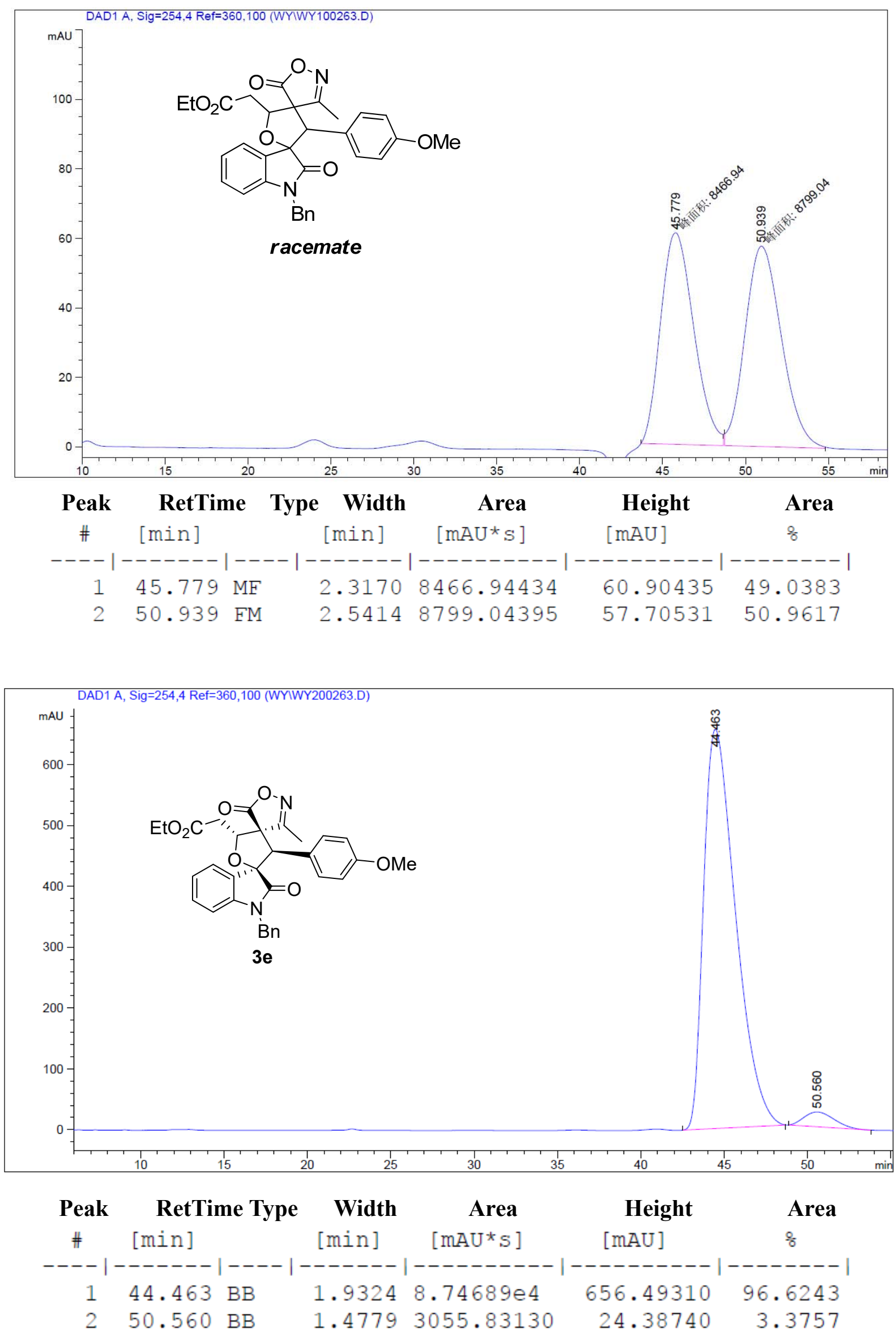

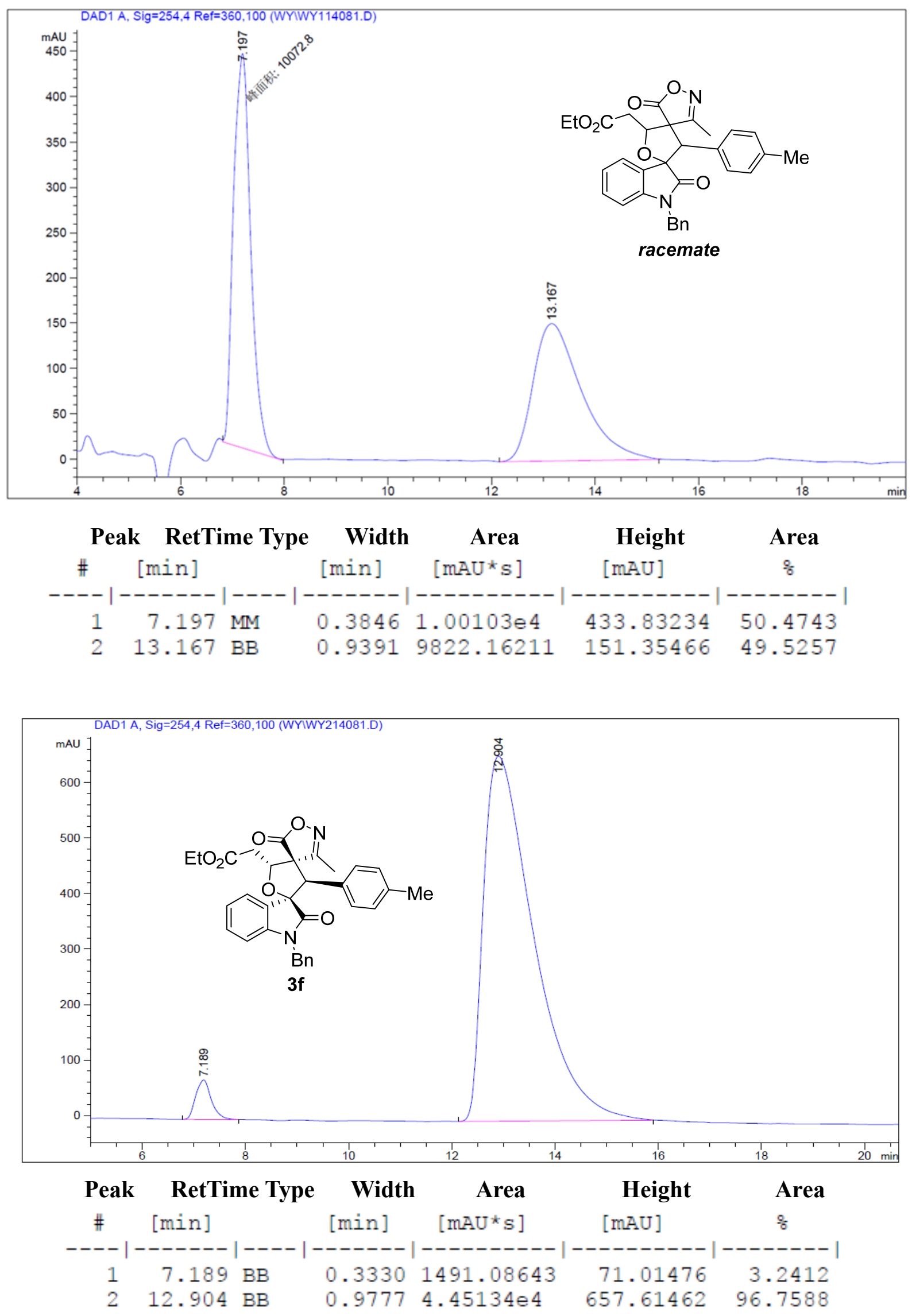

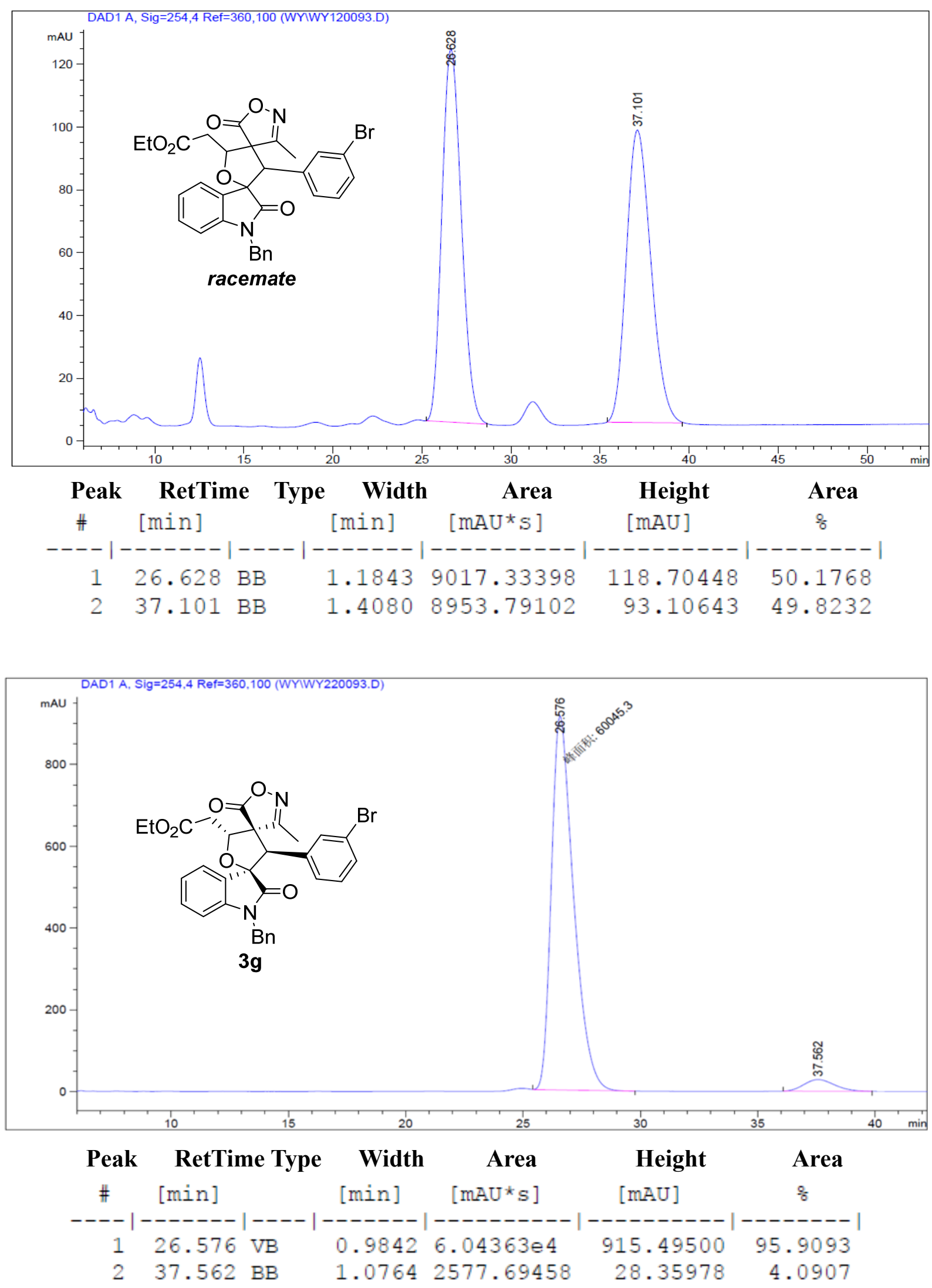


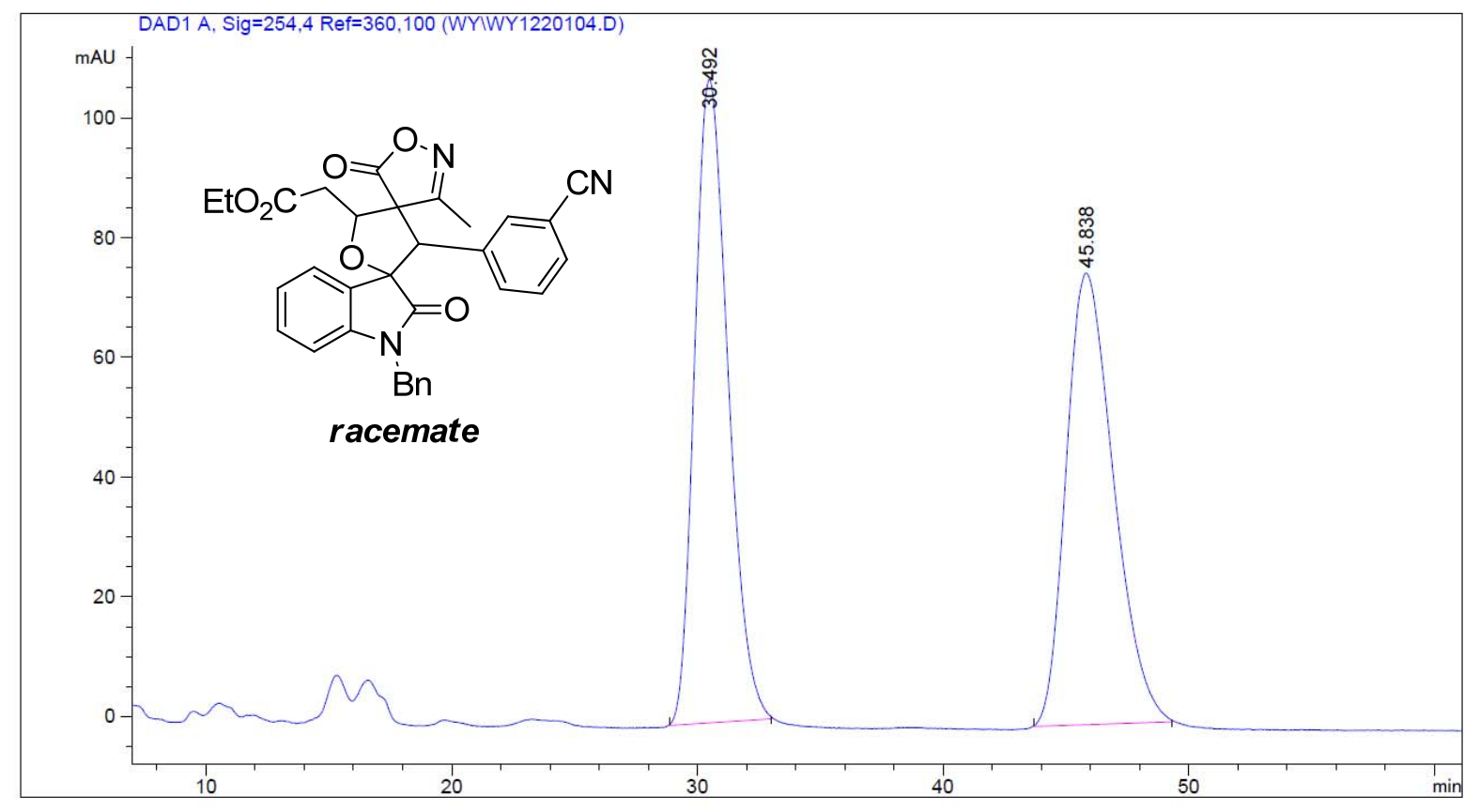

Peak RetTime Type Width Area Height Area

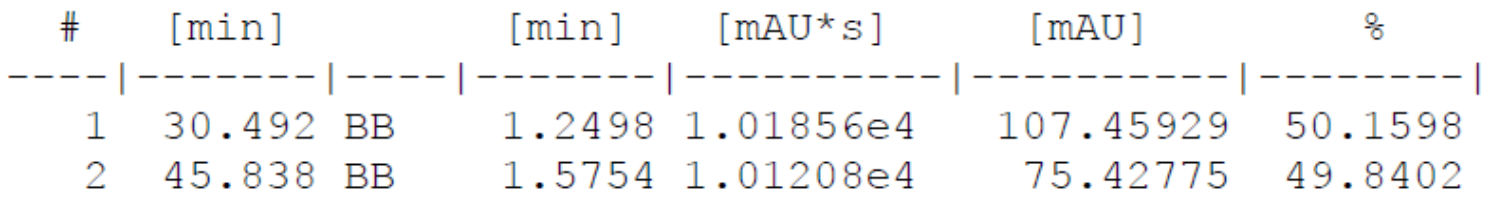

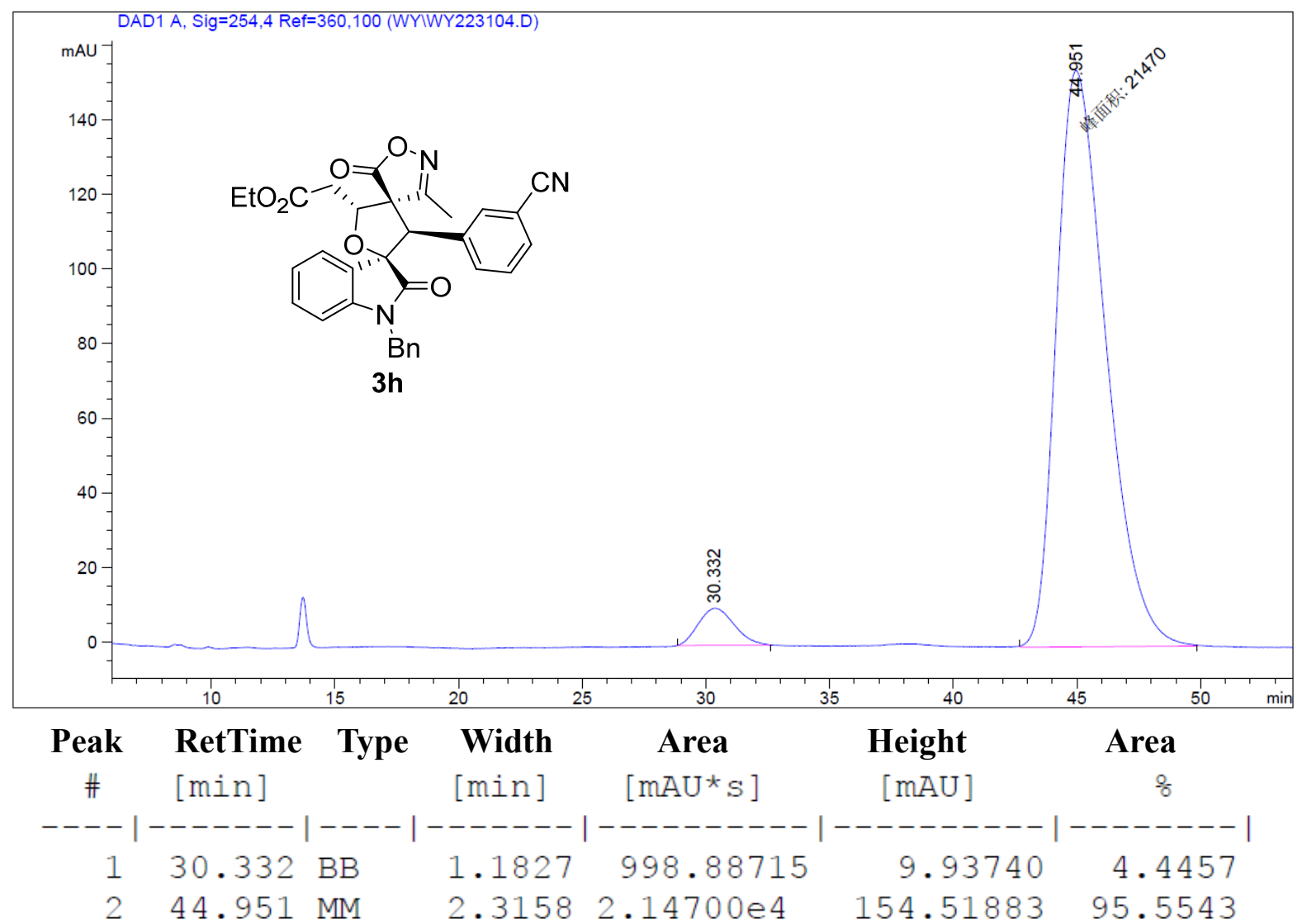



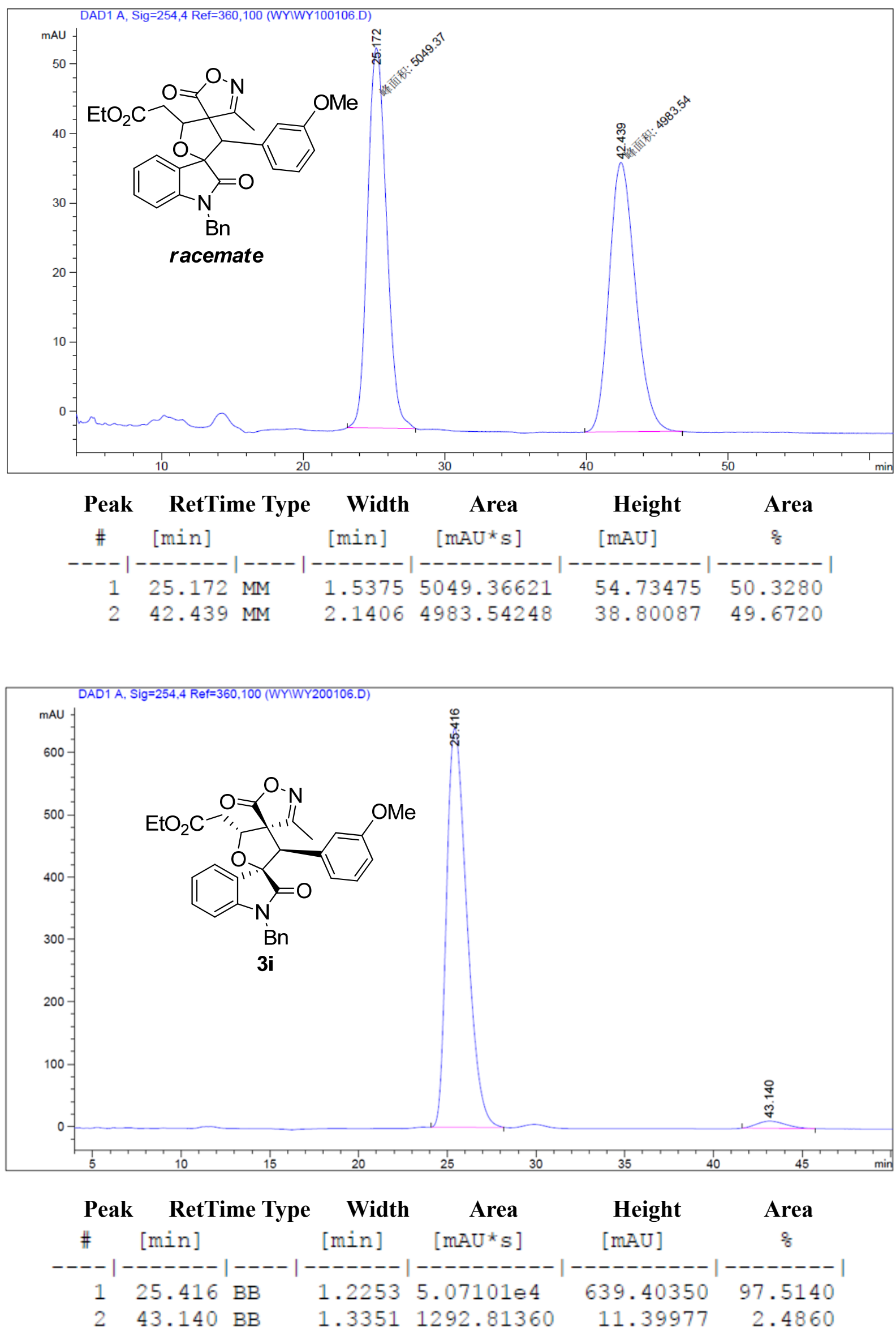

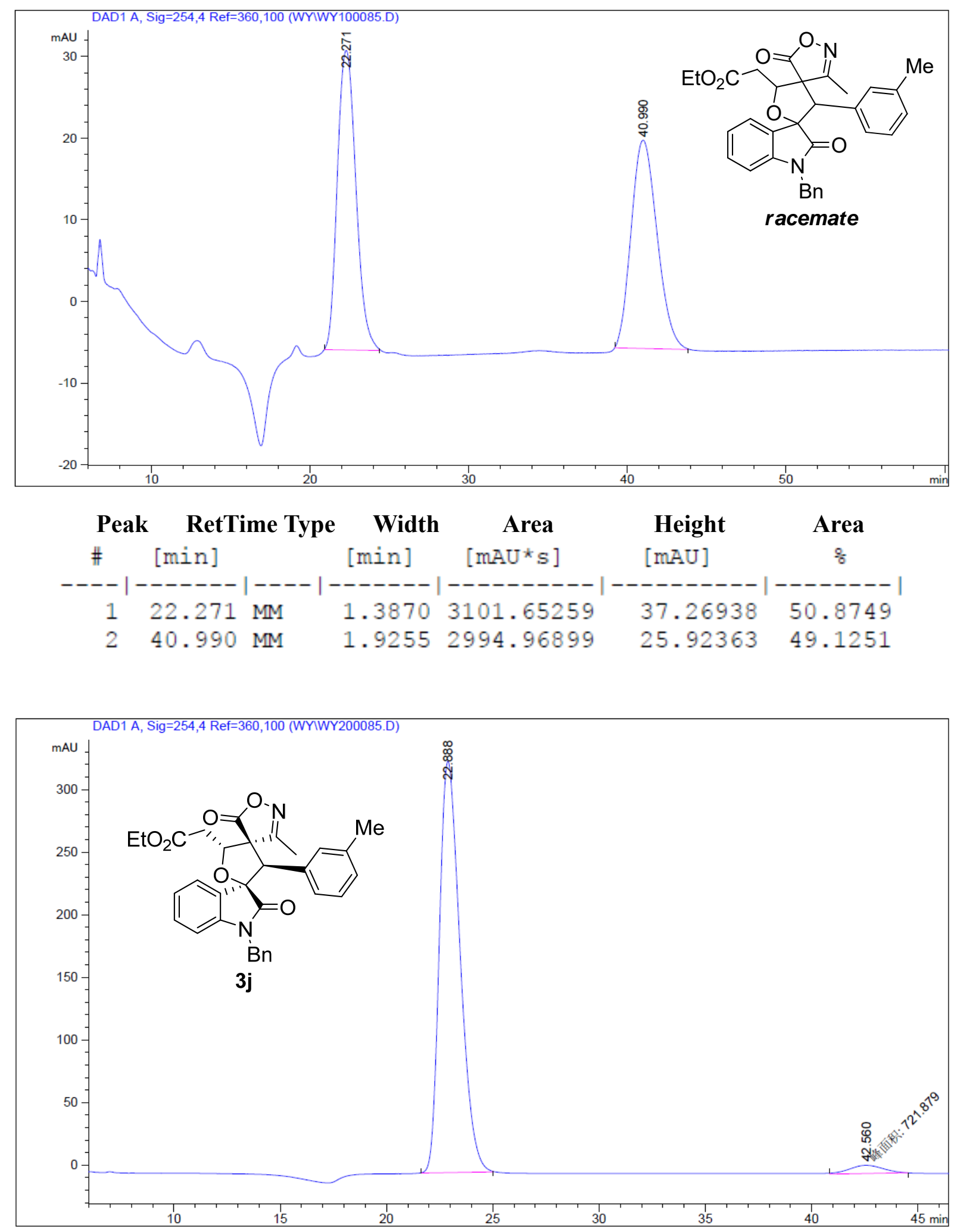

\begin{tabular}{|c|c|c|c|c|c|}
\hline Peal & RetTime Type & Width & Area & Height & Area \\
\hline$\#$ & {$[\mathrm{~min}]$} & {$[\min ]$} & {$\left[\mathrm{mAU}^{*} \mathrm{~s}\right]$} & {$[\mathrm{mAU}]$} & 웅 \\
\hline 1 & $22.888 \mathrm{MM}$ & 1.1347 & $2.24167 e 4$ & 329.26276 & 5438 \\
\hline 2 & $42.560 \mathrm{MM}$ & 1.6355 & 564.47577 & 5.75239 & 2.4562 \\
\hline
\end{tabular}



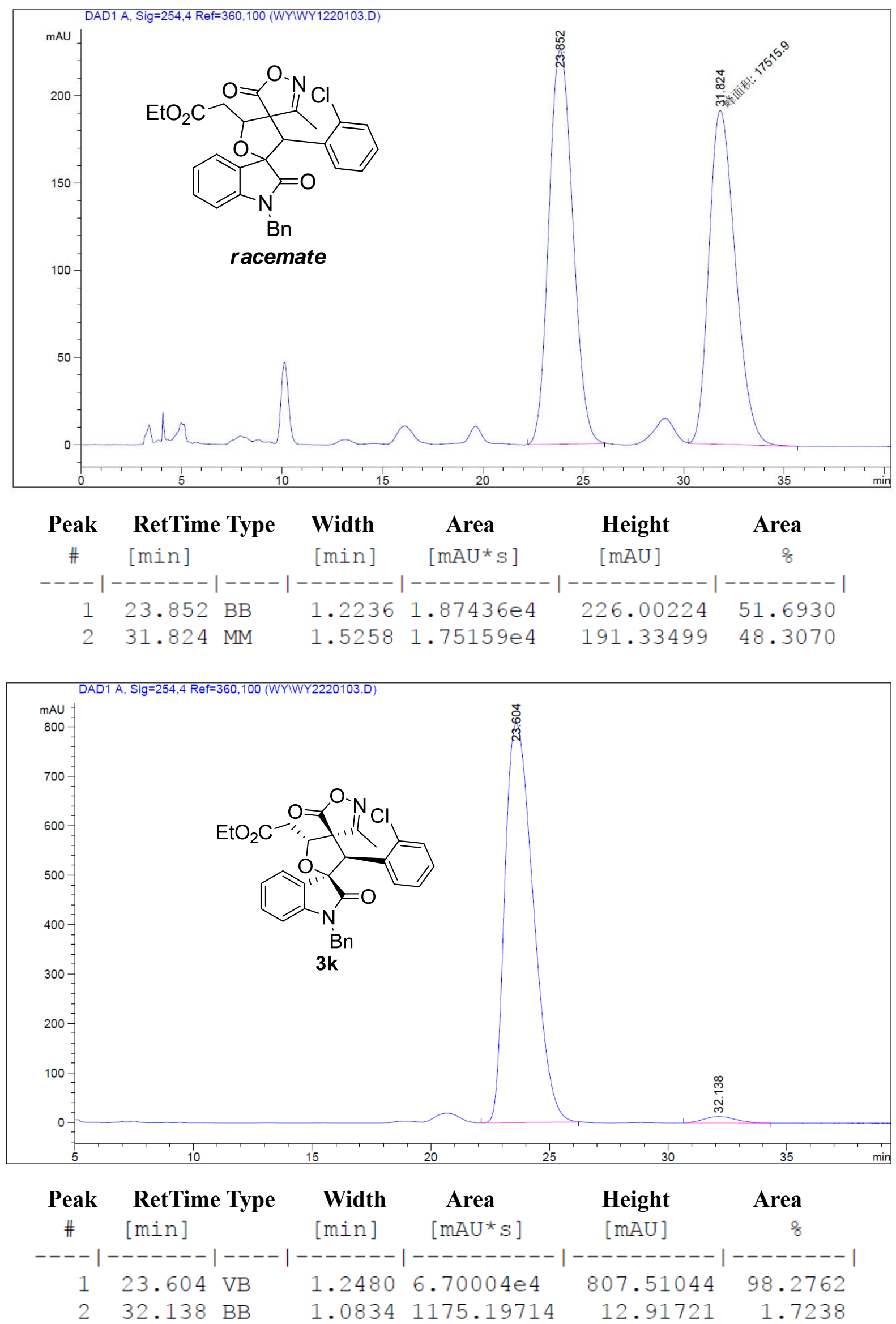

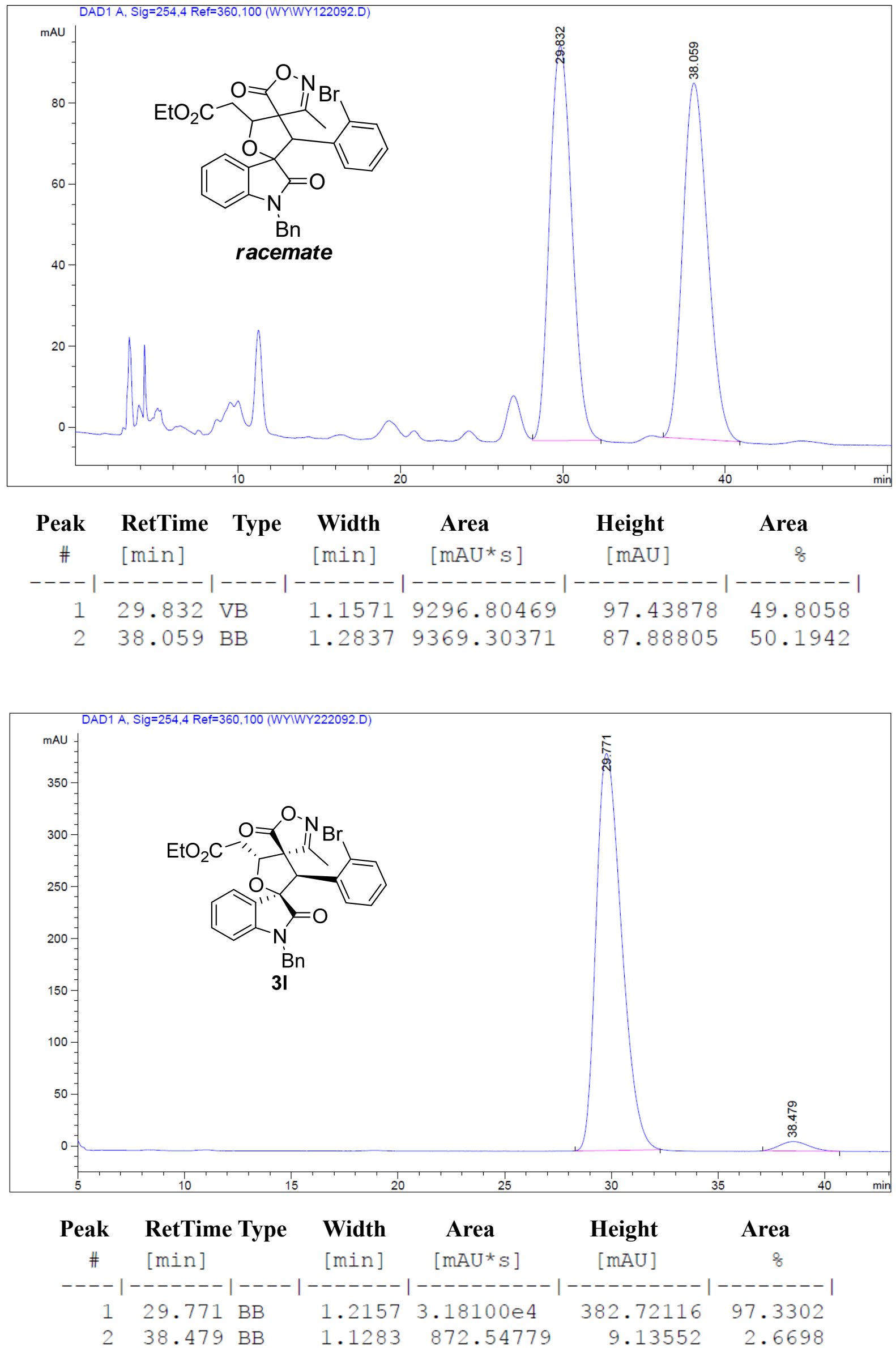

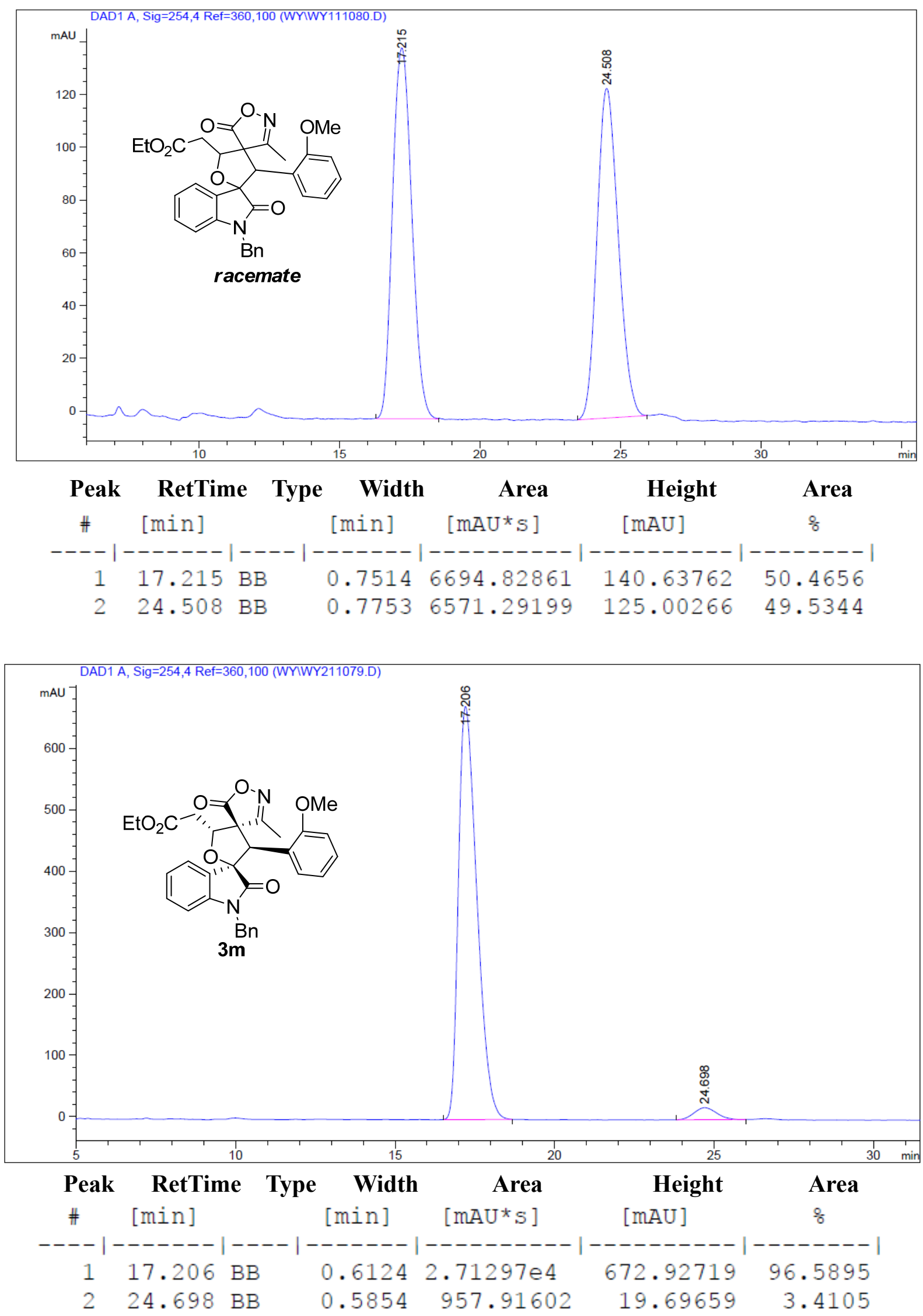

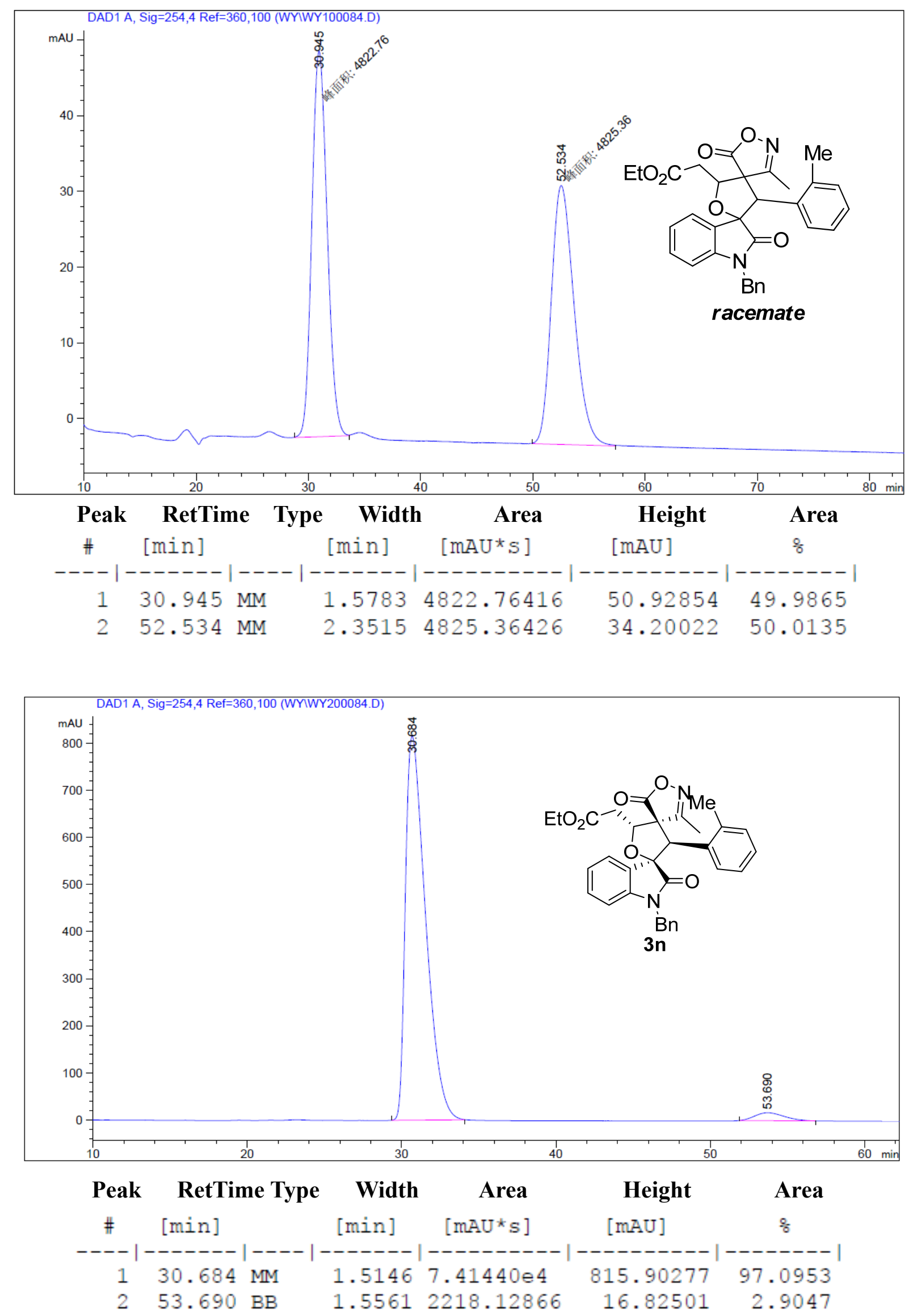

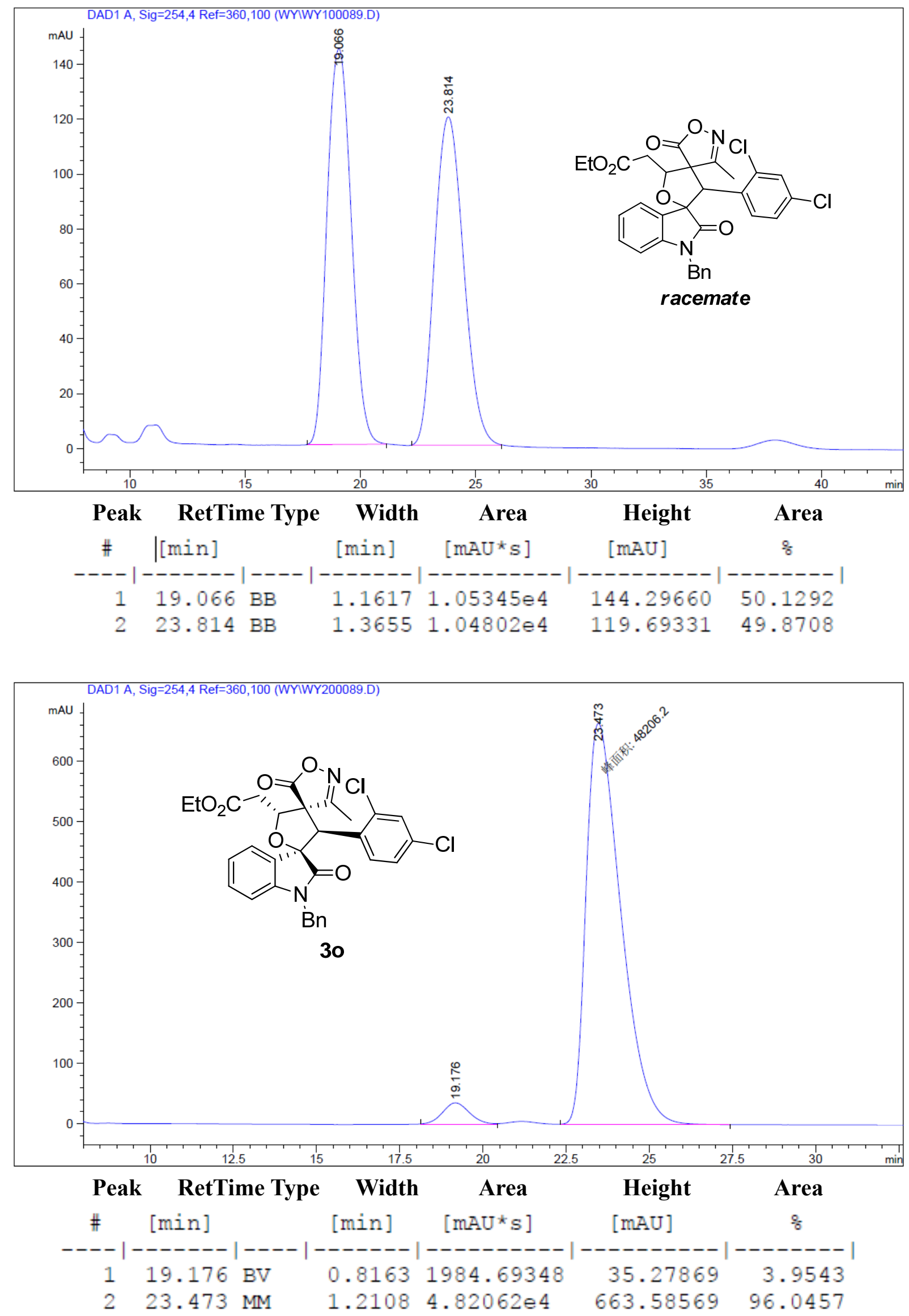

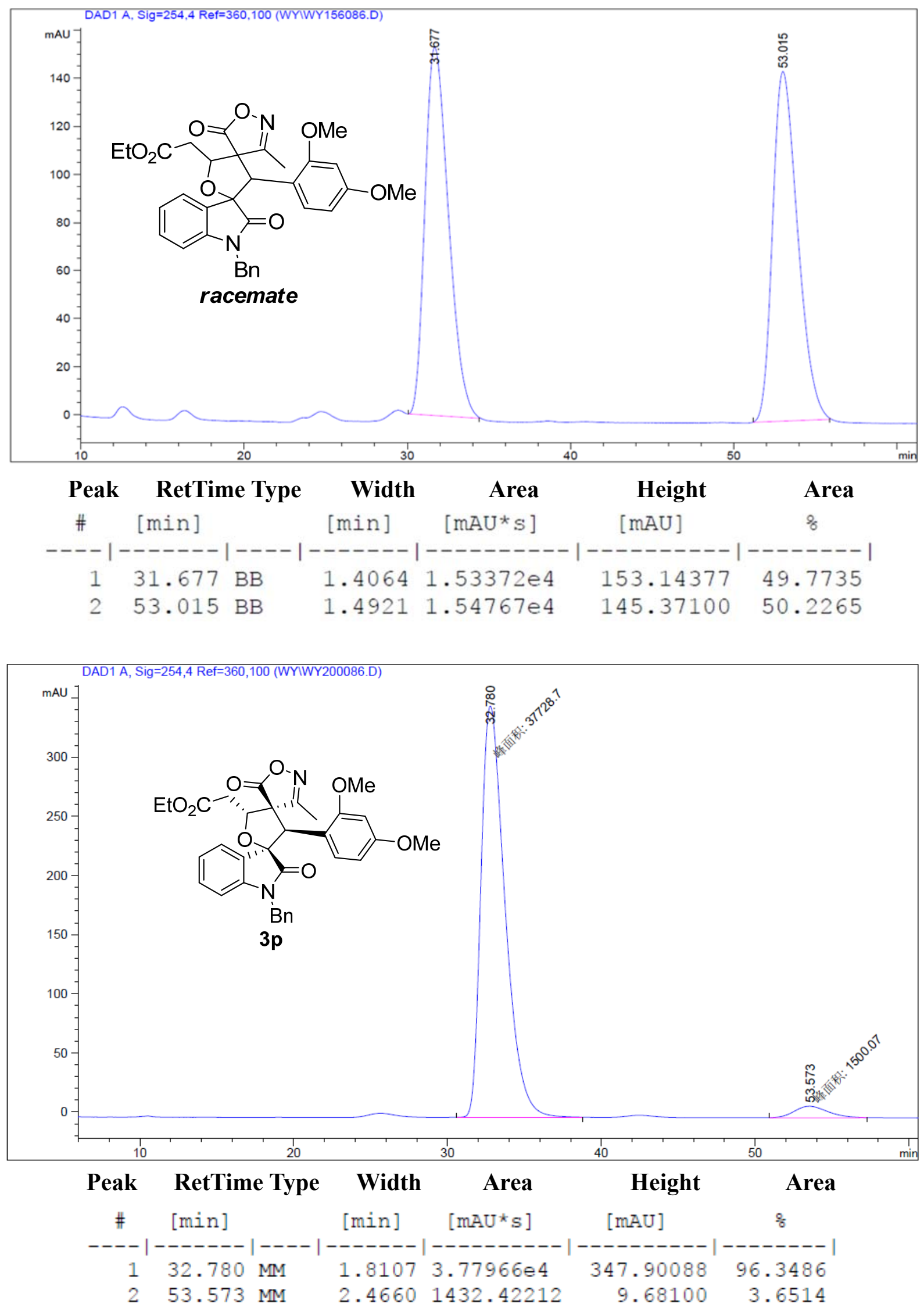

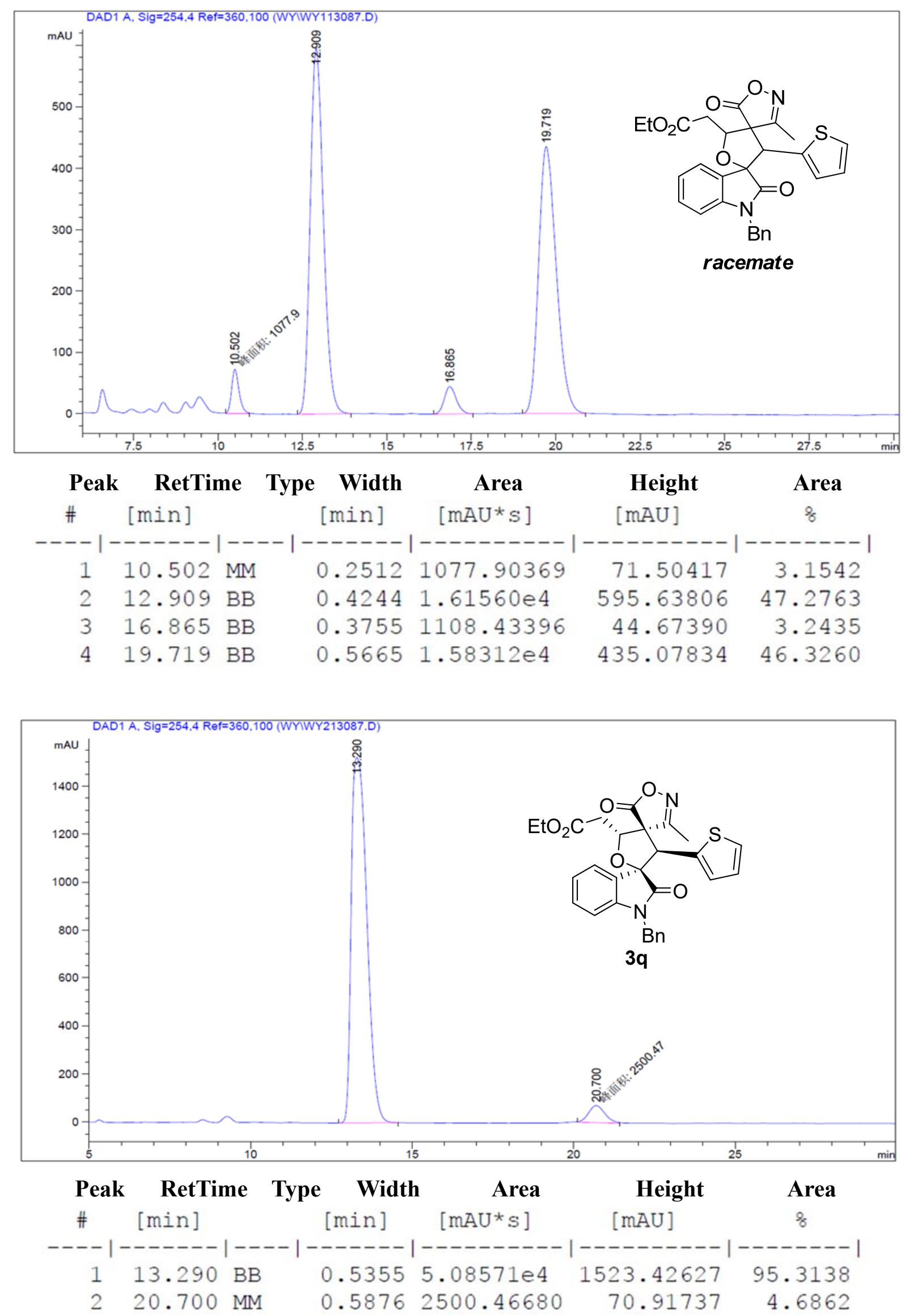

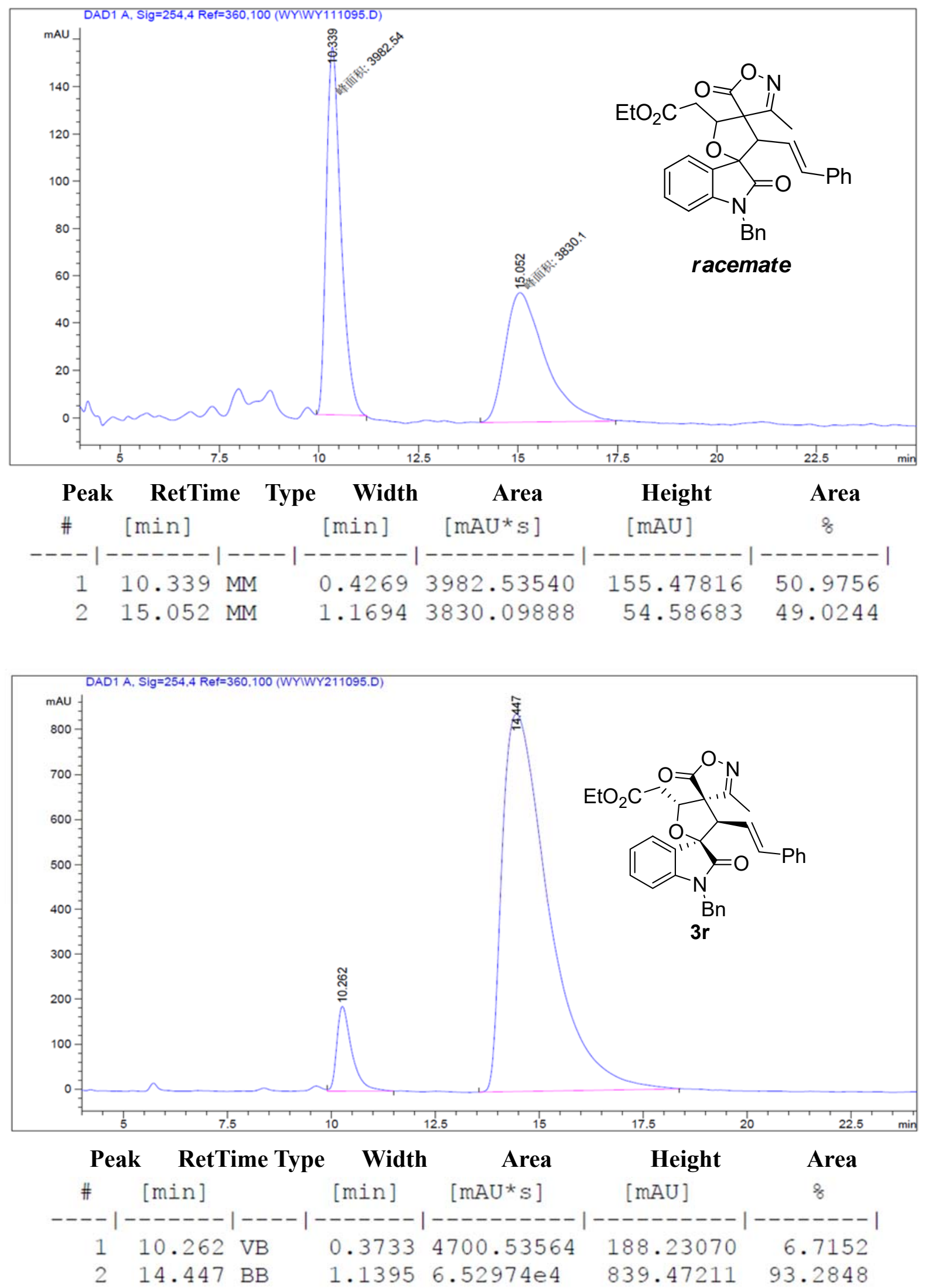

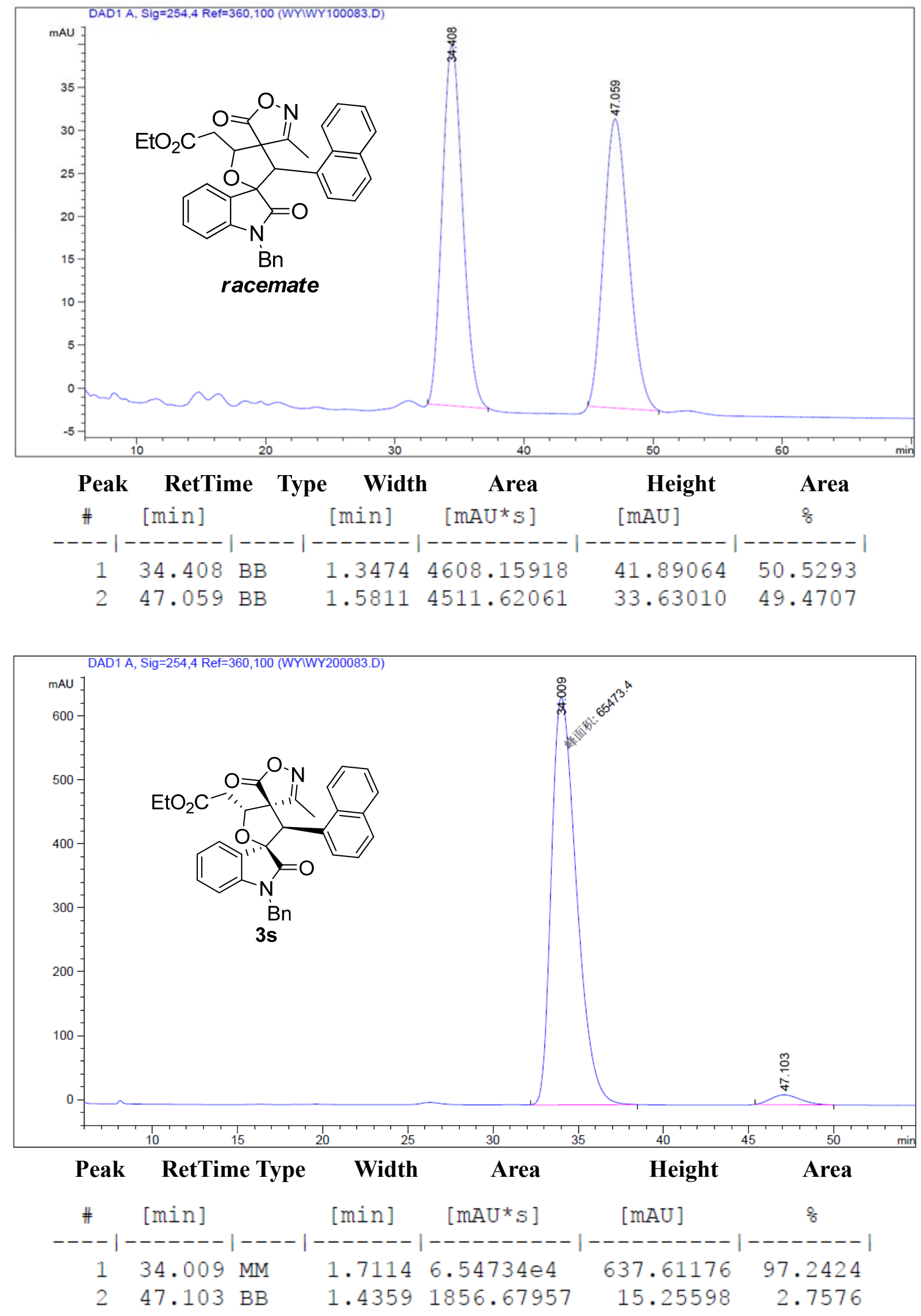

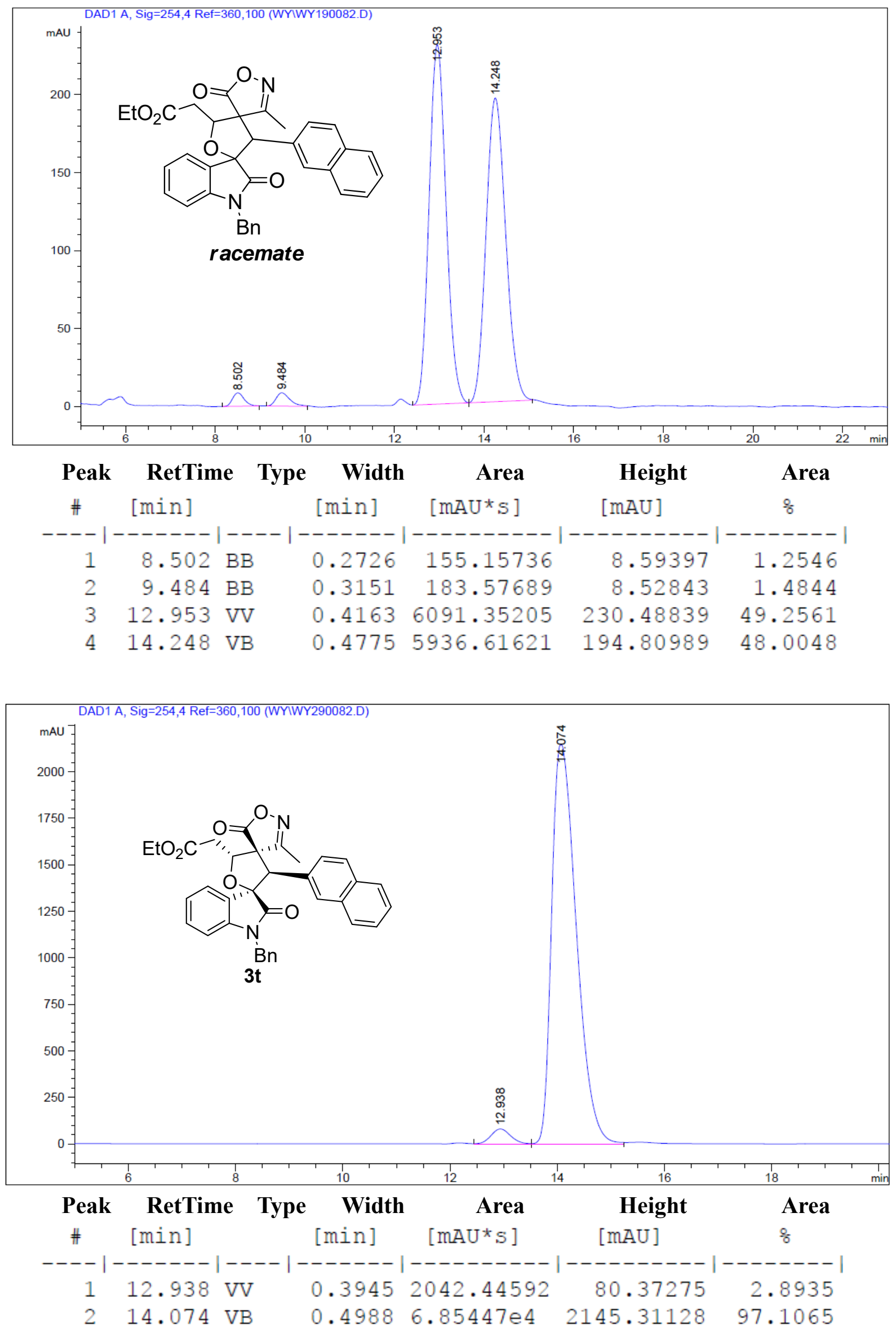

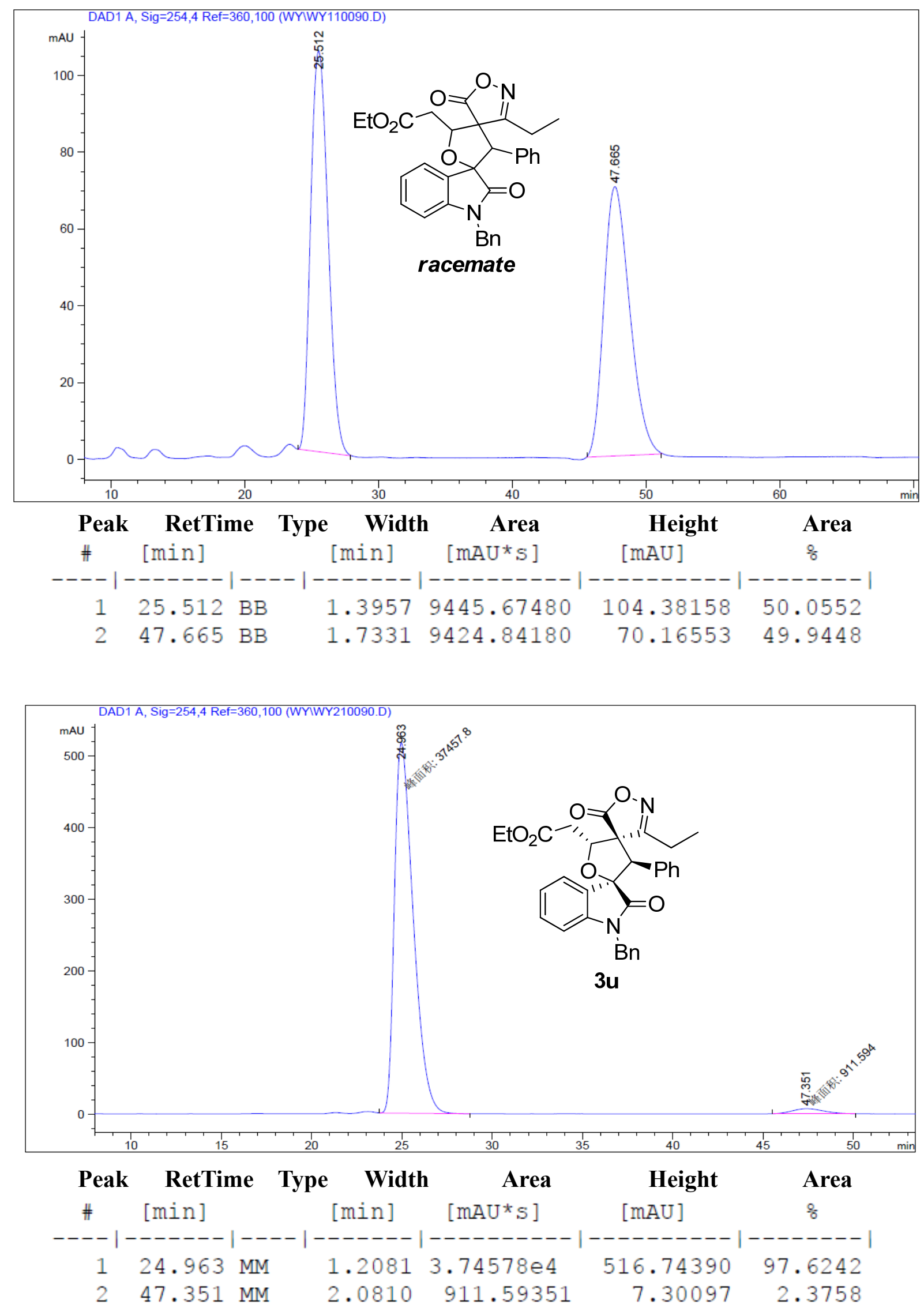

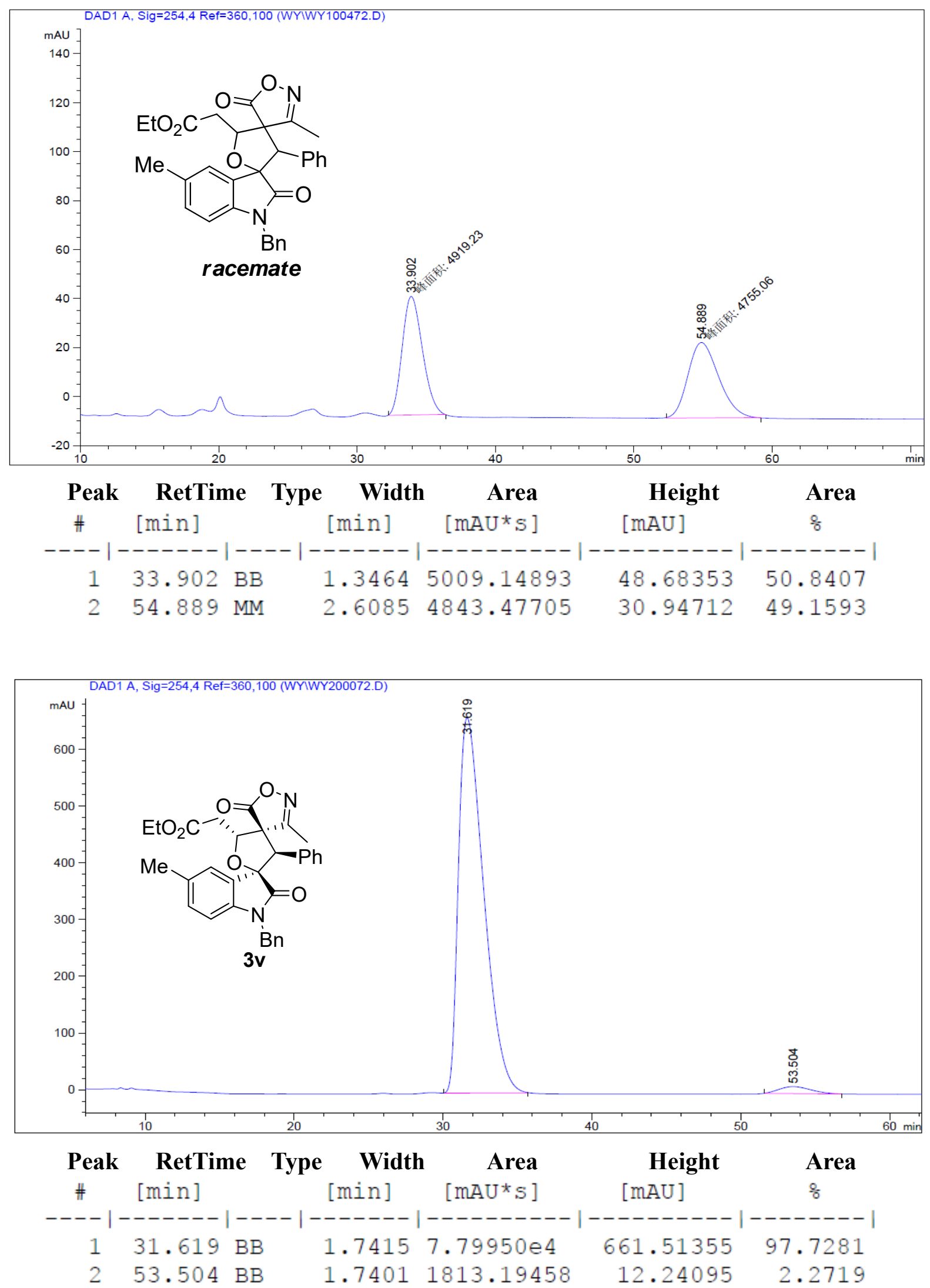

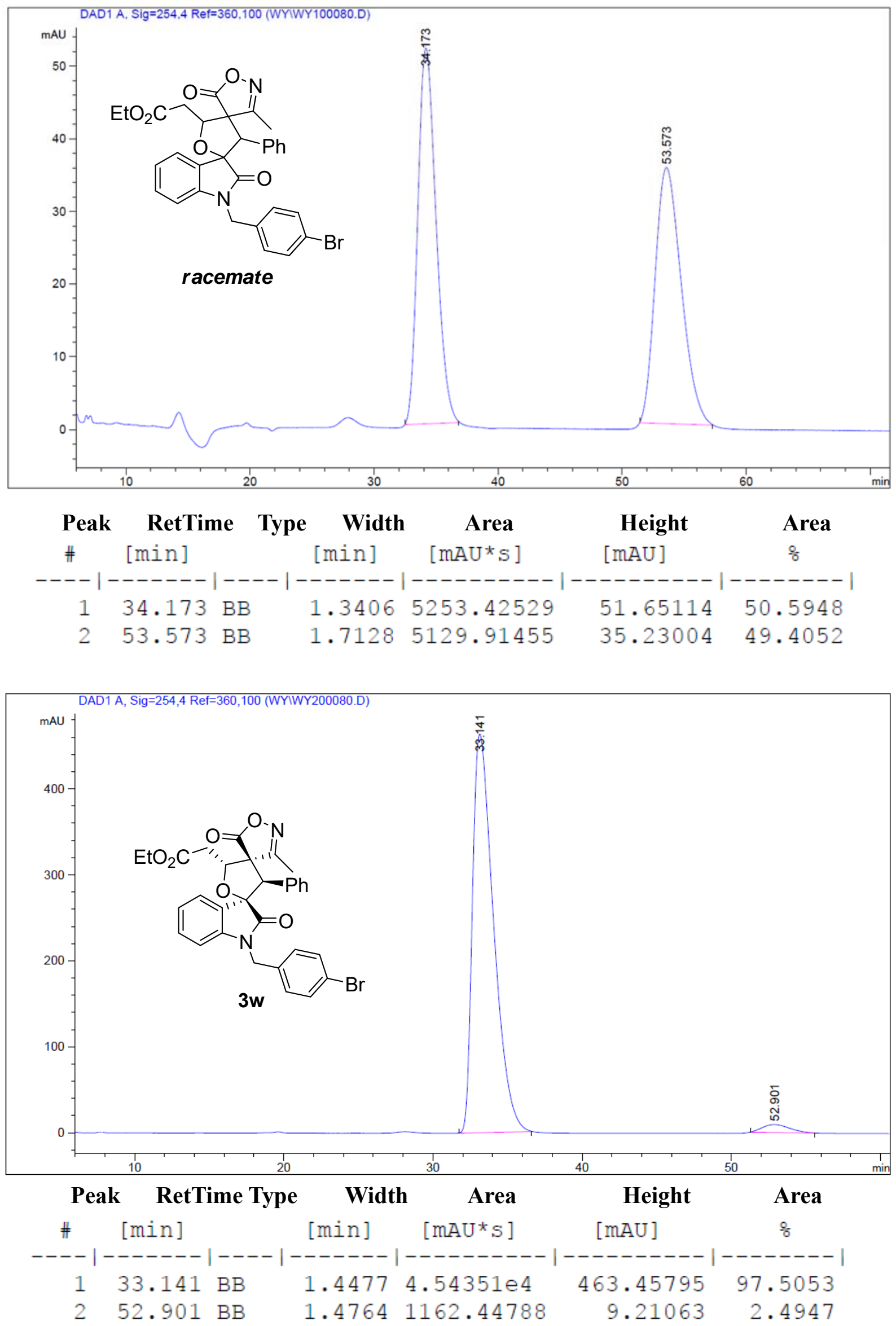

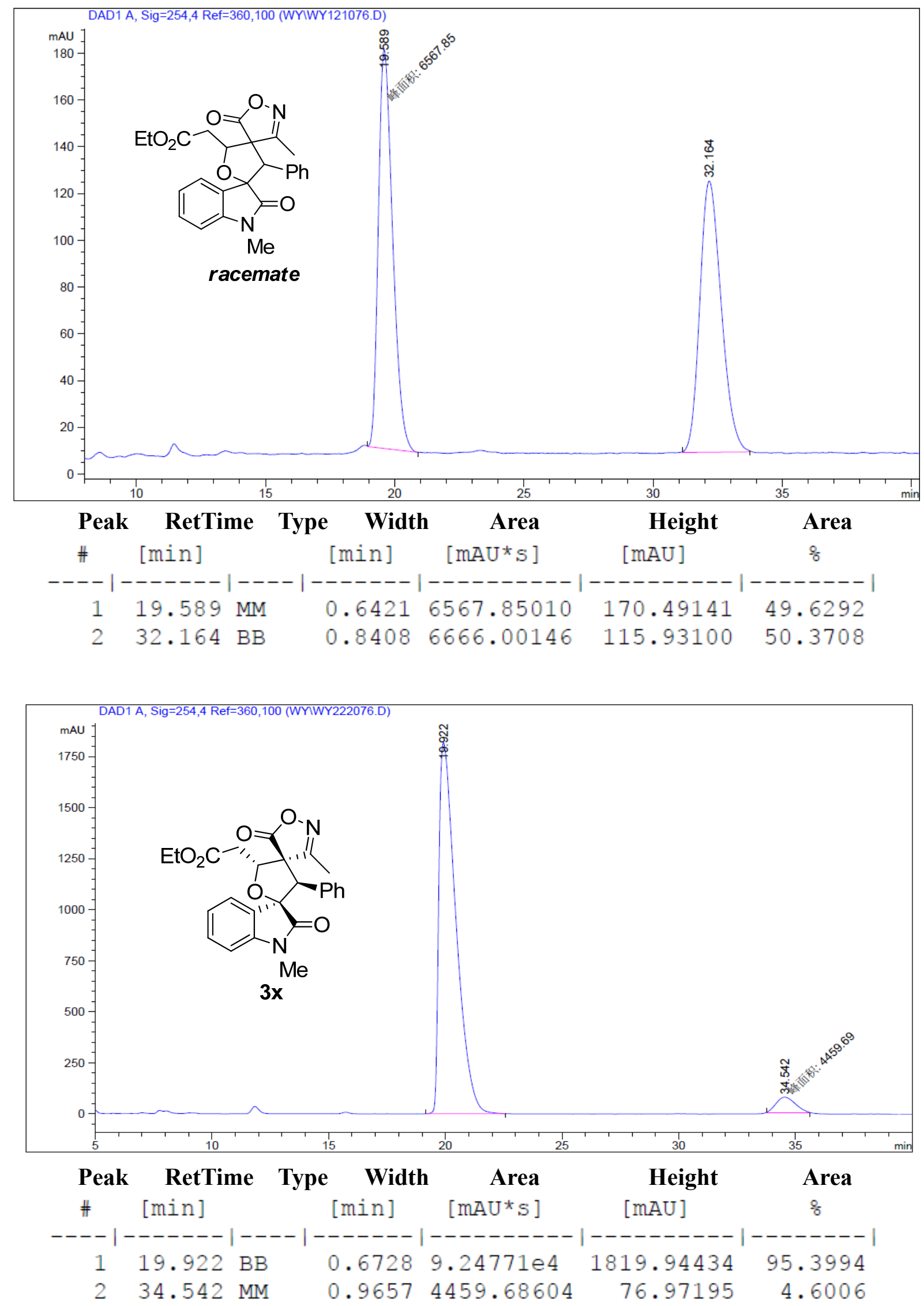

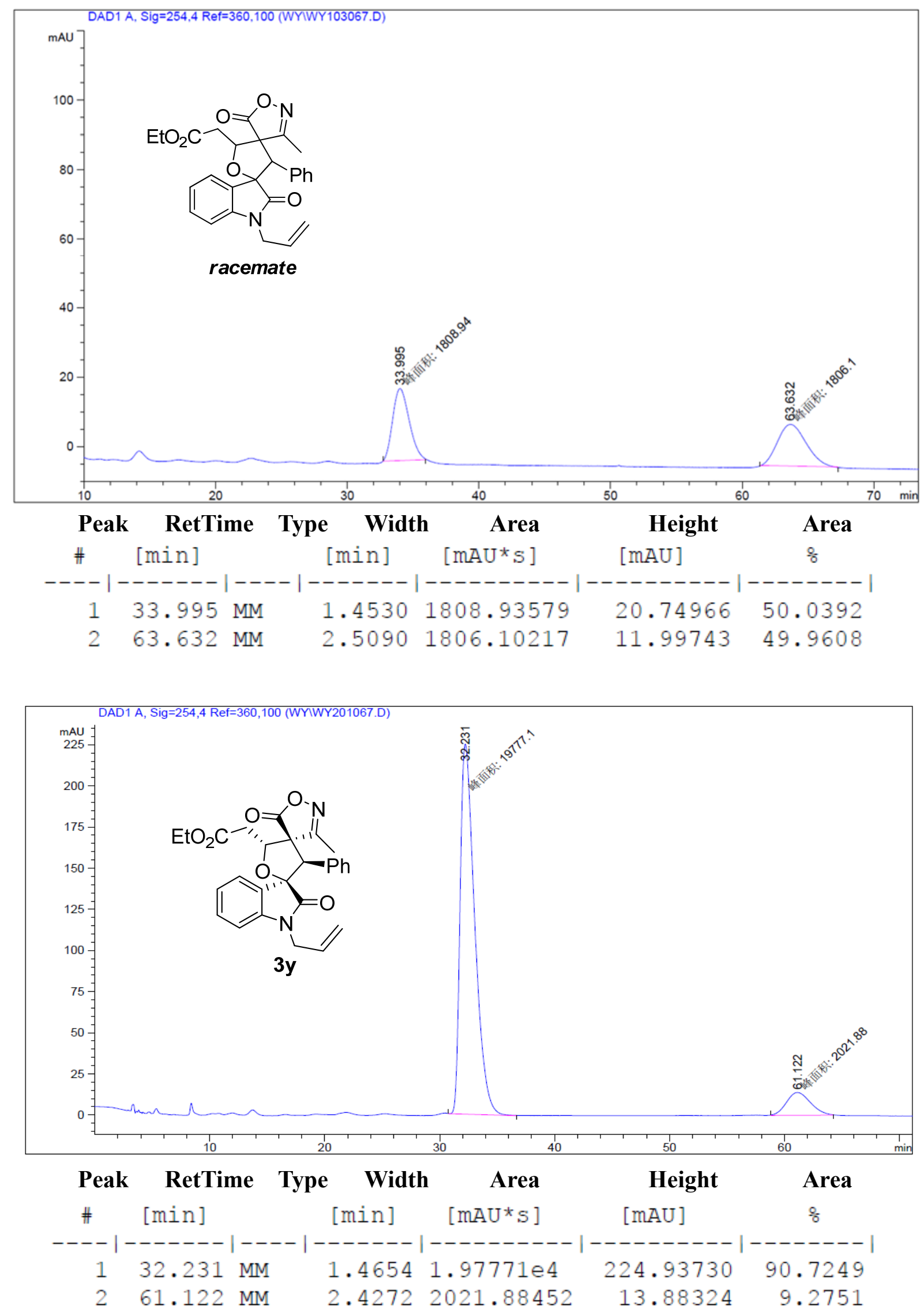

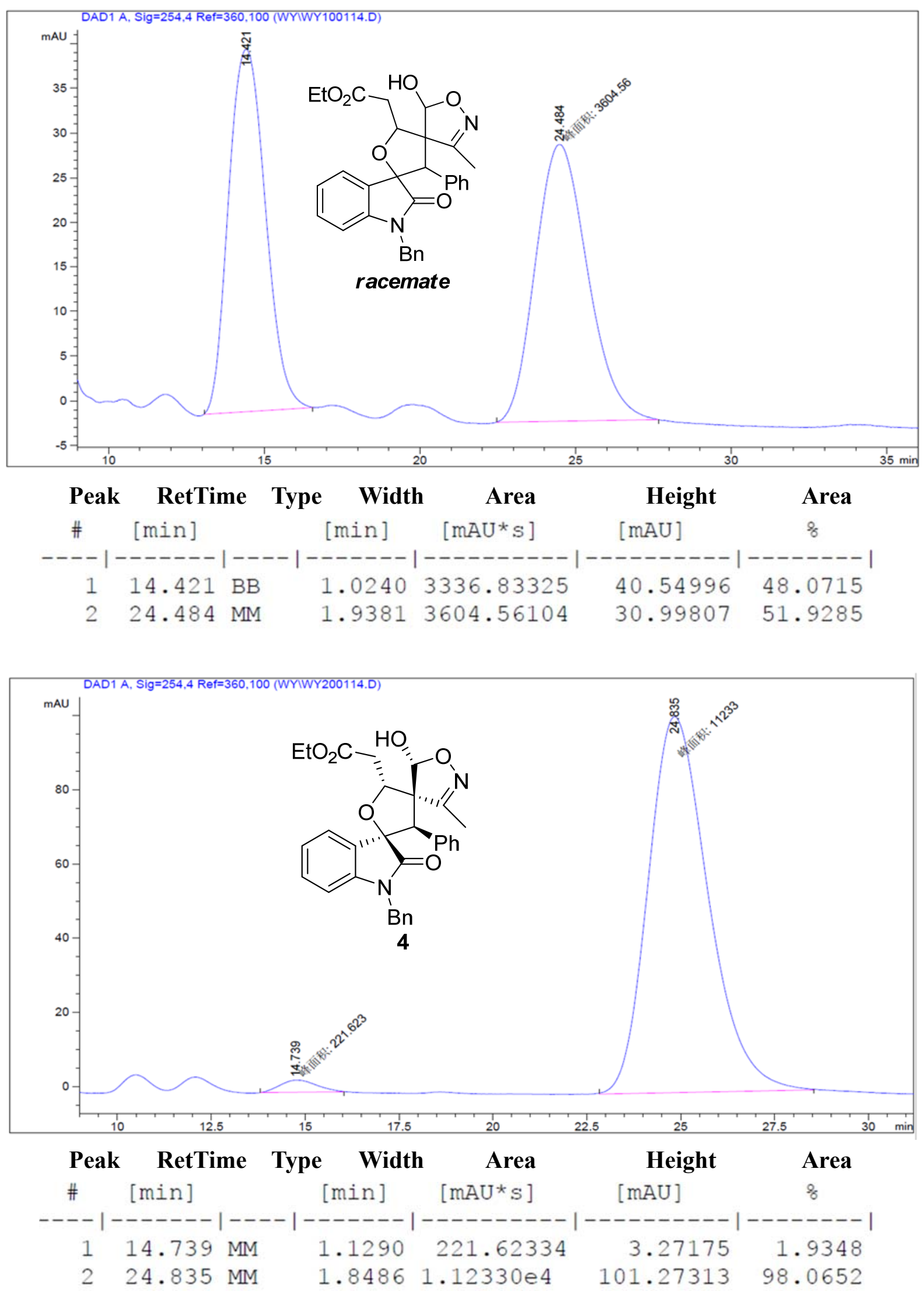

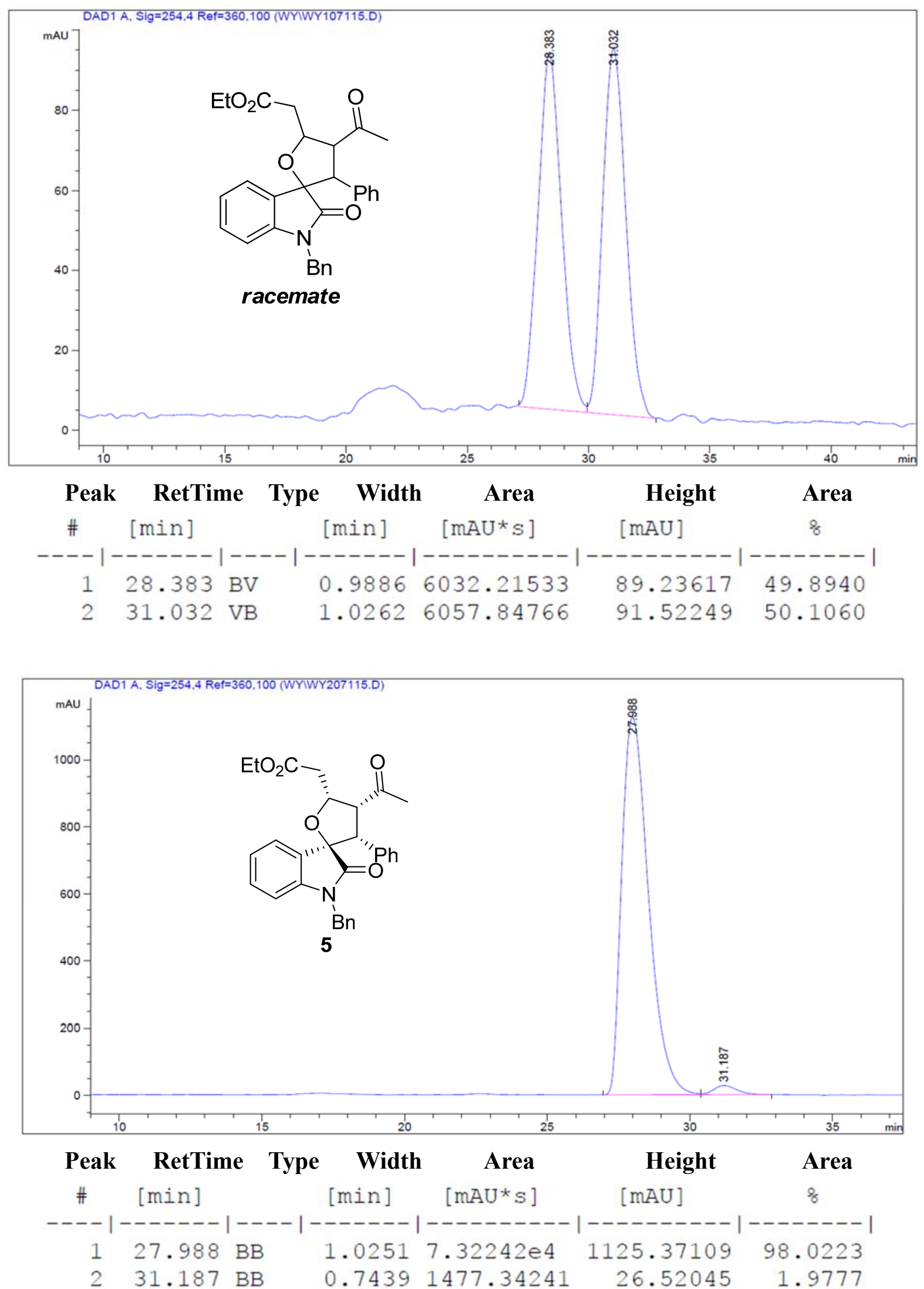